THE INTERNATIONAL

REVIIEW OF RESEARCH IN

OPEN AND DISTANCE LEARNING

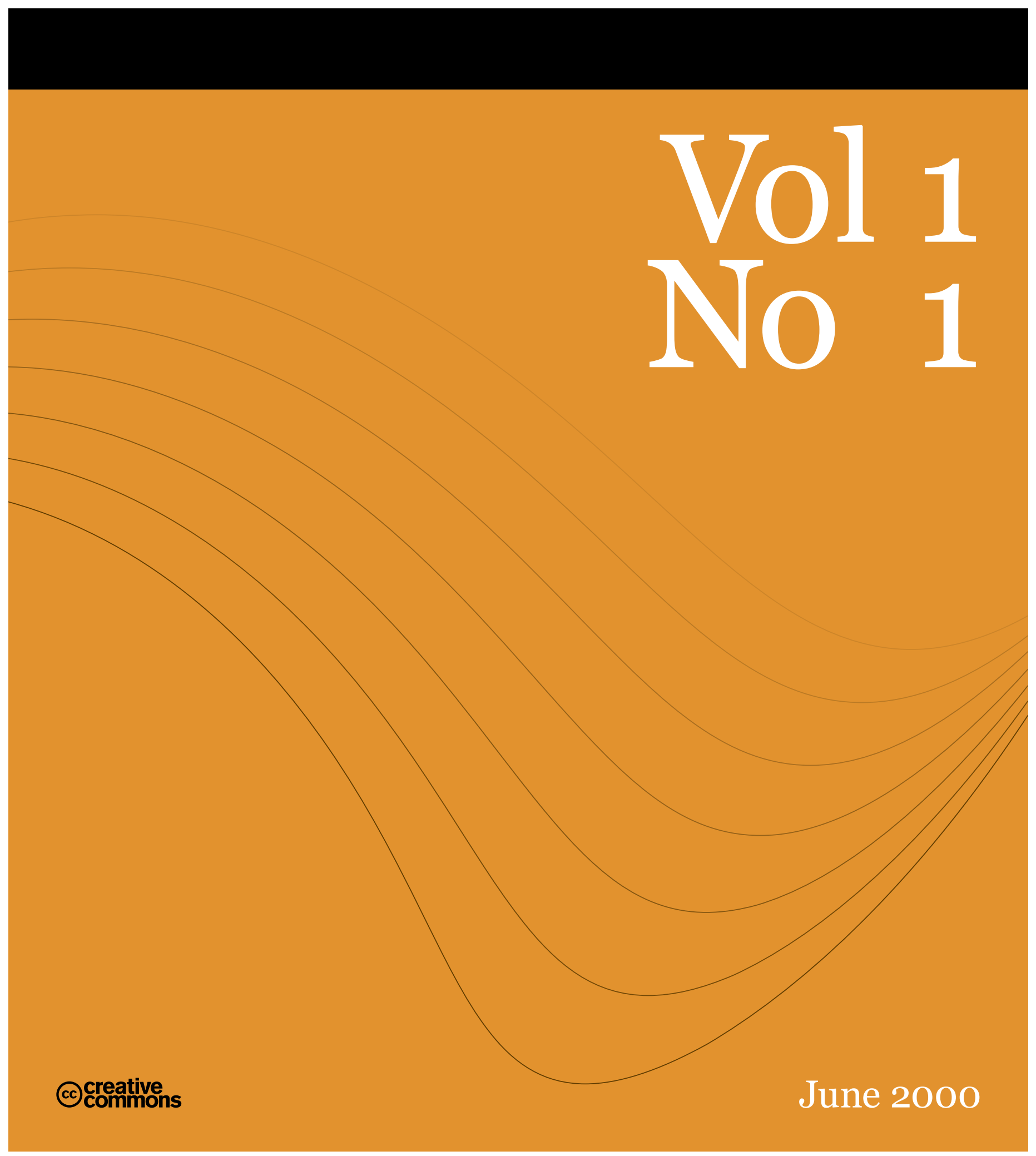


International Review of Research in Open and Distance Learning (c)

ISSN: $1492-3831$

Vol. 1, No. 1 (June 2000)

\section{Editorial}

Peter S. Cookson

Athabasca University

irrodl@athabascau.ca

I extend a warm welcome to you as a reader of this inaugural issue of The International Review of Research in Open and Distance Learning (IRRODL). In this, my first editorial, I explain the meaning of the journal's name, purpose, content, and structure. I also explain the theme of the articles in this initial issue and express appreciation for the many people whose support has been instrumental in converting IRRODL from an idea to reality.

\section{What's in a Name?}

The aim of this journal is to live up to its name:

- International. IRRODL welcomes manuscripts relevant to open and distance learning from prospective authors throughout the world. Available without cost to anyone anywhere with an Internet connection, its primary intent is to serve an international audience.

- Review. As well as original work, the journal welcomes manuscripts that present systematic reviews of existing literature on open and distance learning theory, research, and practice in open and distance learning.

- Research. The journal welcomes not only manuscripts that feature systematic inquiry, but also articles on theory and best practice that have implications for research.

- Open and Distance Learning. Both distance learning and distance teaching may be regarded as essential sub-sets of the more inclusive term distance education. Despite its ambiguities, it was decided to have the title of this journal refer to distance learning as a synonym for distance education, defined as organized educational activities in which there is a physical or temporal separation between the learner and an educational agent. One particular kind of learning, open learning, refers to learning or education for which efforts are made to minimize constraints to learner participation. As with distance education, this term encompasses what has been variously referred to as distributed learning, flexible learning, online education, web-based education, independent learning, correspondence instruction, etc. 


\section{Purpose of this Journal}

The purpose of this refereed, interactive, online journal is to contribute and disseminate to practitioners and scholars worldwide scholarly knowledge in each of three areas: theory, research, and best practice in open and distance learning. Because our aim is for IRRODL to become the premier international journal of open and distance learning, we seek high quality submissions in each of these three areas. In harmony with the open learning philosophy that distance education should serve to remove barriers to those who, given their geographical location, previous level of schooling, or other life circumstances would otherwise not be able to access distance education opportunities, subscriptions are free to individuals. Regardless of geographical location, anyone connected to the Internet will have free access to the journal.

\section{Content}

Despite its title, The International Review of Research in Open and Distance Learning is intended to be a journal in which readers can inform themselves about distance education developments in theory, research, and best practice. Our aim is to have all three elements present in every issue. Some articles will stress one of the elements more than the other two. Other articles will combine two or three elements. Ideally, the collection of articles selected for each issue will convey to readers an overall sense of balance among all three elements.

Theory. Articles that focus on theory will highlight plausible or empirically determined principles offered to explain various distance education phenomena. There are numerous ways to categorize theory. One way is indicated in the terms: idiothetic versus nomothetic. Because of the predominantly applied nature of the field of open and distance learning, most theory in open and distance learning - when it is articulated - tends to be idiothetic, that is intended to explain the circumstances of single cases. There are relatively few examples of nomothetic theory, i.e., theory intended to explain phenomena in multiple cases. Articles in IRRODL that stress theory should enable readers to see how the theory relates to the existing distance education literature and to gain new levels of understanding about the nature and interrelationships among specific distance education phenomena. Such articles should clearly articulate the implications of the theory offered for research, improved practice and/or further theory development.

Research. Authors are invited to submit for publication well-written reviews of the theoretical and research literature on specific topics as well as original research reports of systematic data collection, analysis and interpretation. Both quantitative and qualitative research are acceptable. The choice of which type of research to conduct is dictated by the kinds of questions driving the study,

International Review of Research in Open and Distance Learning 
the nature and availability of the data, and the means to collect and interpret the data. These will vary from study to study. Often studies will combine both types of research analyses. Any type of research - as long as it has been conducted systematically in a responsible and defensible manner - will be considered for publication in IRRODL. Articles that consist of either literature reviews or reports of original research should clearly articulate implications for theory development, improved practice, and/or further research. Not generally acceptable for publication would be articles based on exploratory research, i.e., research conducted to generate insights that can inform subsequent research to be conducted with more methodological rigor.

Best Practice. Authors are invited to submit for publication manuscripts that focus on "best practice," highlighting the experience of individuals and/or institutions engaged in the process of distance learning/teaching, from which distance educators in other settings may gain insights regarding how they might improve their own performance. "Best practice" articles may consist of detailed descriptions of particular open and distance learning activities. Alternatively, they might present cogent arguments or proposals for enhancement and/or expansion of existing open and distance learning activities. Featured "best practices" may include learners' experiences, methods, techniques, delivery systems, policies, issues, etc. If an article is based on conclusions that have been reached after careful observations that, although not conducted with the rigor of a formal research project, nevertheless appear to be well grounded, it may well be considered for inclusion in this category. To increase the usefulness and generalizability of their reports, authors should explain how the best practices described in their articles relate to the existing distance education literature and clearly articulate the "so what" for distance education theory, research, and/or practice in a wide variety of cultural, national, and institutional settings.

\section{Structure}

With the possible exception of "theme issues," each issue of IRRODL will contain the following sections:

- "Main section": scholarly articles, refereed, featuring theory, research, and or best practice in open and distance learning

- "Notes": containing information designed to provide distance educators with news concerning developments regarding research, practice, additions to the literature, and conferences related to open and distance learning.

- "Web Conference": For 30-45 days following release of each issue, readers will have the opportunity to carry on online conversations, via computermediated communication, with article authors and other readers.

International Review of Research in Open and Distance Learning 


\section{Explanation of the Theme for Number 1}

Addressing the theme "The Problems and the Promise: Into the New Century," distinguished and internationally recognized scholars have written the six articles that appear in this first issue. Two articles address each of three areas: theory, research and best practice in open and distance learning. Reflecting the different perspectives of their authors, these articles review both the record and prospects of advancement of open and distance learning in each of these areas. Although not exhaustive in their respective reviews, these articles will inform both those who are seasoned veterans as well as those who are newcomers to the field of open and distance learning. Collectively, the authors in this first issue present many insights for the advancement of theory, research, and practice in open and distance learning.

Clearly theory can inform both research and practice. Research can confirm and refine theory and, at the same time, provide guidance for improved practice. When reflected upon, practice, in turn, can inform theory and inspire research. Despite the generally recognized value of these interrelationships, it is surprising how little those who are engaged in the provision of education and training at a distance draw on the theoretical foundations of the field. It is also surprising how seldom systematic and rigorous research is conducted to test, confirm and refine theory. The challenge facing the field of open and distance learning is to be aware of the theoretical foundations of the field, conduct research that will enable expansion of those foundations, and to thus engage in the more knowledgeable and effective practice of open and distance learning. The content of this first issue of IRRODL constitutes one response to that challenge.

\section{A Word of Appreciation}

The establishment of IRRODL and the launching of this initial issue have resulted from a significant team effort. For that reason I take this opportunity to express appreciation to the Executive Group of Athabasca University - Canada's Open University - for their vision in deciding to make the journal an institutional priority; the Associated Editors whose advice and assistance have been crucial to the determination of the policies and structure of the publication. I especially commend our Managing Editor, Ms. Jan Thiessen, without whose extraordinary "second," "third" and even "fourth mile" service, IRRODL would still be on the drawing board. I express appreciation to the Editorial Board and Consulting Editors who from different countries on every continent have agreed to lend us a hand in this enterprise. I acknowledge the assistance of the moderators and assistant moderators of the three computer conferences that follow the release of this first issue. I am grateful, too, to Mike Sosteric and his assistants who have been responsible for establishing a technical "home" for IRRODL with the International Consortium for the Advancement of Academic 
Publication.

Finally, I express appreciation to you, our reader. Your comments in response to this initial issue and your manuscript contributions are most welcome. I look forward to hearing from you.

Citation Format

Cookson, Peter S. (2000) Editorial. International Review of Research in Open and Distance Learning: 1, 1. http://www.icaap.org/iuicode?149.1.1.11

International Review of Research in Open and Distance Learning 
ISSN: $1492-3831$

Vol. 1, No. 1 (June 2000)

\title{
Theoretical Challenges for Distance Education in the 21st Century: A Shift from Structural to Trans- actional Issues
}

\author{
Randy Garrison
}

\begin{abstract}
The premise of this article is that theoretical frameworks and models are essential to the long-term credibility and viability of a field of practice. In order to assess the theoretical challenges facing the field of distance education, the significant theoretical contributions to distance education in the last century are briefly reviewed. This review of distance education as a field of study reveals an early preoccupation with organizational and structural constraints. However, the review also reveals that the theoretical development of the field is progressing from organizational to transactional issues and assumptions. The question is whether distance education has the theoretical foundation to take it into the 21st century and whether distance education theory development will keep pace with innovations in technology and practice.
\end{abstract}

Distance education methodologies have come into prominence during the last decades of the 20th century. The confluence of the need for continuous learning and unprecedented technological innovation in communications have pushed distance education approaches to the forefront of educational practice. However, whether the leaders of these initiatives are the technically literate or the politically powerful, they generally lack a coherent understanding of distance education practice and the full range of possibilities available to achieve desired outcomes. Senior administrators in higher education have become focused, not on educational issues, but the fiscal implications (i.e., cost savings) of distance education, and technology companies see profits (Feenberg, 1999).

Conceptual confusion is created with the advent of new terminology (virtual, open, distributed and distance education), new technologies, new program demands, new audiences, and new commercially competitive providers. These developments present enormous challenges for educators to make sense of the distance educational options available. In the context of current change, competition and confusion, distance educators have an unprecedented opportunity to provide leadership and direction. The challenge is to provide theory that will explain and anticipate distance education practices for a broad range of emerging educational purposes and experiences. The question is whether distance 
Theoretical Challenges for Distance Education in the 21st Century: A Shift from Structural to Transactional Issues

education possesses the theoretical foundation and commitment to take it into the 21 st century.

How well distance educators understand and communicate the principles of, and approaches to, distance education will determine their leadership role in the broader educational field. Leadership requires that the field's theories reflect the diversity and choice open to educators when adopting new technologies and approaches to teaching and learning at a distance. In much of traditional education there is a great deal of rhetoric about the need to adopt distance education methods. However, progress has been limited because few have the conceptual understanding to create a viable strategic plan for adopting distance education methods congruent with their institutional values and goals. Theory is an essential tool for educators to rethink how they will meet the needs of their institution and students when adopting distance education approaches.

Recent and rapid technological developments raise questions whether distance education theory has kept pace with new, affordable applications of communications technology and the changing educational needs of a learning society. We might ask whether distance education theory has captured the full range of possibilities made available by the rich and diverse developments in the field of communications and information technology? Does distance education as a field of study possess a synthesis of the principles and concepts capable of explaining and predicting developments in distance education in the 21st century?

In addressing these questions, this article will review the significant theoretical developments and contributions to the study of distance education. It will be shown that the study of distance education in the 20th century was primarily focused on distance constraints and approaches that bridged geographical constraints by way of organizational strategies such as the mass production and delivery of learning packages. This has generally been identified as the industrial era of distance education. More recently, we shall see that the focus in the study of distance education has shifted to educational issues associated with the teaching-learning transaction, specifically, the concerns regarding real, sustained communication, as well as emerging communications technology to support sustained communication anytime, anywhere.

As a consequence of documenting these theoretical developments, it will be argued that the 21st century represents the postindustrial era where transactional issues (i.e., teaching and learning) will predominate over structural constraints (i.e., geographical distance). From this, the challenges facing theory development in distance education will be identified as will a strategy for the development of theory that reflects current practice. However, before reviewing distance education theory, it would be advantageous to understand what is meant by theory and its value to a field of practice.

International Review of Research in Open and Distance Learning 
Theoretical Challenges for Distance Education in the 21st Century: A Shift

\section{Expectations of Theory}

Theoretical inquiry is central to the vitality and development of a field of practice - not to mention its recognition and credibility from those not yet initiated into the field. The theoretical foundations of a field describe and inform the practice and provide the primary means to guide future developments. The power of ideas, as represented in our theories, influences practice directly by focusing perspective, revealing knowledge and suggesting alternatives. Since ideas and ideals shape distance education practice, attention and effort must be devoted to the development of coherent, rigorous and valid theory. Theory is not limited to describing what is, but good theory should also help predict what will or could be.

Theory is also invaluable in guiding the complex practice of a rational process such as teaching and learning at a distance. Education is a purposeful activity and theory provides us with the understanding necessary to take effective action. Action, otherwise, is fortuitous or capricious. While those who are experts in the practice of a variety of forms of distance education may have the tacit knowledge to intuitively guide their educational decisions and effectively facilitate learning, this is not sufficient for the vast majority in the field. Nor is it helpful in directing new research and generating new ideas and concepts. It is theory that provides a coherent ordering of relevant variables and relationships to guide both practitioners and researchers.

But what do we mean by theory? What constitutes theory? Before we can assess distance education theory, it may be helpful to briefly outline what might constitute a theory.

Definitions of theory are numerous and somewhat problematic. For the sake of our discussion here let us begin with the basic definition that theory is "an explanation, a systematic account of relationships among phenomena" (McMillan \& Schumacher, 1984, p. 11). To expand upon this definition, theory is a coherent and systematic ordering of ideas, concepts, and models with the purpose of constructing meaning to explain, interpret and shape practice. Theory can provide a perspective that reduces complexity while suggesting generalizability. The organized body of knowledge we call theory is an abstract and parsimonious constellation of articulated constructs for the express purpose of understanding and guiding practice.

Theory may have a number of forms. In this article, frameworks, models and concepts are considered important elements of theory and, in some cases, are synonymous with theory. A theoretical framework represents a broad paradigmatic set of assumptions that provides the elements of the theory but without the detail and completeness (nuances) of a comprehensive theory. A model is a less abstract form of a theory and represents structural relationships among the key concepts. It is a replica and often provides visual simplicity that can be 
Theoretical Challenges for Distance Education in the 21st Century: A Shift

grasped at a glance. However, by itself, it may lack the richness of explanation inherent in a theory. Finally, concepts are the building blocks of a theory and evolve from ideas generated from direct experience. In this way they are less abstract and do not have the coherence of a framework, model or theory.

As noted previously, the purpose of theory is to create conceptual order and provide simplicity in describing complex phenomena. This order will reflect the values and assumptions that ultimately shape practice. It provides the foundational framework for the development of a field of study through the coherent description of current practice as well as the analysis and prediction of current and emerging trends. Such developments are revealed and sustained through rigorous and coherent theory building that is open to critique, discussion and confirmation. Theory is essential to understanding and communicating the purpose, methods and goals of a field of practice.

Good theory will reveal areas of inquiry and suggest potential hypotheses for the continued study and development of a field's theoretical foundation. This need for continuous theoretical development is a particular challenge for distance education as the technology and delivery methods have evolved rapidly. New descriptions and interpretations of practice are necessitated by the evolving practice of the field. In this way theory and practice are inextricably linked and rational action becomes theory-based.

Distance education theory must reflect both the purposeful and spontaneous nature of an educational experience. For this reason, we need theoretical constructs that are coherent and articulated but also flexible enough so as not to constrain critical and creative thought. The practical and evolving approaches to distance education must be reflected in its theory. The emerging practice of distance education is incorporating new and sophisticated communications technology. These technologies allow for the creation of synchronous and asynchronous collaborative communities of inquiry. The pressing challenge facing distance education theorists, therefore, is to adapt current theories to these new realities and, where appropriate, create new theory.

To understand the theoretical challenges facing distance education, it is essential to begin with a selected review of some of the influential theoretical contributions and then provide an analysis and interpretation of the current state of the field in terms of its study. In this regard, the review and analysis will reveal a distinct shift from organizational and distance concerns to transactional and educational issues. The results of this examination also suggest that theory may be lacking in the description of current developments in distance education practice, not to mention revealing future possibilities. 
Theoretical Challenges for Distance Education in the 21st Century: A Shift

\section{Major Theoretical Contributions}

While it is not the purpose here to review definitions of distance education, a brief comment may be in order to clarify the place of definitions in theory development. In the past, definitions of distance education have served a useful purpose by explicitly revealing differing perspectives and assumptions. While definitions have provided a valuable first step, definitions in and of themselves do not constitute a theory. A definition may delimit the practice or identify specific principles but it is neither explanatory nor suggestive of future practice. Generally, the field has moved beyond definitional issues and has focused on the systematic development of theoretical frameworks and models.

We start our review of the theoretical contributions to distance education with the influential work of Charles Wedemeyer. In the 1960s Wedemeyer broke from the concept of correspondence study and focused instead on independent study or learning. In doing so he noted that a "particular philosophy of teaching and learning usually lies behind" (Wedemeyer, 1971, p. 548) the concepts of independent study and learning. It was clear that this was not merely a change in terminology. The focus on the pedagogical assumptions of independent study was a shift from the world of correspondence study dominated by organizational and administrative concerns, to a focus on educational issues concerning learning at a distance.

Notwithstanding Wedemeyer's (1971) clear focus on teaching and learning, independent study was focused on the individual as opposed to the group. Wedemeyer (1971) was careful to identify the characteristics and advantages of independent learning - not the least of which was "a democratic social ideal" (p. 549) of not denying anybody the opportunity to learn. Consistent with the principles of equity and access, independent study was also related to self-directed learning and self-regulation. Again we see a concern for learning but under the geographical and temporal control of the learner.

In addition to the obvious separation of teaching and learning tasks and responsibilities, Wedemeyer (1971) also identified defining characteristics such as communication, pacing, convenience and self-determination of goals and activities. He was a great advocate of freedom and choice for the learner. However, most significantly, Wedemeyer (1971) also noted that independent study "courses offer less freedom in goal determination and activity selection" (p. 551). He foreshadowed (or perhaps precipitated) a persistent debate in the literature by critiquing the practice of not individualizing (i.e., personalizing) independent study courses and the general practice and complacency to let the course determine (i.e., prescribe) the goals and activities. In this regard, Wedemeyer (1971) questioned "the seeming rigidity of the format and materials [that] apparently deters teachers and students from more completely exercising their respective options" (p. 551). He insisted that the "independent study method is not, in its basic concepts, different from other teaching-learning methods" (p. 553).

International Review of Research in Open and Distance Learning 
Theoretical Challenges for Distance Education in the 21st Century: A Shift

Wedemeyer's work is surprisingly relevant to a new era of theory development.

A hallmark of Wedemeyer's work was his "contribution to the establishment of the British Open University [BOU]" (Sherow \& Wedemeyer, 1990, p.18). Through the Articulated Instructional Media (AIM) project initiated by Wedemeyer in 1964, it "was proposed that a unique system be developed for a new type of institution ... made possible through course design utilizing media and technology and ... supported by counseling and resource and learning centres" (Sherow \& Wedemeyer, 1990, p. 18). The principles behind AIM were the subject of lectures throughout the United Kingdom in 1965. While the exact influence of his writings and lectures on the establishment of the BOU may be open to debate, clearly Charles Wedemeyer was a pioneer in the study of distance education.

Another person who was clearly linked to the historic development of the BOU was Otto Peters. From the current author's perspective, the most coherent, rigorous and pervasive example of distance education theory to date is the industrial production model of Otto Peters. In this model, conceived in the mid 1960 s, Peters analyzed the structure of distance education and noted the possibility of adopting industrial production techniques such as a division of labor, mass production, and organization to realize economies of scale and reduce unit costs (Peters, 1994a). Considering the structural constraints and the reliance on self-instructional print packages, for Peters, this was the ideal context to adopt industrial approaches to education. While the industrial model had an enormous influence on distance education, it was not a theory of teaching nor of learning, but rather a contribution to clear thought about the organization of distance education. However, it had considerable influence on the creation of the British Open University in the early 1970s, and, in many ways, to this day, it dominates the field of distance education.

Peters' industrial model is an organizational model. It is about organizing the educational process to realize economies of scale. For this reason, teaching and learning issues are not of particular relevance. Peters (1994a) describes the industrial approach as "objectification of the teaching process" (p. 111). According to Peters (1994b), it "reduces the forms of shared learning, and keeps learners away from personal interactions and critical discourse" (p. 16). For this reason, Peters did not advocate this approach for all of distance education.

The dominance of structural and organizational concerns of the industrial model, over teaching and learning issues, is central to understanding theoretical developments and the challenges we face in developing distance education theory in this century. The industrial model placed in clear contrast the zero sum situation in having to choose between independence and interaction and established a constructive debate over the years regarding the inherent trade-off of these issues (Daniel \& Marquis, 1979). In recent years, the advent of computer mediated communication (CMC) rendered this debate moot as it made possible both an independent and collaborative learning experience.

International Review of Research in Open and Distance Learning 
To understand Peters' core philosophical position, we take a brief look at his most recent work. Due to unprecedented changes in society, Peters (2000) offers a new structure for university education to include three basic forms of academic learning - "self-learning, tele-learning and social intercourse" (p. 15). Here he extends independent forms of learning at a distance (i.e., self-learning and tele-learning) with the inclusion of social intercourse. His argument is that communications technology and lifelong learning demands will precipitate a "transformation of the traditional university [and, presumably, all higher education] into an institution of self-study and distance teaching" (Peters, 2000, p. 20). From Peters' perspective, self-learning and tele-learning are very much autonomous approaches to learning.

It is safe to say that Peters remains an advocate for independent, self-study, although enhanced with social intercourse defined in a non-formal and individually controlled manner. While we see a new recognition for interaction, there is still a strong identification with the ideal of independence consistent with his industrial model. His social intercourse seems to support a general social presence among learners rather than academic critical discourse.

The point for Peters (2000) is that face-to-face discussion "can only be reproduced in part, and indeed in a reduced form, by mediated means" (p. 17). This is an important point. Here Peters identifies an important area of needed theory development when he rightly notes the difficulty of replicating face-to-face interaction by mediated means. In fact, Garrison, Anderson and Archer (2000) are studying the issue of learning in a text-based environment in the context of CMC. The theoretical analysis suggests that face-to-face interaction cannot be reproduced in whole within a text-based environment. The communication characteristics are very different and, therefore, the nature of the educational experience will be altered but not necessarily in a negative manner. However, Garrison et al. (2000) argue that a text-based environment may have an inherent communications advantage in supporting critical discourse in a community of inquiry. Regardless, these questions point to the importance of studying emerging issues such as the characteristics of spoken and written communication for the development of theory that helps distance education practitioners understand the use of mediated communication for educational purposes.

Next, we move to another pioneering theorist in distance education, Borje Holmberg, who has made substantial contributions to the theory of distance education over several decades. At the core of his (1989) theory of distance education practice is the concept of "guided didactic conversation" (p. 43). This refers to both real and simulated conversations, although the reliance is upon simulated conversation. As such, the emphasis is very much on the content and conversational character of the written pre-produced course package. Holmberg (1989) does acknowledge that regardless of how conversational the pre-produced course is, "communication between the student and the distance tutor has essential tasks" (p. 64). However, real conversation with the tutor is, by economic necessity, 
Theoretical Challenges for Distance Education in the 21st Century: A Shift

supplementary to the pre-produced course.

Guided didactic conversation, Holmberg (1989) argues, is a "pervasive characteristic of distance education" (p. 43). In essence, his theory posits distance education as "friendly conversation [fostered by] well-developed self-instructional materials [resulting in] feelings of personal relation ... intellectual pleasure [and] study motivation" (p. 43). It is the responsibility of course developers to create this simulated conversation through well-written materials. Although conversation was the defining characteristic in Holmberg's theory of distance education, this theory was directed to the pre-produced course package and clearly within the industrial paradigm.

While Holmberg makes a great effort to place teaching at the core of his theory, his own structural assumptions and the central role of the self-study learning package limit teaching to one-way communication. The question arises as to whether an inert learning package, regardless of how well it is written, is a sufficient substitute for real sustained communication with the teacher as both content and learning expert (a tutor does not always fully meet this standard). The role of the teacher was largely simulated by way of written instructions and commentary. It is also interesting to note that there is no recognition that written communication may be qualitatively different from verbal discourse when guiding students. In sum, the organizational assumptions and principles of the industrial model and the dependence upon written communication seriously constrain and limit the role of conversation and the full emergence of a transactional perspective.

Another seminal work, first introduced in the early 1970s, is that of Michael Moore. Moore recognized the limitation of the structure of the independent learning package by including dialogue as a second variable. Moore's theory of transactional distance is intuitively appealing and moves the field toward the realization of a pedagogical theory. According to Moore (1991), transactional distance is pedagogical, not geographic, and necessitates "special organizations and teaching procedures" (p. 3) composed of two variables (clusters, dimensions?) - structure and dialogue (Moore, 1990; Moore \& Kearsley, 1996). Structure reflects the course's design and is largely a function of the teaching organization and communications media employed. On the other hand, dialogue is also associated with the medium of communication and may include either real two-way communication or Holmberg's internal didactic conversation. In Moore's theory, the most distant program has low dialogue and low structure while the least distant has high dialogue and high structure.

Moore then adds another dimension - learner autonomy. Autonomy appears to be associated with a personality characteristic - that being personal responsibility associated with self-directedness (Moore, 1993; Moore \& Kearsley, 1996). The greater the transactional distance the greater responsibility is placed on the learner. However, previously Moore (1990) defines autonomy as "the extent to which in a programme the learner determines objectives, implementation

International Review of Research in Open and Distance Learning 
Theoretical Challenges for Distance Education in the 21st Century: A Shift from Structural to Transactional Issues

procedures, and resources and evaluation" (p. 13). He suggests that the other end of this continuum is teacher control. The difficulty is that this polarization appears to conceptualize autonomy as less a function of personal responsibility and more a function of structure and the learning materials themselves.

In assessing Moore's contribution, he attempts to incorporate the structure of the industrial approach with the interaction of the transactional approach. In this way he extends the pedagogical perspective but appears to retain the dominant structural features of the industrial model. For example, he states, "what we are normally referring to as distance education is a subset of all educational programmes, the subset characterised by greater structure, [and] lower dialogue" (Moore, 1990, p. 12). More significantly, however, the exact nature of the interrelationships among structure, dialog and autonomy is not clear. There is confusion around whether structure and dialogue are variables, clusters or dimensions. Unfortunately, Moore has used different terms (i.e., variables, clusters, dimensions) at various times. Understanding transactional distance very much depends upon whether we are discussing a two-by-two matrix, a single continuum, or distinct clusters. This confusion is compounded when we add the concept of autonomy with its definitional problems (psychological or educational autonomy) and its relationship to transactional distance. Clearly, Moore's work remains one of the most appealing and well known theories of distance education. Yet, more macrolevel theoretical work is required that goes beyond simply refining this promising and appealing theory (Moore \& Kearsley, 1996). Future work might focus on the interrelationship amongst the variables/concepts of dialogue, structure and autonomy. Are these orthogonally related or do they overlap? In addition to the "infilling of the theoretical spaces" (Moore, 1990, p. 14), the creation of a visual model would go a long way to clarifying the structural relationships among these concepts.

The next contribution to be discussed here explicitly places sustained real twoway communication at the core of the educational experience, regardless of the separation of teacher and student. This is a framework provided by Garrison (1989). While mediated communication is a defining characteristic of distance education and an important design concern, this framework did not redefine the essential nature of the teaching-learning transaction. Garrison and Shale (1990) made a point of emphasizing educational issues and titled their book accordingly - Education at a Distance. As Garrison and Shale (1990) state, they wished to "avoid the restrictive trap of describing distance education based upon its existing forms and structures" (p. 25). These were clear attempts to focus on the functional basis of education first by placing the teaching and learning transaction at the core of distance education practice. This was a clear attempt to break loose of the organizational assumptions of the industrial model.

The theoretical model proposed by Garrison and Baynton (1987) and updated by Garrison (1989) reflects the assumptions of this paradigmatic shift. This model of the educational transaction at a distance placed the concept of control

International Review of Research in Open and Distance Learning 
Theoretical Challenges for Distance Education in the 21st Century: A Shift

at the center of the transaction. Control was defined as the opportunity and ability to influence the educational transaction. This was intended to replace the concept of independence (self-study), often a core element of distance education with a more comprehensive perspective of the educational transaction. Shared control was seen to be reflective of the transactional nature of an educational experience. Two-way communication is central to control and at variance with independence that has the effect of reducing the legitimate and worthwhile role of the teacher and, thereby, risking isolation.

The control model places within the macrostructural level of teacher, student and content the microlevel transactional elements of proficiency (ability and motivation), support (human and non-human resources), and independence (opportunity to choose). Consideration of these transactional elements will determine the appropriate balance of control which can only be assessed and constantly adjusted through sustained two-way communication. Independence necessitated by structural constraints reflects only one set of variables to be considered in a complex educational transaction.

A more promising and somewhat more current contribution generated from a collaborative educational perspective is a framework and analytical model provided by Henri (1992). This framework was aimed at helping distance educators understand the learning process and the facilitation of interaction for collaborative learning. The analytical model consists of five dimensions of the learning process - participation, interaction, social, cognitive, and metacognitive. While these dimensions are in need of verification, the framework has informed and framed several studies of collaborative learning by way of computer mediated communication (Angeli, Bonk \& Hara, 1998; Fabro, 1996; Hara, Bonk \& Angeli, 2000; McDonald, 1998).

Perhaps Henri's real contribution is that it is a collaborative view of teaching and learning and provides a potential structure for coding CMC messages to study the nature and quality of the discourse. Henri's framework is a psychosocial, transactional perspective focusing specifically on teaching and learning facilitated through mediated communication. Interestingly, this framework is silent with regard to structural or distance constraints. Henri's framework focuses on educational and transactional issues and, therefore, is a significant shift away from the industrial model.

The previous descriptions certainly do not exhaust the many theoretical contributions to the field of distance education. Other contributions were not noted due either to their overlap with those described previously (e.g., Saba, 1989); their focus on definitional and historical descriptions (e.g., Keegan, 1990); or, as is the case of more recent contributions, their importance and impact being less well recognized and understood (Anderson \& Garrison, 1997). It must also be emphasized that only the basic assumptions and concepts were extracted from the theories reviewed, while nuances and other refinements were omitted. However, it can be stated with some confidence that the selected models accurately

International Review of Research in Open and Distance Learning 
Theoretical Challenges for Distance Education in the 21st Century: A Shift from Structural to Transactional Issues

reflect the progression of a theoretical development of the field of distance education along an organizational (structural) - transactional (teaching and learning) continuum. The question now is whether distance education has the theoretical foundation to take it into the 21st century, and what theoretical challenges face distance education in keeping pace with emerging communications technology and new practices?

\section{Progress and Challenges}

In surveying the core theoretical contributions of the last three decades, we see evidence of a sound theoretical foundation. However, it is less obvious as to whether our current state of knowledge development is adequate to explain and shape new practices. It may well be worthwhile to step back and see if we are not dealing with a significant shift in perspective and practice and then assess the coherence and comprehensiveness of distance education theory. As noted previously, the evidence here suggests that we are experiencing the emergence of a new era of distance education characterized by a focus on transactional issues. Advances in communications technology have rendered the structural constraint of distance a relatively minor design challenge. It is the nature of a sustained educational transaction at a distance that must be described, understood and abstracted in a manner accessible to the broader field of educational practice.

Interestingly, it is Peters (1993), the theorist who provided the industrial model, who asks whether there are "early signs of a 'new era' which might be called 'postindustrial'?" (p. 40). The results of the previous review and similar arguments elsewhere (Garrison, 1997) suggest that we are entering a postindustrial era of distance education characterized by the ability to personalize and share control of the educational transaction through frequent two-way communication in the context of a community of learners. Moreover, this can be accomplished in an affordable manner along with access to educational resources and information via networks that may well provide educational experiences superior to traditional face-to-face educational experiences. An educator, as a member of a community of learners and not solely as a member of an organizational team of curriculum developers creating prepackaged self-study learning materials, may facilitate education at a distance in a timely and adaptable manner.

After having argued that a transactional approach (postindustrial) to distance education is emerging, it is important to qualify this statement by emphasizing that postindustrial technologies will not replace industrial approaches to distance education in the near future (Annand, 1999). Distance education theory should not be viewed as advocating "one-for-all practical recipes" (Sfard, 1998, p. 10), regardless of whether they are on the structural or transactional end of the distance education theoretical continuum. Having both valid structural and transactional theories are "our protection against theoretical excesses" (Sfard,

International Review of Research in Open and Distance Learning 
Theoretical Challenges for Distance Education in the 21st Century: A Shift from Structural to Transactional Issues

1998, p. 10). Orthodoxy of practice and certainty of perspective is detrimental in both short-term successes and long-term development of any field of study and practice. The ultimate theoretical challenge of any field of practice is to achieve a synthesis of perspectives and theories (i.e., global theory) that reflects the complete continuum and is inclusive of a full range of practices. At the same time, it must be noted that this is not a realistic expectation for distance education theory in the near term.

This century will see the emergence of a postmodern era of distance education characterized by increased diversity and choice. Such development is made possible by new communication technologies, as exemplified by the evolution of the open universities in their adoption of new models to complement the traditional self-paced, independent learning model of the industrial era (Davis, 1999). With continuous refinements, the ideal of the industrial era will become increasingly difficult to find in practice, but it still provides an important conceptual marker in the evolution of distance education as a field of study and practice. However, amongst the approaches to postindustrial distance education are principles and characteristics based upon the assumptions of a transactional model. If the field is to be relevant and credible in the 21st century, it is these assumptions, principles and characteristics that will inform new theoretical frameworks, models and concepts needed in distance education.

The challenge the field of distance education faces is the construction of theories addressing specific components and concerns of postindustrial distance education. For example, the creation of distance education theory that informs and explains computer mediated communication is both an opportunity and challenge. Asynchronous collaborative learning may well be the defining technology of the postindustrial era of distance education. It has been argued that this technology, along with audio and video conferencing, represents a paradigmatic shift in distance education, making it possible to adopt collaborative approaches to learning at a distance (Garrison, 1997). However, this challenge and opportunity for theoretical development are associated with the reality that this medium is based upon written communication. Asynchronous written communication represents very different characteristics than real-time verbal communication. The former encourages reflection and precision while the latter is spontaneous and fleeting. While distance education practice has relied heavily on print, only recently have distance education theorists begun to recognize the unique characteristics of text-based communication and realize that such communication may impact the facilitation of learning outcomes in different ways (Garrison, et al., 2000; Peters, 2000).

Theories must be developed that speak to the needs and concerns of new audiences. One of the new audiences is traditional higher education institutions which have a strong interest and stake in adopting distance education approaches but are in conflict internally (Garrison \& Anderson, 1999). Higher education institutions are concerned about compromising their values and the

International Review of Research in Open and Distance Learning 
Theoretical Challenges for Distance Education in the 21st Century: A Shift

educational quality associated with a highly interactive and adaptable educational transaction. For this audience, the perception of distance education is that of the industrial model, which is anathema to their idealized (but seldom approached) teaching-learning assumptions and values. Models and approaches need to be developed that will address legitimate institutional questions and provide a vision and approach consistent with the values and goals of these institutions.

\section{Conclusion}

Theory provides a means (order and explanation) to make sense of complex practices and phenomena. The need to make sense of complexity is compounded in the context of distance education. Ideally, theory can describe current activities and provide direction for new approaches. Moreover, meaningful and relevant theory is essential to the vitality and influence of any field of practice - distance education is no exception. However, I would suggest that distance education is theoretically challenged to provide insightful frameworks that will guide us in what is, most assuredly, a new era of distance education.

The essential finding here of the brief review of prominent theoretical contributions is that, until recently, most distance education theory was dominated by organizational and structural assumptions. Concerns with the standardization of a product outweighed issues related to the adaptability of the educational transaction. While attempts were made in early distance education theories to address transactional issues, they were made to fit the Procrustean bed created by the industrial and structural assumptions of the era. However, much has changed during the last decade of the 20th century with the focus switching to facilitating the teaching and learning transaction at a distance.

The challenge for distance education theorists in the new century is to provide an understanding of the opportunities and limitations of facilitating teaching and learning at a distance with a variety of methods and technologies. This will demand theories that reflect a collaborative approach to distance education (i.e., as opposed to independent learning) and have at their core an adaptive teaching and learning transaction. Distance education will be characterized by an adaptability of design before and during the teaching and learning process made possible by affordable and highly interactive communications technology. This adaptability in designing the educational transaction based upon sustained communication and collaborative experiences reflects the essence of the postindustrial era of distance education. At the same time, this fundamental shift in focus reveals the challenge facing distance education theorists if they are to remain relevant and broaden their influence in the adoption of new and emerging distance learning approaches and technologies. Theory in distance education must evolve to reflect current and emerging innovative practices of designing

International Review of Research in Open and Distance Learning 
Theoretical Challenges for Distance Education in the 21st Century: A Shift

and delivering education at a distance.

The relevance as well as explanatory and predictive power of the theories developed will determine the recognition, credibility and influence of any field of practice. For distance education this means that theoretical developments must reflect changes taking place in the field of practice. When the theory of distance education catches up to recent developments in the practice of distance education, then the focus can shift to predictive models with the potential to shape future practice. In the medium term, however, we are likely to see a range of theories directed toward specific technological and educational needs and purposes. Grand theoretical syntheses may not be a realistic immediate goal of an emerging field of study such as distance education. It remains to be seen whether a masterful and comprehensive theory encompassing the structural characteristics of the industrial era along with the transactional properties of the postindustrial era of distance education can be realized. 
Theoretical Challenges for Distance Education in the 21st Century: A Shift

from Structural to Transactional Issues

\section{References}

Anderson, T. D., \& Garrison, D. R. (1997). New roles for learners at a distance. In C. C. Gibson (Ed.), Distance learners in higher education: Institutional responses for quality outcomes. Madison, WI: Atwood Publishing.

Angeli, C., Bonk, C., \& Hara, N. (1998). Content analysis of online discussion in an applied educational psychology course. CRLT Technical Report No. 2-98. Retrieved May 15, 2000: http://crlt.indiana.edu/publications/crlt982.pdf

Annand, D. (1999). The problem of computer conferencing for distance-based universities. Open Learning, 14(3), 47-51.

Daniel, J. S., \& Marquis, C. (1979). Interaction and independence: Getting the mixture right. Teaching at a Distance, 14, 29-44.

Davis, A. (1999). Good practice and distance education technologies at Canada's open university. Paper presented at TEL-isphere 99, Barbados.

Fabro, K. G. (1996). Computer conferencing in higher education: An exploration of communication and cognitive development issues. Unpublished master's thesis, University of Calgary, Calgary, Alberta, Canada.

Feenberg, A. (1999). Reflections on the distance learning controversy. Canadian Journal of Communication, 24, 337-348.

Garrison, D. R. (1989). Understanding distance education: A framework for the future. London: Routledge.

Garrison, D. R. (1997). Computer conferencing: The post-industrial age of distance education. Open Learning, 12(2), 3-11.

Garrison, D. R., \& Anderson, T. (1999). Avoiding the industrialization of research universities: Big and little distance education. The American Journal of Distance Education, 13(2), 48-63.

Garrison, D. R., Anderson, T., \& Archer, W. (2000). Critical inquiry in a text-based environment: Computer conferencing in higher education. The Internet and Higher Education, 2(2-3), 1-19.

Garrison, D. R. \& Baynton, M. (1987). Beyond independence in distance education: The concept of control. The American Journal of Distance Education, $1(3), 3-15$.

Garrison, D. R. \& Shale, D. (Eds.). (1990). Education at a distance: From issues to practice. Melbourne, FL: Krieger.

Hara, N., Bonk, C. J., \& Angeli, C. (2000). Content analysis of online discussion 
Theoretical Challenges for Distance Education in the 21st Century: A Shift

in an applied educational psychology course. Instructional Science, 28, 115152 .

Henri, F. (1992). Computer conferencing and content analysis. In A. R. Kaye (Ed.), Collaborative learning through computer conferencing: The Najaden papers. (pp. 117-136). Berlin: Springer-Verlag.

Holmberg, B. (1989). Theory and practice of distance education. London: Routledge.

Keegan, D. (1990). Foundations of distance education (2nd ed.). London: Routledge.

McDonald, J. (1998). Interpersonal group dynamics and development in computer conferencing: The rest of the story. In Proceedings of the Annual Conference on Distance Teaching and Learning (pp. 243-248). Madison, Wisconson.

McMillan, J. H., \& Schumacher, S. (1984). Research in education: A conceptual introduction. Boston: Little, Brown.

Moore, M. (1990). Recent contributions to the theory of distance education. Open Learning, 5(3), 10-15.

Moore, M. G. (1991). Editorial: Distance education theory. The American Journal of Distance Education, 5(3), 1-6.

Moore, M. (1993). Theory of transactional distance. In D. Keegan (Ed.), Theoretical principles of distance education (pp. 22-38). London: Routledge.

Moore, M. G., \& Kearsley, G. (1996). Distance education: A systems view. New York: Wadsworth.

Peters, O. (1993). Distance education in a postindustrial society. In D. Keegan (Ed.), Theoretical principles of distance education (pp. 39-58). London: Routledge.

Peters, O. (1994a). Distance education and industrial production: A comparative interpretation in outline (1973). In Keegan, D. (Ed.), Otto Peters on distance education: The industrialization of teaching and learning (pp. 107-127). London: Routledge.

Peters, O. (1994b). Introduction. In Keegan, D. (Ed.), Otto Peters on distance education: The industrialization of teaching and learning (pp. 1-23). London: Routledge.

Peters, O. (2000). The transformation of the university into an institution of independent learning. In T. Evans \& D. Nation (Eds.), Changing university teaching: Reflections on creating educational technologies (pp.10-23).

International Review of Research in Open and Distance Learning 
Theoretical Challenges for Distance Education in the 21st Century: A Shift

London: Kogan Page.

Saba, F. (1989). Integrated telecommunications systems and instructional transaction. In M. G. Moore \& G. C. Clark (Eds.), Readings in principles of distance education: Number 1 (pp. 29-36). University Park, PA: American Centre for the Study of Distance Education.

Sfard, A. (1998). On two metaphors for learning and the dangers of choosing just one. Educational Researcher, 27(2), 4-13.

Sherow, S., \& Wedemeyer, C. (1990). Origin of distance education in the United States. In D. R. Garrison \& D. Shale (Eds.), Education at a distance: From issues to practice (pp. 7-22). Melbourne, FL: Krieger.

Wedemeyer, C. A. (1971). Independent study. In R. Deighton (Ed.), Encyclopedia of Education IV (pp. 548-557). New York: McMillan.

Citation Format

Garrison, Randy. (2000) Theoretical Challenges for Distance Education in the 21st Century A Shift from Structural to Transactional Issues. International Review of Research in Open and Distance Learning: 1, 1. http://www.icaap.org/iuicode?149.1.1.2 
International Review of Research in Open and Distance Learning (C)

ISSN: $1492-3831$

Vol. 1, No. 1 (June 2000)

\title{
Digital Learning Environments: New Possibilities and Opportunities
}

Otto Peters

\begin{abstract}
This paper deals with the general problem whether and, if so, how far the impact of the digitised learning environment on our traditional distance education will change the way in which teachers teach and learners learn. Are the dramatic innovations a menace to established ways of learning and teaching or are they the panacea to overcome some of the difficulties of our system of higher learning and to solve some of our educational problems caused by the big and far-reaching educational paradigm shift? This paper will not deal with technical or technological achievements in the field of information and communication which are, of course, revolutionary and to be acknowledged and admired. Rather, the digital learning environment will be analysed from a pedagogical point of view in order to find out what exactly are the didactic possibilities and opportunities and what are its foreseeable disadvantages.
\end{abstract}

\section{Introduction}

Let me start with a preliminary observation which will explain the way in which I intend to deal with this subject. In my country as well as in other western countries learning experts are engaged in a controversy about the nature of learning and about the problem of which reforms are necessary in teaching and learning. To describe it in simplified terms one can say that the traditionalists believe that learning takes place when expository teaching and receptive learning fit together: the teacher presents contents and the learners receive them, store them in their memory and recall them when being asked for in examinations. In fact, this mode of teaching and learning has a long tradition from antiquity to the present day. Lectures in study centres, printed teaching material as well as educational radio and TV presentations provide ample proof of this. The teacher or the programme developer determines, dominates and is responsible for the teaching-learning process in many ways. Therefore this particular kind of learning is called heteronomous learning. All of us have learned in this way at school and at university. We are used to it. And it is easy to continue in this way.

Then there are the progressives (e.g., Arnold, 1993; Boud, 1988; Dohmen, 1997; Friedrich \& Mandl, 1997; Knowles, 1975; Zimmerman \& Schunk, 1989) who 
are opposed to this kind of learning on the ground that it is basically only cognitive, that the students remain relatively inactive or even passive, that the idea that large groups of students could be offered the same content and would then learn the same is an illusion. They maintain that the competitive industrialised information and learning society needs a new type of learning which calls for active learners who are able to initiate, plan, implement, control and evaluate and also apply their learning themselves. Not only is factual knowledge important, but also competence in using the methods of obtaining it as well as the competence of co-operating with others. Here the learners dominate the teaching and learning process whereas the role of the teacher is reduced to that of a facilitator and advisor or counsellor. The learners have to take over responsibilities for their own learning. And they must be active in order to be able to learn. As no external person or institution interferes, this learning could be called autonomous. We are not used to it. And it is a very demanding and ambitious way of learning.

I hold the view that both approaches are and will remain important, especially in distance and open education.

\section{Heteronomous learning}

Supporters of a type of teaching and learning in which the teachers plan the learning process as far as possible, articulate and present the learning content, control its course by means of interventions, and guarantee results, should be particularly attracted by the opportunities provided by a digital learning environment. Among these I include those behaviourists who interpret the teaching and learning process above all with the help of stimulus/response schemata. Expository learning according to this theory means setting stimuli in the hope and expectation of corresponding responses, a procedure which usually expects to achieve its success by means of small steps and close guidance. It is therefore not surprising that programmed computer-supported learning was practised first in digital learning environments, especially as twenty years of experience was already available. Drill and practice programmes are mainly offered in this way. New were the electronic file courses from the tradition of carefully developed distance education materials and the "guided tour" through hypertext and hypermedia, in which the "guide" not only determined the path but also the type and number of "objects" to be "visited."

If we analyse this form of mainly presentational teaching, four new possibilities spring to mind which are specifically and pedagogically relevant for distance and open learning:

- several presentation methods can be combined and integrated

- multi-sensory instruction can be considerably strengthened 
- interactivity can be extended quantitatively and qualitatively

- the support system can be extended and improved

\section{The combination and integration of several pre- sentation methods}

If we reconsider the combination and integration of presentation methods in a digital learning environment we continue to be amazed by the new possibilities relevant especially to distance education. In the latter system, the printed word is the main form of presentation, but now also interesting possibilities are made available for the spoken word in the planning and design of presentations in the digital learning environment. For thousands of years this has been the most highly regarded form of presenting teaching content. When it was replaced in distance teaching about 150 years ago by the printed word, this was a sharp break with tradition and had considerable pedagogical consequences. But now in the digital learning environment the traditional spoken word is regaining importance for teaching and learning, at first only here and there, but there will be more in future, and this necessitates a (this time completely different) structural adaptation in distance education, and pedagogical consequences which we will have to be familiar with.

But there is even more. Also the image of the teacher can have an effect on students. This does not have to make an impression of a certain degree of external monotony, such as, for example, occurs in a lecture simply as a result of the lecturer standing at a podium and the students sitting at their desks. The image of the teacher can now be made more dynamic by means of different camera angles and settings, and can lead to an impact and intensity of the images never before experienced. There are possibilities here for pedagogic film direction and dramaturgy in distance education whose criteria are unknown to us.

These two innovations of the spoken word and the image of the teacher alone would be an achievement which could considerably alter the methods and efficacy of distance education, because it would then become more stimulating, because the abstraction of the presentation through letters and printing can be withdrawn where required, because the person doing the teaching becomes visible and can be experienced, and the presentation of the teaching content can become more variable, more interesting, more diversified, more intensive, more concise and more colourful, both literally and figuratively.

The problem of how these new possibilities and chances for digital learning can be used in distance education is now of considerable pedagogical importance, and the following questions should be asked:

International Review of Research in Open and Distance Learning 
- When and why should work on the screen be done with written texts?

- When and why should teachers themselves "say something" and "put in an appearance"?

- When and why is it right to combine and integrate both forms of presentation?

- When and why is it better for a neutral voice "off" to be used?

There is no doubt that these are new questions for most teachers that demand decisions from them, may not be made schematically nor at their discretion. We are confronted here with fundamental questions of digital teaching and learning which we probably will not be able to answer by means of experience gained with analogue teaching films.

\section{Multi-sensory presentations}

The exactly calculated combination of the spoken and the printed word, and still and moving pictures of the lecturing professor represents merely a small, almost minimal section of the many other pedagogical possibilities and chances. Naturally, many more new possibilities and chances that multimedia systems make available are obvious. We do not mean in this context the amazing and remarkable digital technology, which can change contents disseminated in various modes of presentation into flows of bits (Kaderali, Müller \& Rieke, 1994), which means that they can all be transmitted, disseminated, stored and even integrated and processed in accordance with pedagogical aspects in exactly the same way. It is in fact pedagogical aspects which lead to the combination and integration of these presentation modes. The multisensory impression can be used for presenting, recognising, understanding, processing, testing and experimenting, or simply for repeating. Not only the spoken and the written word are combined and integrated with a pedagogical intention, but also, where this is required, image, audio and video information, animation and even virtual reality, for example in the form of three-dimensional spaces. What we are faced with here is a cumulation, compression and intensification of presentation that has never been seen before, because it was never before possible. What a difference there is between writing on a board in a classroom, graphics printed in a study letter, monochrome pictures in a textbook, which are usually much too small anyway, and the potential audiovisual land of milk and honey into which the digital learning environment can lead us.

Heteronomous presentation can be taken to excess in certain phases here, e.g., where the student's attention is to be steered in extremely small steps because this is necessary if a very complex abstract situation is to be understood at a

International Review of Research in Open and Distance Learning 
greater depth. The student is then led by the hand by the teacher, who uses the multimedia presentation to do this.

The development of these intensive phases cannot be done by the way, because the work involved is hard, time-consuming and demanding. The pedagogical criteria which are important here must be brought to mind and reflected on before the interplay between the individual presentation sequences is planned, designed and then realised technically in a detailed script. On the other hand, the digital learning environment saves teachers from having to acquire, set up, try out and operate several different presentation apparatus, and this is certainly a great relief. The pedagogical benefit can be very great, as can be seen from the following example of a multimedia course at the FernUniversitaet.

This is an animated graphical presentation which is built up in steps in front of the students and is explained and commented on by the professor who is doing the talking. The colour makes the stages more clear, flashing draws the attention to the terms referred to for exact periods measured in seconds. Students' attention is steered and held in a special way by the movement which the picture gains by means of the parallel displacement of cross-sectional lines. This makes a regularity clear to students at a high level of abstraction. But even more: by clicking a button students can retrieve every single stage of the presentation of these graphics in any sequence they like, which means that the concept and the appropriate commentary can be repeated and understanding and comprehension strengthened and deepened. Multisensory presentation is used here for repeating and practising. The multimedia presentation on the screen can be seen in high resolution and brilliant colours. Sections of the graphics can be magnified by up to 800 percent and made much clearer in this way.

By the way, when carrying out experiments with multimedia in a digital learning environment it may be advantageous if the teacher has an idea of other specific pedagogical functions which this method of intensified illustration can have. According to Michael (1983, p. 77), it not only supports impressive presentations and, as in this case, recognition of a regularity and concept formation, but it can also serve as an aid for motivation and reproduction. In Michael's opinion however, it may also be essential to avoid an abundance of illustrations, because this can in fact be counterproductive. What teachers should do is to select the critical points in a course or course unit in which the efforts required for multimedia are best placed to illustrate learning progress and the acquisition of knowledge. Once again, genuine pedagogical considerations are required.

There may of course be objections to the increased and intensified iconic presentation, in particular from academic teachers, possibly with an indication that "illustration" is primarily a method used in teaching in schools. The first argument we can use to counter these critics is that overhead projectors are being used increasingly in scientific lectures, including even those given to experts of the highest capacity of mind. We accept and even demand this type of visual 
support because the influence of television has greatly altered our visual habits. Secondly, we should remind them of Aristotle's dictum that "even the most abstract human knowledge is based on sensory perception" (Wolf, 1970, p. 50).

\section{Higher levels of activity and interactivity}

Jerome Bruner (1974) the American learning psychologist, differentiates between three methods of confronting reality and acquiring it in the learning process:

- enactive: directly active dealings

- iconic: dealing in the media of images, schemata and sketches

- symbolic: dealing in the media of thoughts, terms and arguments

In traditional distance education, of course, the symbolic method of dealing with reality was decisive, and this also conforms to the cognitive structure of academic studying. In distance education the symbolic transformation of content is taken still further, because not only is language the decisive medium but also the alphabetically transformed and printed language. The dominant foundation of teaching and learning behaviour in first-generation distance education is writing and reading teaching texts. In the previous section we saw how the digital learning environment can considerably intensify the iconic method of dealing with reality through the use of multimedia systems. We will now look at the enactive method of confrontation.

Criticism of closed learning situations with the dominance of presentational and strictly controlling teaching, which was received "passively" by students, led to the demand that mature students should participate actively and acting in their own learning process and in doing this achieve a higher level of interactivity. The break with behaviourist learning models and the turn to structuralist models encouraged this paradigm change still further, because learning was now seen in many cases as the activity of individuals in the construction and development, and amendment, of their own cognitive structures, and comprehended as a holistic process. From the approach of learning theory this presupposes the activation of the students themselves. Interactivity with the teaching material and with other persons in the pedagogical field has been discussed and regarded as important since then - particularly in academic teaching.

In first-generation distance education interactivity is aimed at by making efforts to activate students by means of assignments, problems, stimulation to reflection and self-tests. This includes stimulation to organise partnerships or small groups with other distance students. An additional aim here is to develop interactive skills (cognitive and social skills).

International Review of Research in Open and Distance Learning 
Second- and third-generation distance education intensify this interactivity even more. Because of the presence of a digital learning environment students find themselves in a much more favourable starting situation. This situation differs markedly from that of students reading and working through printed distance education course material with a pencil in their hand. It is as if students had an opposite number, not just the screen of the monitor but also the teaching software, which can react in different ways to their activities. And behind all this is the network with a tremendous depth of penetration because it links the digital learning environment with many virtual databases, institutions, libraries and individuals. Continuous contact can be made with this opposite number, and maintained, by using the keyboard, and this contact is integrated in the learning behaviour and with time becomes a force of habit. Depending on the feedback, i.e., the computer's "replies," feelings of satisfaction, relaxation, self-confidence, but also of disappointment, amazement, surprise or annoyance are triggered and determine the situation. Bernhard Koring (1997) may well be right when he remarks that the use of a computer is often intuitive, which restricts the abstract-cognitive dimension, while the eventful-concrete, even physical dimension gains in importance. Interaction then takes on the character of continued and continuous action which is more physical and more adapted to the technological opposite number and more rich in forms than in first-generation distance education. Interactivity here is more marked than in externally controlled learning, occurs more frequently and is more polymorphic and imposing. Maybe this is the reason why students like to learn in such a digital environment and many are even fascinated by it. Another factor is possibly the integration of the three methods of confrontation with reality which makes this type of learning so attractive.

Teaching programmed courses in digital learning environments aims among other things, at the following student interactions:

- answering questions and reacting to feedback as in programmed teaching

- selecting and working through prescribed links

- participating in a simulated tutorial dialogue

- opening a notes window for writing margin notes

- opening a comments window

- placing "bookmarks" to mark defined pages

- working with a search menu which can be opened by means of central terms in the text

- working with several indices, each of which enables access to different abstraction levels of theoretical dimensions

International Review of Research in Open and Distance Learning 
- amending teaching texts in accordance with own points of view: placing sections or chapters under different points of view, storing important sections, editing ones "own" teaching text

- searching for sections of text containing the same term

- completing recommended "drill and practice" programmes

- replacing a standard teaching text by a longer or shorter teaching text

- explorations with simulations of economic models, electronic circuits, biological systems, etc. Students can enter their own parameters and in this way acquire their own insights and knowledge

- conducting real experiments

These are just a few of the possibilities for increasing students' activity and interactivity. It puts students in a position to retrieve information, to take a look at learning programmes whenever they wish, to amend and to manipulate teaching texts, to try out something new and to reverse incorrect decisions. If we now include visits to a virtual museum, virtual visits to parts of towns and application of acquired knowledge in an experimental situations, dimensions of interactivity become visible for which there are no examples in traditional pedagogics.

For teachers, all this means the demanding task of mastering these and other activities and interactivities not merely from the technical aspect, but also of deliberately pursuing pedagogical aims when doing so. Teaching software can diagnose what previous knowledge is already present, students can be motivated and counselled, and different learning paths can be provided, offered and used. Finally, and Anthony Bates (1995, p. 191) points this out, a skilful combination of tests, feedback, repeats and diagnostic tasks can lead all students to a mastery of all requirements in the sense of mastery learning.

\section{More and improved support}

One of the most impressive practical advantages of the digital learning environment is the speeding up of communication between students and correctors as well as between students and tutors. The turn-around time for submitted assignments, which takes normally four to six weeks at the FernUniversitaet, can be reduced to a couple of days. This is certainly a most important didactic achievement and compensates for a structural weakness of traditional distance education caused by the slowness of the communication by mail.

Furthermore, students can interact with their tutors more easily and more often, individually or in groups - asynchronously or synchronously. In a New

International Review of Research in Open and Distance Learning 
Zealand experiment, virtual tutorial groups of three or four students proved very successful (Rajasingham, 1997, p. 3). The students and the tutors each sat in front of a computer with a telephone headset on. A student would present her or his written assignment on the monitor, read it and explain it. The tutor could scroll through the text and highlight it. The students could discuss what they were looking at and what they were hearing. A very intensive cooperation evolved and really cooperative learning took place. This is a very convincing example of the interactivity highly desirable in distance and open education.

\section{Commentary}

There is no doubt that the digital learning environment can challenge students to more activity and intensified interactivity, not only with regard to quantity but also to quality. As we have seen, this is already true for learning controlled by teachers and software developers, in other words mainly heternomous learning. Much greater activity and interactivity are required in the case of autonomous and self-directed learning, and we will now take a look at these forms.

\section{Autonomous learning}

The use of the digital learning environment to present computer-based learning programmes, integrate audiovisual sequences or even digitised printed teaching texts is really misuse because its specific potential is not even seen, let alone actually used. These examples simply show how the presentation of conventional forms of expository teaching and therefore of externally controlled learning can be intensified and increased. We could even draw the conclusion that if expository teaching and receptive learning is a pedagogical error in many respects, this error is made here with particular emphasis and skill. Habitual modes of behaviour are being extended into the digital age and this causes us to misunderstand the special opportunities provided by "digital learning."

This has to happen, because what is being developed at present in the sector of digital learning is more than we can imagine. Is it not so that these explosive technological developments have long since surpassed human comprehension? Our thoughts and actions like to remain on the ground, with familiar things. The first cars and railway compartments were designed to look like traditional coaches, because at the time people were not yet able to comprehend the new opportunities that the technology of the steam engine and the petrol engine opened up for them. With digital learning as well, new and it seems completely unknown opportunities are being opened up that are based on computer, media, network and hypertext/hypermedia technologies. One of these is the intensified development of autonomous learning as self-planned, self-organised and selfassessed learning. The digital learning environment provides even now unusually

International Review of Research in Open and Distance Learning 
favourable preconditions that enable and simplify this special type of learning in a variety of ways. We will now examine these ways.

\section{Different starting situation}

The new and completely different learning situation - already referred to - is advantageous for this. An interrelationship, an interplay, even a quasi-symbiotic relationship is created in the digital learning environment between the individual and the software. According to Nickerson (1987), the strange dyad individual/digitised learning environment displays criteria of interpersonal communication: "bidirectionality, mixed [reciprocal] initiative ... shared situational context, peer [equal] status of participants" (p. 681). It does not matter how critically we regard these comparisons; in practice people experience the particular attractions of this learning environment everyday. It fascinates because students enjoy mastering a complicated system, controlling and steering the processes, initiating the acquisition of information themselves and discovering correlations. In doing this, they experience themselves as actors. This starting situation itself appears to encourage, provoke and even incite students to selflearning. This peculiarity of the starting situation appears to be particularly advantageous to autonomous learning.

If we take a closer look, we can see other characteristics of the digital learning environment which make independent, self-planned and self-regulated learning easier. We say that students have all the information in the world at the tips of their fingers. They have access to many relevant data pools and can even use search engines to make this access even more comfortable. They can retrieve electronic books or course files as if by magic. And if they have the latest technology available, they can even have these read out. Spoken commands, such as "meaning" or "encyclopaedia" automatically trigger additional explanations and commentaries which make understanding easier. Students can use the World Wide Web (WWW) to download teaching programmes and texts from authors all over the world. All they need to do is say words such as library, catalogue, subject, browse, download and they can access the growing fund of digitised books. Nicolas Negroponte from MIT even believes that in future we will work with a single book, which we can "load" with the contents we require at any particular moment. As a result of the networking of learning environments, a cosmos of information will develop, including teaching contents and stocks of knowledge which autonomous learners can open up for themselves, step by step, by downloading what they need onto their own hard disks, printing and working through the texts. In the history of teaching and learning there has never been a more favourable starting situation for independent and automatic learning.

Let us take a closer look at this cosmos. It seems that there are above all the three following disjunctive activity fields in the digital learning environment:

International Review of Research in Open and Distance Learning 
- learning in hypertext

- network-based learning

- learning through virtual communication.

\section{Learning in hypertext}

With hypertext, students are confronted with text blocks representing "cognitive units" and which may be located on various cognitive levels. Thus students are forced to find an interesting start to their studies themselves. To do this they browse through the cognitive units offered and develop an activity for which there is no corresponding example in traditional pedagogics. The word "browsing" reminds us of course of grazing animals, which eat something here and there. Once a student has found an important starting point, he or she can start to "navigate" through an unknown "sea" of information, and this is also a completely new term for an unusual pedagogical activity. What they are looking for here are those cognitive units of information that supplement and expand the information they have already acquired - and here again they are guided by their own interests, needs and objectives. And in doing this they activate and coordinate elements of text, image, graphics and video files. This is made possible by various links, namely the interfaces to information units that lead the students still further. All cognitive units that are linked with one another (nodes) form a network, and this is presumed to be helpful in the formation of semantic networks in the student's own head (cf. Schulmeister, 1997, p. 252). The students' job consists of finding their way around this network and taking their own learning paths. In this they enjoy a great deal of curricular freedom.

Here we come across the decisive and momentous innovation which will have to be interpreted with regard to autonomous learning: the break with linear presentation in set sequences and the establishment of non-linear and non-sequential learning. "Digitisation and computer manipulation cancel the sequentiality of the different media, their sequence can be manipulated at will ... and made interactively accessible. This assigns an emphatic role to the interactivity between the user and the system" (Schulmeister, 1997, p. 22). The required activation of the students and the interactivity enabled here will probably form the fundamental basis of future pedagogical design.

We must now pause here and consider for a moment what this procedure (disseminated and imposed on us by information science) actually brings. After all, this change has fundamental effects on the pedagogical structure of learning. We are dealing here with a pedagogical paradigm shift. The traditional "articulation" of learning, i.e., the binding of selected teaching contents to defined locations, times, persons and sequences in courses or training has now been abandoned, although it has determined teaching and learning since time 
immemorial. A completely different type of learning is being created, learning which does not aim at declared and defined learning targets and which cannot be tested by means of appropriate tests. We are therefore confronted with a break with tradition never seen before. However we judge this process, the removal of the above bindings leads to a flexibility and variability of learning which was never before possible. There is now a free space which can be used for autonomous learning.

This approach is so interesting because it lets new elements of learning behaviour become visible which can become fundamental for the autonomous learner of the future. In the way searching is actually carried out in practice four types can be seen, which Kuhlen (1991, p. 128) names as follows:

- targeted browsing, picking things up along the way

- targeted browsing in which important information is found which was not the subject of the search

- random browsing

- associative browsing

Other authors use other terms for the different forms of navigating, namely, along with browsing, scanning, searching, exploring and wandering (Canter, Rivers \& Storrs, 1985). The expression path finding is also found. No matter how we look at these differentiations, it is abundantly clear that when the students develop, design and control their learning they are left to their own resources from the very start and have to develop activities in the interest of their own learning, and also accept responsibility for this. Their search movements and efforts at selection form the basis of their learning. This means that we are dealing here with self-directed learning in which all learners pursue their own goals, go down their own learning paths and can arrive at different learning results. Hypertext is a convincing vehicle for promoting autonomous learning.

A fundamental structural difference becomes abundantly clear here. Whereas in traditional learning the presentation and absorption of knowledge determines the structure, autonomous learning comprises searching, finding, selecting, evaluating and applying information.

\section{Network-based learning}

Networks offer even greater opportunities and chances for autonomous learning, for example, the World Wide Web. The rapid availability of information encourages students to search for things that interest them and to find them. There are many ways of doing this.

International Review of Research in Open and Distance Learning 
Relevant information, for example, can be obtained easily by means of access to electronic works of reference, with the opportunity of saving important facts, articles, etc. to the user's hard disk and printing them for intensive, long-term work. The 32 volumes of the Encyclopaedia Britannica are available on CD-ROM, for example, but can also be accessed in an updated version via the Internet. Large newspaper groups have already opened their digitised archives. "Digital libraries," some of which do not have a single book of their own, help searchers to examine and find the required literature by means of digital catalogues and abstracts. Already digitised texts and illustrations are being offered more and more. The American Gutenberg Project (http://promo.net/pg/history.html) is planning to be able to provide about 10,000 electronic books (classics which are no longer protected by copyright) on the Internet by the year 2001 (Collis, 1995, p. 166). Increasingly, digitised academic journals are becoming available.

In network-based learning the implicit and often subtle heteronomous steering of the learning process which is still found in hypertexts is missing, in spite of the curricular freedom. This is because the cognitive units were of course written by authors whose attitudes and ways of thinking still shine through even where this is not intended or is even supposed to be avoided. Here students are able from the very beginning to work through subjects they have selected themselves and to pursue their own aims, although this is, of course, accompanied by the risk of failure.

\section{Learning through virtual communication}

Networks also offer another important area of autonomous learning by opening up opportunities for communication from computer to computer. Students at the Open University in Great Britain who have not been able to understand a text or solve a problem by themselves have sent calls for help to "everyone." This can be regarded as an independent activity. Interestingly enough, it is claimed

that all these questions are answered within eight hours. Students can also discuss their learning problems with fellow students, tutors or course counsellors on their own initiative and for their own purposes by exchanging e-mail. In addition, they can also use their own initiative to work with the bulletin board, which is set up for certain courses or departments and constantly updated. Here they can read messages from other students and can also pass comments on the subjects the boards contain. Interactivity here develops outside official teaching and learning programmes. It challenges students and makes them more independent.

On the periphery, these activities are often enriched by chatting about subjects of general interest. This sort of "association" with other students whom the chatter knows or is friendly with can have a positive feedback effect on self-

International Review of Research in Open and Distance Learning 
directed learning.

Computer conferencing has been developed the furthest under present conditions for this purpose. Examination of contextual problems on a discussion basis, something which tended to come off second best in first-generation distance education, can now take place virtually. If students initiate computer-supported discussions on the basis of their own decisions, and possibly with their own strategies in mind, what they are doing is controlling their own learning themselves. Virtual seminars are now held in great numbers. Whether they are successful depends to a great extent on the active cooperation of the distance students themselves.

From the point of view of pedagogics, by making active participants in discussions out of receptive students while at the same time granting them autonomy, these virtual seminars play such an important role because they individualise the heavily structured course based on the industrialised mass-production model, which calls for the same instruction for all distance students. Worthy of note is an IT course at the Open University in Great Britain in which 1,364 students took part. They each received a book consisting of newspaper articles and watched 16 teaching films on television. But instead of counselling in study centres they took part in computer conferencing. A total of 65 virtual seminars were set up, each led by a tutor. The pedagogical advantage: contributions from participants were recorded by the computer, and this can be a great advantage for assessments and research purposes. For example, it can be verified just how many autonomous suggestions, stimuli and initiatives there actually were.

A particularly attractive form of self-directed and self-responsible learning can be achieved if a knowledge building community can be established in which several students communicate via a central computer. They work jointly on the same subject and inform each other regularly about what they have experienced, discovered and worked out. At the same time they express criticism or praise for information and texts they have received. In this way a virtual project group is created which produces new knowledge through joint discussions and individual contributions. The pedagogical advantages are obvious: not only are we faced here with an ambitious form of autonomous learning (found originally in research) but also with partnership learning and group learning, which strengthens the components of communicative learning. Furthermore, new knowledge structures are developed here jointly, which can be interpreted roughly in accordance with the radical structuralist learning model (cf. Siebert, 1996, p. 16).

Computer conferencing is a form of autonomous learning that leaves expository teaching and receptive learning far behind because they are replaced by independent achievements. The new learning behaviour manifests itself in the search for, assessment and application of suitable information and in careful (written!) communication and cooperation. The proximity to learning by doing research and to academic work in general can be quite astounding.

International Review of Research in Open and Distance Learning 


\section{Commentary}

The teaching behaviour that is created in these three basic forms of digital learning has different approximations and pedagogical potentials with regard to autonomous learning. Their advantages and disadvantages would have to be described in terms of pedagogics for distance education. Proposals for a suitable combination and integration of these types of learning forms, which could lead a great number of new configurations, would have to come both from theoretical approaches and from reflected initial experience. A clear distinction has to be made as to whether this autonomous learning is inserted like islands in conventional distance education, or whether whole programmes of study should be created by individual students and thus be autonomous through and through. Models for this approach are available. The most convincing of these, pedagogically speaking, are probably the ones developed by the Empire State College of the State of New York (cf. Peters, 1996, p. 286).

As far as the social and working forms of teaching and learning are concerned, the digital learning environment enables a greater variability which autonomous learners can make full use of. According to Paulsen (1995, p. 120), four different models have emerged in current practice: the one-alone method (the WWW paradigm) is probably the most marked. The one-to-one method (the e-mail paradigm) can be used for tutoring and counselling autonomous learners as well as for communicating with other students. The one-to-many method (bulletinboard paradigm) can be used on the one hand for teaching events, such as lectures and symposia, and on the other hand students can act in accordance with the one-alone method and send messages to all and wait for feedback. Finally, the many-to-many method (the computer conferencing paradigm) can be interpreted as an interplay of largely autonomous learners in the form of discussions, simulations, role playing, brainstorming and project groups.

If we see things correctly, elements of a pedagogics of digital learning are being introduced here which will have to be developed still further. Often, a paradigm shift is referred to in this context. We can also encounter the supposition that traditional pedagogical thought could erode as a result of the incursion of working methods from communications technology. Anthony Bates (1995, p. 202) assumes on the other hand that this process is merely the continuation of traditional social and working forms. We are faced here with a fundamental problem which will have to be clarified theoretically.

\section{Summary}

Digital learning environments open up new opportunities and chances not only for heteronomous but also for autonomous learning. One could conclude that they make heteronomous learning even more heteronomous - and autonomous 
learning even a great deal more autonomous.

With heteronomous learning, the pedagogically substantiated combination and integration of two or more modes of presentation means that multimedia teaching of content can be offered on a multisensory basis, thus enabling precise close overlapping of stimuli whereby better learning can be prepared, effected and strengthened. In addition, much higher levels of activity and interactivity can be achieved.

With autonomous learning there is in addition a wealth of desirable preconditions. In the first place, the starting situation is different because students are brought immediately into an interactive relationship with all types of information. This increases accessibility to the findings of scientific research as well as to academic teaching programmes stored in the media. The digital learning environment enables open learning situations and learning based on active interactions. Instead of "passive" receptive learning we find the independent and self-determined and self-regulated acquisition of knowledge based on the student's own strategies for searching, finding, selecting and applying. Learning by research and discovery can become a fundamental paradigm of academic teaching. Furthermore, different forms of teleconferencing enable not only academic discourse, something which is neglected in traditional distance education, but also partnership and group work. Collaborative learning is given a much more prominent part to play than in traditional distance education - with the remarkable exception of the television universities of China where obligatory group meetings take place regularly. Teleconferencing establishes a new configuration for distance education, whose special features have been aptly characterised as "learning together apart" (Kaye, 1992, p. 1) and "teaching face-to-face at a distance" (Keegan 1995, p. 108). Learners will have to be accustomed to dealing with many virtual partners and communities.

If what is in fact important today is that we get away from the pedagogics of instruction and create and implement a pedagogics of enablement in its place, as Rolf Arnold (1993, p. 53) demands, the digital learning environment will probably be the most efficacious "enabler" of independent and self-determined learning. This approach is promising because it does not modify the traditional methods of presentational teaching and receptive learning, but provides a completely different fundamental challenge for learning.

On the whole, the pedagogical restructuring required in distance education is deep and extensive. Some experts (e.g., Collis, 1996, p. xxii) demand even a "re-engineering" of distance education. We could in fact start to speak of the beginning of a new era, in which distance education will develop into an extraordinarily open, flexible and variable form of teaching and learning which can be adapted and adjusted to the learning requirements of students, who will differ greatly from one another with regard to their age, social background and vocational orientation and position. A clear student-oriented form of studies will have been created.

International Review of Research in Open and Distance Learning 
The new opportunities and chances of digital learning in distance education have great significance for the future of our information and learning society. Helmut Hoya, the present Rector of the FernUniversitaet, underscores this statement by telling visitors that the university of the future will look much more like a distance teaching university than a traditional one. 


\section{References}

Arnold, R. (1993). Natur als Vorbild. Selbstorganisation als Modell der Pädagogik. Frankfurt/Main: VAS-Verlag für akademische Schriften.

Bates, A. W. (1995). Technology, open learning and distance education. London: Routledge.

Boud, D. (Ed.). (1988). Developing student autonomy in learning. London: Kogan Page.

Bruner, J. (1974). Entwurf einer Unterrichtstheorie. Düsseldorf: Schwann.

Canter, D., Rivers, R., \& Storrs, G. (1985). Characterizing user navigation through complex data structures. Behaviour and Information Technology 24, 93-102.

Collis, B. (1995). Telelearning in a digital world. London: International Thomson Computer Press.

Dohmen, G. (1997). Selbstgesteuertes lebenslanges Lernen? Bonn: GustavStresemann-Institut.

Friedrich, H. F., \& Mandl, H. (1997). Analyse und Förderung selbstgesteuerten Lernens. In Enzyklopädie der Psychologie, Band 4: Psychologie der Erwachsenenbildung. (pp. 237-293). Göttingen: Hogrefe.

Kaderali, F., Müller, H., \& Rieke, A. (1994). Media publishing in distance teaching. EADTU-Workshop in Hagen.

Kaye. A. (1992). Learning together apart. In A. Kaye (Ed.), Collaborative learning through computer conferencing: The Najaden papers. (pp. 1-24). Berlin: Springer Verlag.

Keegan, D. (1995). Teaching and learning by satellite in a European virtual classroom. In F. Lockwood (Ed.). Open and distance learning today. (pp. 108-118). London: Routledge.

Knowles, M. (1975). Self-directed learning. A guide for learners and teachers. New York: Association Press.

Koring, B. (1997). Lernen und Wissenschaft im Internet: Anleitungen und Reflexionen zu neuen Lern-, Forschungs- und Beratungsstrukturen. Bad Heilbrunn: Klinkhardt.

Kuhlen, R. (1991). Hypertext. Ein nichtlineares Medium zwischen Buch und Wissensbank. Berlin: Springer.

Michael, B. (1983). Darbieten und Veranschaulichen. Bad Heilbrunn: Klinkhardt.

International Review of Research in Open and Distance Learning 
Nickerson, R. S. (1987). On conversational interaction with computers. In R. M. Baecker, \& W. A. Buxton, (Eds.). Readings in human-computerinteraction: A multi-disciplinary approach. (pp. 681-693). San Matteo, CA: Morgan Kaufmann Publishers.

Paulsen, M. F. (1997). Teaching methods and techniques for computer-mediated communication (abstract). The 18th ICDE World Conference: The new learning environment: A global perspective. (p. 120) State College, PA: Pennsylvania State University.

Peters, O. (1996). Die Autonomie der Lernenden und ihre Bedeutung für das Fernstudium. Referat, gehalten am 26. Oktober 1996 auf dem Symposium "Studium on line: Orientierungskompetenz und Qualitätsbeurteilung als Aufgabe der Didaktik des Fernstudiums. Hagen: FernUniversitaet.

Rajasingham, L. (1997). The research path to the virtual class. ZIFF-Paypiere 105. Hagen: FernUniversitaet-Gesamthochschule, Zentrum für Fernstudienforschung.

Schulmeister, R. (1997). Grundlagen hypermedialer Lernsysteme. München: Oldenbourg.

Siebert, H. (1996). Didaktisches Handeln in der Erwachsenenbildung. Neuwied: Luchterhand.

Wolf, A. (1970). Anschaulichkeit. In Lexikon der Pädagogik. Freiburg: Herder.

Zimmerman, B. J., \& Schunk, D. H. (1989). Self-regulated learning and academic achievement. Berlin: Springer Verlag.

Citation Format

Peters, Otto (2000) Digital Learning Environments: New Possibilities and Opportunities.

International Review of Research in Open and Distance Learning: 1, 1.

http://www.icaap.org/iuicode?149.1.1.7

International Review of Research in Open and Distance Learning 


\title{
Research in Distance Education: A Status Report
}

\author{
Farhad Saba
}

\begin{abstract}
Since the 1950s and expansion of social science research, distance education has been studied in comparison to face-to-face or classroom instruction. Although researchers continue to conduct comparative studies, their usefulness in revealing more information has diminished over the years; invariably, they have returned a "no significant difference" result between various forms of instruction. In recent years, researchers have moved beyond atheoretical, experimental comparative studies and have introduced new methods, such as discourse analysis, and in-depth interview of learners. These new methods overcome many methodological and theoretical limitations of the physical science view of distance education. These studies have further revealed the complexity of distance education, indicating the many variables involved in the concept. Starting with the core issue of instructional interaction and grounded on the theory of transactional distance, a new strand of research using methods related to systems dynamics, hierarchy and complexity theories, promises a more comprehensive understanding.
\end{abstract}

\section{What is Research?}

The purpose of this article is to present a coherent view of the state of research in distance education. As such, it is appropriate to clarify what is meant by research first.

Traditionally, research has been synonymous with the scientific method; and in education, until recently, experimentation has been the dominant mode of inquiry (Best, 1977). Experimental research was the method by which physical sciences obtained their dramatic results in the last century and achieved their current status.

Originally designed for the laboratory where the environment could be carefully controlled, experimental research found its way to social sciences where laboratory conditions were difficult, if not impossible to obtain. As such, researchers adopted the idea of random selection of their subjects to control for the effect of the experimental variable. In other words, if members of only one of two groups of randomly selected subjects are exposed to an experimental variable (e.g., distance education), and if the test scores of the experimental group show 
a difference as compared to the control group, then the chances are that the difference can be attributed to the experimental variable.

However, in education research most classrooms are pre-selected by factors other than experimental requirements. As such, the concept of experimental research was modified and acquired the name of quasi-experimental research to reflect this change. So far, distance education research has been dominated by quasiexperimental research which compares the effectiveness of distance education to classroom instruction, face-to-face education, or traditional education.

\section{Comparative Studies}

Since the rapid expansion of instructional television in the 1950s and the ascendance of social science research after the Second World War, comparing distance education with the so-called face-to-face education has been a favorite of education researchers. In the 1960s, Wilbur Schramm conducted studies which compared instructional television (ITV) with classroom instruction. Also, Schramm (1962) summarized the results of more than 400 "scientifically designed and statistically treated comparisons of ITV and classroom teaching" (p. 66). He concluded: "we can say confidently that students learn from it, and that they learn fast and efficiently" (p. 66). Furthermore, "the conclusion has been "no significant difference' between learning from television, and from classroom teaching" (p. 66).

After Schramm arrived at this conclusion many other researchers have compared classroom instruction to distance education. A recent example is a study conducted by Johnson, Aragon, Shaik, and Palma-Rivas (2000). Researchers in this study compared learning outcomes of an online course with a similar course taught face-to-face. The study concluded that "there was no difference between the two course formats in several measures of learning outcomes" (Johnson et al., 2000, p. 29). Wetzel, Radtke, and Stern (1994) have summarized the results of comparative studies until the mid 1990s. Invariably, comparative studies of distance education and classroom instruction show "no statistically significant difference." Another recent meta-analysis of 19 studies out of an original pool of 700, which met the carefully selected criteria of authors, Machtmes and Asher (2000) confirmed previous conclusions that "there does not appear to be a difference in achievement between distance and traditional learners" (p. 43).

\section{An Absence of Theory}

Absent from most comparative research in distance education is a discussion of theoretical foundations of the field. Research questions are rarely posed within

International Review of Research in Open and Distance Learning 
a theoretical framework or based on its fundamental concepts and constructs. Although research within a theoretical framework is not a requirement for inductive inquiry, a post facto theoretical discussion of research results would be helpful in making studies relevant to the work of other researchers, and possibly even to the practitioners in the field. Comparative researchers, however, have shown little or no interest in the theoretical literature of the field either before or after conducting their studies.

\section{Theory-based Research}

In the past ten years, however, a few researchers have conducted rigorous studies that are based on theoretical foundations of the field, or theories of fields closely related to distance education. Fulford and Zhang (1993) studied learner perception of interaction in instruction and concluded that perception of the level of interaction is a critical predictor of learner satisfaction. They stated "overall interaction dynamics may have a stronger impact on learners' satisfaction than strictly personal participation. Vicarious interaction may result in greater learner satisfaction than would the divided attention necessary to ensure the overt engagement of each participant" (Fulford \& Zhang, 1993, p. 19). The ramification of this conclusion for instructional design is to devise strategies to increase and improve learner perception of overall interaction.

Gunawardena (1995) studied the ramification of social presence theory for community building in computer mediated conferencing (CMC). She concluded: "in spite of the low social context cues of the medium, student perceptions of the social and human qualities of the medium will depend on the social presence created by the instructors/moderators and the online community" (Gunawardena, 1995, p. 164). Tsui and Ki (1996) studied social factors affecting computer mediated communication at the University of Hong Kong. The study revealed that communications among participants were bilateral. Some participants stated that they were reluctant to enter a dialog started by two participants, since

they might have been considered as "intruders." Also, researchers pointed to the relative lack of knowledge of the participants about CMC, highlighting earlier findings by Fulford and Zhang (1993), as well as Gunawardena (1995) that interaction strategies must be built into the design of a course or instructional session for it to be effective.

McDonald and Gibson (1998) studied group development in asynchronous computer conferencing through patterns of interpersonal interaction of participants. They concluded that participants could deal with and resolve interpersonal issues in an asynchronous teaching and learning environment and form a cohesive working group.

Chen and Willits (1999) conducted their study in a synchronous videoconferenc-

International Review of Research in Open and Distance Learning 
ing environment, and showed that the concept of interaction in this and other similar environments is multidimensional and includes "in-class discussion, outof-class electronic communication, and out-of-class face-to-face interaction" (p. 61). The study was grounded in Moore's theoretical analysis of independent learning as well as interaction in distance education, classified into three categories of teacher-student, student-instructional material, and student-student interactions (Moore, 1989).

\section{Interaction: A Common Theme}

A common theme in distance education research is the concept of interaction, which indicates its centrality in conceptualizing the process of teaching and learning. Furthermore, these studies are mostly paradigmatic. That is, their discussion of interaction transcends the idea of distance in its physical sense, and embraces the discussion of teaching and learning in general. The fact that in mediated education the teacher and learner might be physically separated is secondary to the consideration of factors affecting quality of their interaction. By being paradigmatic, this line of research also negates the implied assumption in most comparative studies that there is meaningful interaction in the classroom merely by the virtue of the physical proximity of the teacher and the student.

\section{Beyond the Confines of the Experimental Method}

Another consideration in distance education research is its methodology. The definition of research presented at the beginning of this article was limited to the transference of experimental method from physical to social sciences. The pure experimental method, it was mentioned, had to be modified to quasiexperimental to fit the special consideration of education research. In the new lines of research outlined above, new methods are employed which, although empirical and data-driven, go beyond the narrow confines of experimentation. These new methods cast a wider net for capturing the data generated by the interaction between the teacher and the learner in both of its qualitative and quantitative forms.

These researchers used student self-reporting through a survey study, (Fulford \& Zhang, 1993; Gunawardena, 1995), extensive interviewing of students (McDonald \& Gibson, 1998), conversation and discourse analysis (Chen \& Willits 1999; Tsui \& Ki, 1996) or a combination of these methods to collect the necessary data. These methods indicate a clear break from the traditional scientific method and experimental studies for understanding important factors in distance teaching and learning. Furthermore, these studies are focused on a smaller group of subjects, but take a deeper look at the subjects' verbal and written behaviors. This

International Review of Research in Open and Distance Learning 
is in sharp contrast to the methods employed by quasi-experimental researchers who sought to eliminate individual differences between the control and experimental groups in order to measure and demonstrate the effect of the treatment. This is an important step in refining research methods in distance education, and capturing a wider and richer range of data.

\section{Theory Building and Research}

Researchers, therefore, are showing increased attention to methodological issues, within the framework of the appropriate theoretical foundations to their studies. This is apparent from theoretical and methodological articles which have been published in recent years. These strands of literature are analytical in nature and provide the necessary interplay between theory and research which a maturing field needs in order to bolster its foundations.

For example, Smith and Dillon (1999) revisited the issue of comparing distance learning and classroom learning and suggested a framework for "defining categories of attributes embedded within each delivery system and the media used by the delivery system that may support learning in different ways" (p. 19). The authors thought that a new set of categories and "clearly defined constructs of both media and delivery systems" (Smith \& Dillon, p. 20) would facilitate comparative studies, and might cure the "no significant difference" syndrome.

Cookson and Chang (1995) drew from previous research and theory in smallgroup interaction analysis, classroom interaction analysis, and audioconferencing to "develop an instrument appropriate for the tabulation, analysis and interpretation" (p. 18) of audioconferences. Gibson (1996) depicted various aspects of academic self-concept as a construct related to persistence, and curbing attrition in distance education.

Also, Gunawardena and Zittle (1997) continued the study Gunawardena had initiated and reported in 1995, and presented further data, adding a more elaborate method of analysis. Likewise, Sherry, Fulford, and Zhang (1998) presented a follow up study to Fulford and Zhang (1993). This continuity in research is noteworthy, since it is rare in the literature of distance education.

\section{Advancing the Field}

Comparative studies were grounded in the physical science paradigm and its related experimental method. They required reduction of experimental concepts to their simplest form, and elimination of environmental elements to establish a direct cause and effect relationship between the experimental stimulus and the

International Review of Research in Open and Distance Learning 
response emitted by the subjects in mass. Furthermore, subjects in these studies were treated as a group, and their individual differences in learning aptitude, and prior knowledge of the subject matter were ignored or eliminated so that the experimental and control groups would be rendered comparable!

Focusing on interaction and looking at learning and other instructional outcomes, such as learner satisfaction, researchers cited above have:

- stepped beyond the experimental method, and its ancillary comparative studies

- grounded their studies on theoretical foundations of the field

- used new methods of inquiry, such as discourse analysis

They have thus made valuable contributions to the field, and have moved research in distance education to higher grounds.

\section{Comprehending the Field}

These efforts in theory-based research, unlike earlier atheoretical comparative studies, reveal the complexity of distance education. The studies mentioned so far were concerned with learning outcomes and interaction in instructional settings. As much as it is central to any educational endeavor, the field of distance education goes beyond instruction, and includes a host of other concerns such as, management and cost-effectiveness, instructional design, evaluation, as well as legal, social and international issues, just to name a few. One of the major challenges of researchers in distance education in the future will be to devise methods of data collection and analysis that correspond to the theoretical complexity of the field.

Starting with the core issue of instructional interaction in distance education, and grounding their study in the theoretical concept of transactional distance, Saba and Shearer (1994) used discourse analysis for data collection, and a systems dynamics simulation method for analyzing the data. A systems method for data analysis was selected in order to be able to respond to the complexity of concepts and variables in distance education. In sharp contrast to the experimental method, systems as a method of inquiry allows researchers to collect data from various sources such as management and legislation, and to study their ramifications on instruction and learning outcomes, as well as several other systems variables. Systems methodology also provides a platform for integrating concepts in hierarchy theory, as well as complexity theory, and for study of learning at a distance as a self-adaptive, non-linear activity of the learner. Based on the 1994 study, these methods are currently being refined to ensure

International Review of Research in Open and Distance Learning 
inclusion of individual differences. It is anticipated that this research will lead to development of personalized, self-adaptive learning systems.

\section{Summary and Conclusions}

Since the 1950s and expansion of social science research, distance education has been studied in comparison to face-to-face or classroom instruction. Although researchers continue to conduct comparative studies, their usefulness in revealing more information has diminished over the years; invariably, they have returned a finding of "no significant difference" between various forms of instruction.

In recent years, researchers have moved beyond experimental comparative studies and have introduced new methods, such as discourse analysis, and in-depth interview of learners. These new methods not only afford a theoretical framework to these studies, something that was lacking in atheoretical comparative studies, they also bypass many methodological and theoretical limitations of the physical science view of distance education.

These studies have further revealed the complexity of distance education, indicating the many variables involved in any instructional setting, not to mention other elements involved in distance education, such as social, economic, and global issues affecting the field.

Starting with the core issue of instructional interaction and grounded on the theory of transactional distance, a new strand of research using methods related to systems dynamics, as well as hierarchy and complexity theories, promises to provide a more comprehensive understanding of the field. 


\section{References}

Best, W. J. (1977). Research in education. (3rd. ed.). Englewood Cliffs, NJ: Prentice-Hall.

Chen, Y-J., \& Willits. F. K. (1999). Dimensions of educational transactions in a videoconferencing learning environment. The American Journal of Distance Education, 13(1), 45-59.

Cookson, P. S., \& Chang, Y. (1995). The multidimensional audioconferencing classification system (MACS). The American Journal of Distance Education, $9(3), 18-36$.

Fulford, C. P., \& Zhang, S. (1993). Perception of interaction: The critical predictor in distance education. The American Journal of Distance Education, $7(3), 8-21$.

Gibson, C. C. (1996). Toward an understanding of academic self-concept in distance education. The American Journal of Distance Education, 10(1), 23-35.

Gunawardena, C. (1995). Social presence theory and implications for interaction and collaborative learning in computer conferencing. International Journal of Educational Telecommunications, 1(2-3), 147-166.

Gunawardena, C. N., \& Zittle, F. J. (1997). Social presence as a predictor of satisfaction within a computer-mediated conferencing environment. The American Journal of Distance Education, 11(3), 8-26.

Johnson, S. D., Aragon, S. R., Shaik, N., \& Palma-Rivas, N. (2000). Comparative analysis of learner satisfaction and learning outcomes in online and faceto-face learning environments. Journal of Interactive Learning Research, 11(1), 29-49.

Machtmes, K., \& Asher, J.W. (2000). A meta-analysis of the effectiveness of telecourses in distance education. The American Journal of Distance Education, 14(1), 27-46.

McDonald, J., \& Gibson, C. C. (1998). Interpersonal dynamics and group development in computer conferencing. The American Journal of Distance Education, 12(1), 7-25.

Moore, M. G. (1989). Three types of transaction. In M. G. Moore, \& G. C. Clark (Eds.), Readings in principles of distance education (pp. 100-105). University Park, PA: The Pennsylvania State University.

Saba, F., \& Shearer, R. L. (1994). Verifying key theoretical concepts in a dynamic model of distance education. The American Journal of Distance 
Education, 8(1), 36-59.

Schramm, W. (1962). What we know about learning from instructional television. In Educational television: The next ten years. Stanford CA: The Institute for Communication Research, Stanford University.

Sherry, A. C., Fulford, C. P., \& Zhang, S. (1998). Assessing distance learners' satisfaction with interaction: A quantitative and a qualitative measure. The American Journal of Distance Education, 12(3), 4-28.

Smith, P. L., \& Dillon, C. L. (1999). Comparing distance learning and classroom learning: Conceptual considerations. The American Journal of Distance Education, 13(2), 6-23.

Tsui, A. B. M., \& Ki, W. W. (1996). An analysis of conference interactions on TeleNex - A computer network for ESL teachers. Educational Technology Research and Development, 44(4), 23-44.

Wetzel. D. D., Radtke, P. H., \& Stern, H. W. (1994). Instructional effectiveness of video media. Hillsdale, NJ: Lawrence Erlbaum Associates.

Citation Format

Saba, Farhad (2000) Research in Distance Education: A Status Report. International Review of Research in Open and Distance Learning: 1, 1. http://www.icaap.org/iuicode?149.1.1.3 


\title{
Rethinking the Research Agenda
}

\author{
Hilary Perraton
}

\begin{abstract}
Research is seen as something grounded in theory that can lead to improved practice. Without a theoretical basis it is unlikely to go beyond data gathering. The theoretical insights leading to good research are more likely to come from educational and social theories generally than from an attempt to develop a theory of open and distance learning. An examination of existing research shows that it is often atheoretical and predominantly descriptive. Research on the context of open and distance learning, considering its purposes, outcomes, and relevance to major educational problems, has been relatively neglected as contrasted with research on its application. Significant research issues today include: problems posed by globalisation, including issues of governance and consumer protection; ways of maximising public benefit from new communication technologies; the development of strategies for AIDS education; and the continuing need for educational expansion.
\end{abstract}

Research lies midway between the other two themes of this issue - theory and good practice. This paper advances four propositions about the links between them and follows them with four proposals about important areas of research.

\section{Proposition one: research and theory}

First, unless research is grounded in theory, it cannot be much more than data gathering. The development or existence of a theory makes it possible to generate hypotheses about good practice, to frame questions that will test them, and so to develop more soundly based guides to practice. (This assumes that our concern with theory and research is mainly to help solve problems. It may not be. We may be interested in research on education purely in order to widen our understanding of human behaviour. This is a defensible and interesting posture, but not the starting point for the four propositions and suggested research agenda). To illustrate: the International Research Foundation for Open Learning (IRFOL) recently completed a research project for the European Commission on the cost-effectiveness of various technologies used in open and distance learning within European Union member countries. ${ }^{1}$ We wanted to help solve the administrator's problem of choosing between alternative technologies that might include, among others, print, videoconferencing and various 
computer-based approaches. We grounded our methodology in theories that came from learning and from classical microeconomics. From learning, we took as a starting point the theory of media equivalence, that there are no significant differences in teaching effectiveness between different media (cf. Clark, 1983; Perraton, 1987). From classical microeconomics we took well-tried methods for analysing the costs which allowed us to determine some of the conditions under which we might find economies of scale in using the technologies (cf. Jamison, Klees \& Wells, 1978; Jamison, 1982; Orivel, 1987). This work in turn led us to develop a number of propositions to guide practice; the research suggests, for example, that it there is always an onus upon the course designer to justify the use of any medium other than print, so that the costs of print can be regarded as a default option, and that, if lecturers are to be employed at each location and we neglect the opportunity costs of student time, then videoconferencing is always more costly than face-to-face education (Hülsmann, 2000). Neither proposition is earth-shattering but they serve to illustrate the nexus between problem, theory, research and good practice.

\section{Proposition two: traditions of educational think- ing}

They take us to the second proposition, that theoretical insights are more likely to be found from a range of educational and social theories than from attempts to develop theories of open and distance learning. Four traditions of educational thinking illustrate the argument. Caricaturing them only slightly, we could label them the Jencks thesis, the Rutter argument, the learning theory approaches, and the neo-marxist tradition. An excursion among the traditions helps illuminate the strengths and weaknesses of research within open and distance learning.

In his examination of American education, Jencks found that, despite the American dream and mythology, education was singularly ineffective in promoting equality. He concluded that, "as long as egalitarians assume that public policy cannot contribute to economic equality directly but must proceed by ingenious manipulations of marginal institutions like the schools, progress will remain glacial" (Jencks, 1973, p. 265). This reads like a counsel of despair for egalitarian educators. But his arguments can be used to generate research questions for those who argue that open and distance learning has particular strengths in widening access asking, for example, 'how if at all can distance-teaching institutions redress the structural inequalities that mark much conventional education?'.

In their opening chapter Rutter and his colleagues refer to the apparent conflict between Jencks' conclusions and their own work on the effects of secondary education in London. Rutter and his colleagues found that:

International Review of Research in Open and Distance Learning 
schools do indeed have an important impact on children's development and it does matter which school a child attends. Moreover, the results provide strong indications of what are the particular features of school organisation and functioning which make for success. (Rutter, Maughan, Mortimore \& Ouston, 1979, p. 1).

Using the title of another book in the same tradition, School Matters (Mortimore, Sammons, Stoll, Lewis, \& Ecob, 1988), their findings suggest that one may seek to identify the features within the process of education that are likely to correlate with successful or unsuccessful outcomes Within open and distance learning there is, similarly, a vein of research that suggests changes in methodology, usually in terms of instructional design or student support, that will improve outcomes. As we will see below, the vein is surprisingly narrow.

Learning theories, which seek to specify the conditions under which learning is enabled or hindered, have been used as the starting point for some research and practice in open and distance learning. In his examination of the issue, and drawing on the work of Bruner, Gagné, Ausubel and Bààth in particular, Holmberg (1995) concluded that "distance education and thinking about distance education are firmly based in general educational theory" (p. 160). In a more imaginative approach, and suggesting a programme of research that no-one, sadly, has picked up since he died, Lewis (1973) sought to set up a theoretical framework to help solve "hard practical problems of course design" (p. 197) that would encourage students to develop higher-order problem-solving skills and enable them "to challenge and extend and even transform the knowledge [they are] ... given" (p. 203).

Within the neo-marxist tradition, education is seen as an activity which reinforces and helps reproduce existing social structures but contains internal contradictions between the free examination of ideas necessary for effective education and the interests of the capitalist state and, potentially at least, between the teaching profession as an interest group and other elements within society (cf. Bowles \& Gintis, 1976). This analysis might lead us to conclude that open universities, for example, are a powerful device for containing educational demand at modest cost and so allowing more conventional universities to continue in their traditional role (cf. Perraton, 2000, pp. 198-90). The research questions we derive from the tradition will depend on our own political stance. If, at one extreme, we have an instrumental view of training to meet labour-market demands, we may want to discover how to design a distance-learning system that satisfies an employer's needs while discouraging labour mobility. At the other, we may ask how open and distance learning can be deployed to exploit the contradictions inherent to the educational system in the interests of seeking a more equitable society.

We could go on, seeking to generate other important questions from standpoints within sociology and political science among other domains as well as from ed-

International Review of Research in Open and Distance Learning 
ucation. Morgan (1996), for example, pointed out the relevance of the work of Rogers, Bruner and Giddens to research on open and distance learning. One point of the excursion is to show that existing theory will help us in framing questions that matter and therefore of value in seeking answers that will improve practice. More than that, it suggests that social literature generally is more useful than much of the discourse within open and distance learning. There, for example, we have much concern with definitions. Holmberg, for example, in his epitomizing theory presentation, seems deeply concerned to differentiate distance education from other forms of education, even though he does go on to seek refutable hypotheses that may follow from it $(1995$, p. 175, 181). Keegan argues that "a firmly based theory of distance education will be one which provides the touchstone against which decisions ... can be taken with confidence" (Holmberg, 1995, p. 157). But when he comes to set out his own theoretical propositions they are in forms such as: "It is hypothesized, therefore, that distance students have a tendency to drop out in those institutions in which structures for the reintegration of the teaching acts are not satisfactorily achieved" (Keegan, 1996, p. 120). The caution in the second half of the sentence makes it look like what Lakatos (1980) derided as degenerative problem shift and severely limits its capacity to provoke good research questions. The excursion also serves to remind us that good research does not need to begin with theory. Indeed, as argued below, much of it will begin with a problem. But we need then to know what our theoretical starting point is in order to design and justify our research approach.

\section{Proposition three: about the existing research}

The discussion so far suggests that research in open and distance learning needs to be grounded in theory, that there are often benefits in drawing theory from outside narrow educational confines, and that research will suffer unless this is done. An examination of existing research literature confirms that much of it suffers from an apparently atheoretical approach. In a review we did before launching the International Research Foundation for Open Learning we found that most research fell under five headings:

1. Description. There are many descriptive accounts of courses and institutions. Indeed the bulk of the literature on open and distance learning, whether specifically labelled as research or not, is essentially descriptive, discussing some combination of management, students, teaching methods and outcomes of a course or institution.

2. Audience studies. We have many studies of the audiences for open and distance learning .... In some cases these studies also examine the performance of students in relation to variables associated with the methods of study.

International Review of Research in Open and Distance Learning 
3. Cost-effectiveness studies. There is a growing literature on cost-effectiveness with a fair measure of commonality in the methodology used....

4. Methodology. There are studies, again often descriptive, of the various methods used to teach, support and counsel open and distance-learning students....

5. Social context. Some recent work has been concerned to examine the social context of open and distance learning. (Perraton, 1997, pp. 17-18)

If it were not so predominantly descriptive one might claim that the second group of studies were implicitly accepting a Jencksian view of the educational world, assuming that the important thing was to know our audience and that the fourth were following the Rutter approach in looking at variables in process. But in practice few studies begin even by genuflecting towards theory and, in consequence, make it the more difficult to draw any general conclusions. More than that, our third proposition is that where research has gone beyond description towards explanation, it has tended to be about the application of open and distance learning rather than about its context. In the same report we used the term "application" for questions of methodology and "issues about the most appropriate ways of using open and distance learning for a given audience and purpose" (Perraton, 1997, p. 19). In contrast questions about context

concern the purposes for its use, its role alongside other forms of education and its outcomes. The questions cluster around issues about the legitimacy, quality, effectiveness and outputs of open and distance learning that are particularly significant for policy makers (p. 19).

As a result of these biases, we are short of well-founded research findings on many aspects of open and distance learning, while findings about its context, critical for policy makers, are especially scarce. At the same time there are plenty of problems. Just on applications - not the main theme of this paper - for example, problems of choice of methodology arise because we have little more than rules of thumb to guide us on key issues like media selection, the case for combining media (always asserted, but barely established), and instructional design (discussed further in Perraton, 1995, pp. 16-17). More specifically, and to illustrate, we know that the methods of open and distance learning lend themselves to rote learning. We should be able to develop research strategies that started with the kind of hierarchy of learning proposed by Gagné and ask how one would research approaches designed to achieve learning at the upper end of the hierarchy. 


\section{Proposition four: research on context as well as application}

The fourth proposition is that the more important and more difficult part of the agenda is about context. It needs to be grounded in theory and grapple with the major educational problems that confront us. At the recent World Education Forum in Dakar the emerging new contexts for educational development and expansion were seen as including:

- the political, social and economic shifts in Eastern and Central Europe;

- the rapid development of the Internet as a pervasive lever of change for the organisation of life, commerce, entertainment and education;

- the emerging new economy based on intangible capital and calling for much increased adaptability to rapid change and a new repertoire of entrepreneurial capabilities and attitudes.

- ... and in some regions ... the disastrous spread of the HIV-AIDS pandemic (Skilbeck, 2000, p. 14)

If open and distance learning is to play more than a peripheral role in education we should therefore expect its research agenda to address issues that follow from these changes such as the role of private and public sector institutions in a world of neoliberal hegemony, the gap between the information-rich and the information-poor, educational responses to HIV-AIDS and, of course, educational expansion. We look at each in turn. They are briefly spelt out in order to establish that each of them demands more attention, and a higher priority from distance education researchers, than the audience studies and descriptive accounts, or the development of how-to-do-it guides on the application of distance education.

\section{Four areas worth researching}

A generation back, social theory argued that market forces had no good part to play in the social sector and that their effects were likely to be malign. Titmuss demonstrated this in his classic comparison between the safe, voluntary-based supply of blood to hospitals in Britain and the, inferior, pay-basis supply in the United States (1970). In her debunking of the Famous Writers School,

Jessica Mitford quoted counsel for the Federal Trade Commission's Bureau of Deceptive Practices who argued "there is a basic contradiction involved when you have profit-making organizations in the field of education" (Mitford, 1979, p. 169). These views no longer represent a social consensus. At the same time,

International Review of Research in Open and Distance Learning 
the new technologies have made it easier for distance-teaching institutions to operate internationally, even globally. Mitford's work showed that there never were adequate constraints on sharp practice even within frontiers. Within public sector higher education, the community of scholars has traditionally controlled quality but conventional structures do not operate easily at a long distance; some universities have sought to bypass their regular systems of checks and balances in order to operate internationally and competitively. ${ }^{2}$ One part of a broad set of problems about the intersection of the public and private sector is easy to define: given globalisation, how can we establish systems of governance and regulation that will protect individuals with imperfect information who are seeking to enrol in courses available at a distance? (It matters both to the individuals and to bona fide institutions where an educational Gresham's law may operate, allowing bad institutions to undercut and drive out good). We probably need to draw from political science in order to generate the research questions about governance needed to help answer this question, chosen to illustrate the range of problems facing educators and the public in a changed political environment.

Globalisation sets the context for the next set of issues about the gap between the information-rich and the information-poor. The problem was identified in the Briggs report (1987), which set out the proposals for what became the Commonwealth of Learning. It argued that while "the new communications technologies make it possible for learners to have access to the world's knowledge no matter where they live" there remained a danger that "there could be an even further widening of the gap between rich countries and poor in their access to information" (Briggs, et al., 1987, p. 8). The development of the Internet has since dramatised the differences and at the same time revealed a further problem within the problem - of differential access to communication media between town and country. Some of the issues here are conceptually simple about the allocation of resources to new and old technologies - though they may be politically tricky: within the United States "while textbooks ran chronically short in poor school districts, and while some 200 traditional colleges shut their doors over the decade to 1997, politicos and corporate executives prattled on about the need to wire up additional 'cyberschools"' (Schiller, 1999, p. 200). Others are more complex involving curricular and economic questions about the educational purpose of particular types of investment in technology, and the educational outcomes that may be expected from that investment. Again we are short of research data, especially about developing countries. ${ }^{3}$ But the issues are stark: how, through research, can we find ways of maximising public and international benefits from the new information opportunities?

An African consultation on education for all identified the third theme:

1. The EFA 2000 Conference recognises that HIV/AIDS has the potential to undermine much that education seeks to achieve as well as the education system itself.

2. The conference also recognises that there is little systematic information

International Review of Research in Open and Distance Learning 
on how the education sector can cope with the pandemic, reduce its further spread and lessen its impact. (RTAG Secretariat, 2000, p. 26)

The African meeting went on to recommend that HIV-AIDS should become a major theme, along with five more specifically educational ones, for the Dakar world conference. Existing theory and research can go some way towards developing the strategies called for by the African meeting. Demographic modelling should make it possible to calculate the effects of AIDS on teacher recruitment and supply; work on the multistep theory of human communication suggests ways of using the mass media for health education (Rogers, 1971); a thorough study of communication-based education in agriculture and nutrition summarises what we know about nonformal education programmes (Hornik, 1988). Together these suggest that it should be possible to set up programmes, incorporating formative evaluation and research, that integrate mass-communication programmes of education with practical activities including the distribution of condoms. In learning from such a programme the researcher would need to draw both from the traditions and assumptions of action research but also insights from sociology and social psychology on the religious and cultural obstacles in the way of AIDS education and containment.

On educational expansion we come back to the more conventional educational research agenda. Two specific issues look among the most important. First, what are the most appropriate structures that will help governments expand effective university education in the south? Second, can we devise structures for junior-secondary education that will harness open and distance learning to meet the new demands that are following, and will follow, the earlier expansion of primary education? In both cases, the record of experience is patchy, with many called to nonconventional education but few chosen to succeed. We have ample descriptive literature on open and distance learning at both levels of education and summaries of what can be learned from it (cf. Perraton, 2000). Perhaps to tackle the real problems that follow from the modest achievements of the existing programmes we need to begin by asking about the nature of the learning process and the difficulties faced by relatively unsophisticated learners. Or we need to address the political issues that would be involved in mixing and matching education on and off-campus so that all students study partly in each mode. Or: the plea is for hard thinking, and good research questions, that will result in findings to help better practice.

\section{Conclusion}

Education can help us to a better world. It will help us get there if we rely more on good research and less on under-informed trial and error.

International Review of Research in Open and Distance Learning 


\section{References}

Bowles, S. and Gintis, H. (1976). Schooling in capitalist America: Educational reform and the contradictions of economic life. New York: Basic Books.

Briggs, A., Adesola, A., Christodoulou, A., Crocombe, M., Nettleford, R., Reddy, G. R., Rickett, R., Watts, R. L. \& Williams, B. (1987). Towards a commonwealth of learning: A proposal to create the University of the Commonwealth for Co-operation in Distance Education: Report of the expert group on Commonwealth co-operation in distance education and open learning. London: Commonwealth Secretariat.

Clark, R. (1983). Reconsidering research on learning from media. Review of Educational Research, 53(4), 445-459.

Holmberg, B. (1995). Theory and practice of distance education (2nd ed.). London: Routledge.

Hornik, R. C. (1988). Development communication. New York: Longman.

Hülsmann, T. (2000). The costs of open learning: A handbook. Oldenburg: Bibliotheks- und Informationssystem der Universität Oldenburg.

Jamison, D. T. (1982). An introduction to the methods of cost analysis. In H. Perraton (Ed.), Alternative routes to formal education: Distance teaching for school equivalency. Baltimore: Johns Hopkins University Press.

Jamison, D. T., Klees, S. J. \& Wells, S. J. (1978). The costs of educational media: Guidelines for planning and evaluation. Beverly Hills: Sage.

Jencks, C. (1972). Inequality: A reassessment of the effect of family and schooling in America. London: Allen Lane.

Keegan, D. (1996). Foundations of distance education (3rd ed.). London: Routledge.

Lakatos, I. (1980). The methodology of scientific research programmes. Cambridge: Cambridge University Press.

Lewis, B. N. (1973). Educational technology at the Open University: An approach to the problem of quality. British Journal of Educational Technology $3(4), 188-203$.

Mitford, J. (1979). Poison penmanship: The gentle art of muckraking. New York: Knopf.

Morgan, A. R. (1996). Still seeking the silent revolution? Research, theory and practice in open and distance education. In T. Evans, V. Jakupec, \& D. Thompson (Eds.), Research in distance education 4, (pp. 7-17). Geelong: 
Deakin University Press.

Mortimore, P., Sammons, P., Stoll, L., Lewis, D. \& Ecob, R. (1988). School matters: The junior years. London: Open Books.

Orivel, F. (1987). Costs and effectiveness of distance teaching systems: A methodological approach. (mimeo) Dijon: IREDU: Université de Bourgogne.

Perraton, H. (1987). Theories, generalisation and practice in distance education. Open Learning 2(3), 3-12.

Perraton, H. (1995). A practical agenda for theorists of distance education. In F. Lockwood (Ed.), Open and distance learning today. London: Routledge.

Perraton, H. (1997). International research in open and distance learning: Report of a feasibility study. Cambridge: International Research Foundation for Open Learning.

Perraton, H. (2000). Open and distance learning in the developing world. London: Routledge.

Perraton, H. \& Creed, C. (2000). Applying new techniques and cost-effective delivery systems in basic education (Education for all 2000 assessment: Thematic study). Paris: UNESCO.

Rogers, E. M. (with Shoemaker, F. F.). (1971). Communication of innovations. New York: Free Press.

RTAG Secretariat (2000). Report on the all sub-Saharan conference on education for all. Harare: UNESCO.

Rutter, M., Maughan, B., Mortimore, P., \& Ouston, J. (1979). Fifteen thousand hours. London: Open Books.

Schiller, D. (1999). Digital capitalism: Networking the global market system. Cambridge Mass: MIT Press.

Skilbeck, M. (2000). Global synthesis (Education for all 2000 assessment). Paris: UNESCO.

Titmuss, R.M. (1970). The gift relationship: From human blood to social policy. London: Allen and Unwin. 


\section{Endnotes}

1. Here and elsewhere I follow European practice in using the term "open and distance learning" as an overall term (cf. Perraton, 2000, pp. 13- 14).

2. At the annual conference of the Higher Education Research and Development Society of Australasia in 1997 I heard a speaker from one publicly funded university boast that, in the interests of speed, entrepreneurship and an overseas deal, she had found a way round the normal university procedures that controlled quality.

3. Some of the findings are summarised in Perraton and Creed (2000). But the answers to quite simple questions - like why did Britain invest the sums she did in information technology in school - are often far from clear and rarely if ever answered explicitly.

Citation Format

Perraton, Hilary. (2000) Rethinking the Research Agenda. International Review of Research in Open and Distance Learning: 1, 1. http://www.icaap.org/iuicode?149.1.1.1 


\title{
Beauty Lies in the Eye of the Beholder
}

\author{
Judith Calder
}

\begin{abstract}
Best practice can be defined as that combination of structure, educational technology and content of a learning opportunity, which, in certain contexts and for particular groups of learners, is most likely to achieve the purposes of the main stakeholders. However, the rate of change of technological, political, economic, social and cultural contexts suggests that best practice may become a redundant concept, in that what is judged as best one day may not be so judged the next. This article considers what some significant contributions to the literature on open and distance learning practice have to say about the development and provision of best practice and about the place of critical reflection by stakeholders. It also considers the challenges facing the development of best practice presented by change, concluding with the identification of the most significant areas of development yet to be made.
\end{abstract}

\section{Introduction}

How many of us could have anticipated the exponential growth of open and distance learning which we now see around us? What was initially seen as a form of learning provided by a few national universities which specialised in distance teaching is currently ubiquitous across all levels of learning and all forms of institutions. Worldwide there are now thousands of different providers of open and distance learning giving credence to the use of the term . global phenomenon to describe what is happening. Political, religious, military, commercial, industrial and educational organisations are among the agencies in over 102 different countries who offer open and distance learning courses (Calder \& McCollum, 1998). We are not however describing the adoption of some static innovation. As new and different information and communications technologies become more widely available, they allow new delivery systems ${ }^{1}$ to be tested and adopted and new groups of learners to be reached.

Accurate data about this provision is however remarkably difficult to find. The lack of agreed definitions of terms, the lack of systematic, reliable and accessible data at all levels - local, national and international - and the paucity of rigorous research tends to be ignored in the rhetoric surrounding the expansion of open and distance learning. 
In spite of this proliferation of initiatives, or perhaps because of their very newness, there are many who would argue that open and distance learning does not yet constitute a recognised field of study. I suspect that in part this view is held because there is not yet an established and coherent body of knowledge which is recognised as representing the whole field. However the very nature of open and distance learning means that the boundaries to the field are still changing and look likely to continue to change well into the next millennium.

Much of this change is driven by those in government and industry who, in attempting to respond to the profound changes taking place in the global economy, place a perceived link between education, training and the economy at the centre of their thinking. Commentators such as Edwards (1997) have highlighted the "general shift towards technologically mediated and flexible forms of delivery to the extent where it is possible to argue that the boundary between "distance education" and "conventional education" is likely to disappear" (p. 126).

At the same time, technological enthusiasts battle for the widest possible dissemination of their favourite technological innovations. The early adoption of these innovations by what have been termed visionaries is a high-risk activity. New methods of teaching have to be introduced, along with new forms of organisation and quality control of delivery systems and unfamiliar methods of learning. New stakeholder groups such as community leaders, employers, or, with in-company training, line managers, may be involved. While costs can reduce dramatically with high student numbers, at some point the question of output and achievement starts to be raised.

Open and distance education is now a mainstream and widespread phenomenon. The global spread and the diversity of practice which comprises open and distance education at the beginning of this new millennium is a source of both optimism and concern. It is a source of optimism in that the rapid spread and development of an innovation which challenges many of our preconceptions about teaching and learning suggests that there is an openness and receptivity to new ideas among the policy makers and strategic thinkers in many countries. It is a source of concern in that the development and introduction of many open and distance learning initiatives is driven by a desire to achieve simple low cost solutions to complex social and economic problems. In such contexts, the quality of the provision appears often as a fragile afterthought rather than as fundamental to its development.

\section{What is meant by open and distance education?}

The terms open, distance, flexible, and remote learning are used increasingly loosely to describe a growing and diverse variety of learning delivery systems.

International Review of Research in Open and Distance Learning 
The question of just what these terms actually mean has been a source of considerable debate in the literature. The speed of change and the rapid introduction of new developments have presented a considerable challenge to those attempting to capture and to define key concepts. Increasingly the temptation for many is to use some terms interchangeably. There are however critical differences between them. Although many authorities have attempted to define the concept of distance education (Daniel, 1996; Dodds, 1995; Holmberg, 1986; Keegan, 1996; Moore, 1990; Wedermeyer, 1981), Holmberg's definition, first articulated in 1977, appears to have stood the test of time. He declared that:

Distance education thus includes the various forms of study at all levels which are not under the continuous, immediate supervision of tutors present with their students in lecture rooms or on the same premises, but which, nevertheless, benefit from the planning, guidance and tuition of a tutorial organisation. (Holmberg, 1986, p. 2)

In effect, the one common factor appears to be the use of media to enable the time separation and the geographical separation of the teaching process from the learning process. Issues of synchronicity (Daniel, 1996), two-way communication (Holmberg, 1986), the role of face-to-face support (Dodds, 1995), the influence of an educational organisation (Keegan, 1996), transactional distance (Moore, 1990), are all subsumed within this working definition.

It could be argued that the confusion between the terms open and distance was set early on with the establishment of the Open University (UKOU). This model of open and distance learning (ODL), developed in the late 1960s, was designed to give adults a second chance to study at degree level regardless of where they lived, regardless of their work or family responsibilities, and regardless of the lack of any prior educational qualifications. Lord Geoffrey Crowther, in his Installation Address as Vice Chancellor of the UKOU said that "we are open as to people, as to places, as to methods and as to ideas" (Open University, 1973, p. vii). Thus the ideas of openness rather than of distance were emphasised at this time. Key features of this early model of ODL included the design, development and production of courses through the use of teams of academics, educational technologists and media specialists; mass dissemination via a range of different media including print and broadcasting; further dissemination through the use of personal media such as audio and video; and personalised assessment and support to individual learners through the allocation of personal tutors. International practice during the next decade tended to focus on variations of the UK model with the establishment of centralised and government sponsored distance teaching universities such as the Universidad Nacional de Educacion a Distancia (UNED) in Spain, the Sukhotai Thammathirat Open University (STOU) in Thailand and the China Central Broadcasting and TV University (CRTVU) in China during the 1970s. Daniel (1996) has highlighted the appearance and the growth of these mega-universities, defined as distance teaching universities with over 100,000 students studying at degree level.

International Review of Research in Open and Distance Learning 
Recognition of the differentiation between the ideas of distance and of openness was relatively slow in coming. Not until the mid-1980s did authorities such as Lewis, Rumble, Scriven, Robinson and Carr attempt to disentangle what was meant by the term open learning. No consensus emerged. On the one hand were those who, having examined the difficulties in attempting a definition, drew back from the brink, concluding that "there exists no universally-agreed, adequate and comprehensive definition of open learning" (Webberley \& Haffenden, 1987, p. 137). Others preferred to take a more inclusive approach to the problem. While Lewis (1986) conceptualised open learning in terms of a continuum in terms of the choices available to the learner, Carr (1990), and also Robinson (1989), drew a distinction between open access and open pedagogy. As Carr argued, the removal of barriers in terms of the location of the learning, or the

pace at which it progressed had little relationship with the issue of learner centredness in deciding what and how the learner should learn. Thus it became clear that the terms open and distance were not synonymous, but did in fact refer to distinct and different ideas. This explained how some distance teaching provision could, in many respects, be considered closed (Guri-Rozenblitz, 1993). In the same way, open learning did not have to take place within a distance taught mode.

The terms flexible learning, distributed learning and e-learning are relative newcomers to the field, and again, are often used synonymously with the terms open and distance. The term flexible learning came via the vocational training field, and, as Smith points out, bears a distinct resemblance to the concept of open learning by virtue of two key determinants - "extended access to learning through the removal of barriers, and a philosophy of learner-centred provision where learner choice is the key" (Smith, 2000, p. 88). Meanwhile, the terms distributed learning in North America, and e-learning in the UK are used to describe integrated electronic distributed learning environments (or supported online learning) (Inglis, in press).

\section{Best practice}

Given the almost overwhelming range of practice on which would-be providers of open and distance education can draw, what can be said about best practice? How can it be identified, developed and provided? It must be said that relevance of the concept itself is open to debate. My own attempt at a definition would be along the following lines.

Best practice can be defined as that combination of structure, educational technology and content of a learning opportunity, which, in certain contexts and for particular groups of learners, is most likely to achieve the purposes of the main stakeholders. 
This definition raises more questions than it answers for those looking for enlightenment. In particular there are the criteria which should be applied in assessing practice. Questions about the structure of the provision, the media to be used, the content of the provision, and the teaching approach used are usually to the fore. However major texts on practice also draw attention to the issue of learner support (Cookson, 1990; Rowntree, 1992; Simpson, 2000; Tait \& Mills, 1999), to the institutional context and management of the provision (Moore, 1990; Robinson, 1989; Rumble, 1996), and to the necessity of evaluation over the life of the programme in relation to quality. At the same time the issue of costs and resource availability must be taken account of in the debate.

The application of these criteria by individual providers can present problems. While there is a considerable literature on each of these aspects, with guidance being given as to effective and efficient ways of designing, developing and producing materials, it is clear from reports of actual practice that providers new to the field are often unaware of the literature and the knowledge resources available to them. At the same time, the staff charged with designing and developing distance teaching materials, such as academics in higher education, lecturers and teachers in further education, community educators and vocational skills trainers, may have little or no background themselves in open and distance education and may thus have problems in identifying and articulating their own support needs (Abdullah, 1998). The urgent need for staff development in this area is only now becoming widely recognised. Texts which specifically address these needs are now beginning to appear (e.g., Latchem \& Lockwood, 1998).

The other question lies with the issue of whether there is such a thing as best practice or whether a more realistic aim should be good practice. My definition of best practice above attempts to locate the complex set of variables which constitute practice within a framework which is constantly changing. For example, learning contexts at the national, institutional, local and individual levels vary continuously depending on current economic, social and political conditions. Stakeholders' aims, their purposes in establishing provision, and the measures of success they use will also vary. Thus, a particular form of provision which would be claimed by a particular set of stakeholders at one point in time to represent best practice, would not be regarded as such at another point in time. In contrast, good practice is a more robust concept. It is designed to allow for fluctuations and change, and for compromise between the aims of different stakeholders.

For example, the priority aim may be to provide higher education opportunities for school leavers from all sections of society, or for a wider range of employed workers, or to maximise numbers of people with specific skills, the application of skills or knowledge in a range of contexts, or the achievement of critical reflection and awareness of the transformational properties of learning. These purposes will vary with the context in which the provision is offered, and with the culture within which it is offered. The literature on the use of open and

International Review of Research in Open and Distance Learning 
distance approaches to vocational education and training suggests that, while there is evidence that there are a variety of practices provided by both the public sector and within companies, there is often little evidence, particularly in the private sector, of the planning and monitoring systems needed to assess the success of different approaches.

It is also by now well recognised that different groups of stakeholders perceive success in very different ways. Funders, for example, may focus on input measures such as numbers of learners who buy, or register for a course, or the number of employees to whom a CD-ROM is circulated. Providers may look at other measures such as net profits, client satisfaction ratings or relative rankings of their organisation by peer groups. Suppliers of communication channels or of materials may look at gross sales and market share. Learners themselves use criteria such as enjoyment, increased self-confidence and achievement of personal short- or long-term aims. The fact is that there can be a clear potential for conflict both between different stakeholders' aims and their criteria for success.

\section{The place of critical reflection}

While there are plentiful case studies about different examples of practice in the literature, there has been, to date, relatively little critical reflection on experience that has been shared publicly. However providers' concerns can be deduced to some extent from the issues raised in the literature. Three issues in particular are of interest in that reflection: the importance of organisational structure, learning technologies, and learner centredness. Debate on the issues they raise continues unabated.

\section{Importance of organisational structures}

There is no shortage of clear authoritative texts on the structure, composition, and development of open and distance learning courseware. The clear consensus is that in order to achieve effective teaching and learning, not just the design, but also the production and distribution of the teaching and learning materials have to be well planned and controlled. However, the tendency among both public and private providers is for the different systems which are necessary for the development, production, distribution and support of teaching and learning to be organised, and often operated separately. A common scenario is where one person or group of people design and prepare the course content, another person or group of people transfer that content to one or more media, another group bear responsibility for distributing the material to the users, and yet another group or groups actually interact with and support the students during their learning. Recognition of the need to consider issues of course development and production processes and systems, with a few notable exceptions, does not ap-

International Review of Research in Open and Distance Learning 
pear to have been addressed in the early literature. Otto Peters' contribution is perhaps one of the few outstanding exceptions with his pursuit of debate about what he termed "industrial forms of instruction" (Peter, 1993, p. 15). He saw distance education as the product of a particular period in the development of our culture in which "distance study must be carefully pre-planned, prepared and organised, and that there is a division of labour, a growing use of technical equipment to work with, and the necessity of formalised evaluations" (Peters, 1993, p. 15). He first applied this analysis to correspondence education in an original paper in German in the late 1970s, but subsequently a full debate developed about the use of what were termed Fordist and post-Fordist approaches in distance education (e.g., Farnes, 1993; Raggatt, 1993; Rumble, 1996). However recognition of the need for clear and firm management control and agreed upon avenues of communication for monitoring and evaluating progress is now becoming evident. Both Brown (1997) and Robinson (in press) have highlighted in particular the importance of the organisational dimension and the quality of the planning processes and evaluation processes and their effects upon outcomes of innovations in open and distance education.

A number of early writers drew attention to the need to consider the special processes that are used in designing, building, operating, and evaluating nontraditional institutions and programs in relation to the emphasis given to the different technologies and different media used in teaching at a distance (e.g., Rowntree, 1974; Wedermeyer, 1981). Not only was there a considerable interest in the learning technologies which were used, but there was a strong tendency towards focussing on the potential of different technologies rather than on their relative effectiveness with different types of learners in different contexts. Nipper's (1989) timely contribution of the idea of generations of distance education to such debates for example, focussed on the simple recognition of the changing use of technology for distance education. Even here, although the distinction between the first two generations of distance education was clear - with correspondence teaching as the first generation and multiple media as the second - Bates (1991) identified a lack of clarity about the defining characteristics of the third generation. The continuing debate about what constitutes third generation distance education has emphasised the importance of the distinction between the use of technology for distribution purposes, for example via postal services, broadcasts and the Internet, and its use for an interactive exchange between teacher or trainer and learner using audio and videoconferencing, and computer conferencing or e-mail.

\section{Learning technologies}

Concerned by the assumption that the latest technology was necessarily the best one to use, with scant regard for its particular strengths and weaknesses, researchers such as Bates attempted to introduce a note of reality into the debate about media choice and media use in distance teaching. His downbeat

International Review of Research in Open and Distance Learning 
conclusion almost two decades ago that "the greatest media development during [the UKOU's] 12 years of existence has been the humble audio-cassette" (Bates 1982, p. 11) drew early attention to the importance of the teaching and learning issues as well as the technological changes. The same message of caution continues in much of the literature today. In an American review of contemporary research on the effectiveness of distance learning in higher education, Phipps and Merisotis concluded that the higher education community still had much to learn about how technology could enhance teaching and learning at a distance, expressing concern over research which was driven by the information revolution. As they pointed out:

computer mediated learning requires special skills of students and more sophisticated technical support if students are to interact fully. Questions that need to be asked include: What is the "quality" of the access? Does the student have the necessary skills to use the technology? What are the best ways to participate in synchronous communication? Is there adequate technical support? Perhaps most important, will the cost of purchasing a computer and maintaining software be prohibitive for a substantial number of students? (Phipps \& Merisotis, 1999, p. 7)

\section{Learner centredness}

The debates around teaching and learning at a distance have drawn on a range of literatures. American and Canadian research on self-directed learning which was led by the work of Allen Tough (1979) and Malcolm Knowles (1975) has had a major influence on thinking about the learning process in adults. Authorities on adult education such as Stephen Brookfield, commenting on the research which had revealed the vast extent of self-managed and independent learning which adults undertook as part of their daily lives, remarked that "there is now much less likelihood that educators will presume that valid and valuable adult learning can occur only in the presence of an accredited and professionally certified teacher" (Brookfield, 1986, p. 149). Distance educators such as Evans (1994), and Morgan (1993) attempted to open up what they termed the world of the learner by investigating the factors which influenced students' learning and the student experience of the learning process. Literature in this field was underpinned by the work of researchers such as Kolb (1984), Pask and Scott (1972), Marton and Saljo (1976) and Entwistle (1981). Smith's (2000) review of the development and application of ideas on individual learning styles and approaches to learning shows the more recent growth of people working in the field. However, the impact of the work on learners and learning in relation to the development of ideas about the structuring of materials and the need for different types of support by different groups of learners is only now beginning to be felt in open and distance education. The importance of the age of the

International Review of Research in Open and Distance Learning 
student, their previous educational experience, the type of programme in which they are enrolled, and their cultural affiliation are all factors which have emerged as associated with the learners' approach to learning (e.g., Calder \& Wijeratne, 1999; Kember 1999; Richardson, 1997).

\section{Challenges}

The challenges facing the development of best practice, or as I would prefer it, good practice, are many. But I would highlight three challenges in particular which need to be met if open and distance education is to achieve its potential. These are, to develop a better understanding of (a) the effects on curricula when presented through open and distance education, (b) the effects of cultural diversity in determining good practice, and (c) the challenge of access and equity.

\section{Effects upon curricula}

Concern about good practice in teaching at a distance initially focussed on adult learning at degree level. Curriculum design and development followed very much the traditional university curriculum. Any debate about the curriculum tended to revolve around the extent to which laboratory-based subjects such as applied sciences, technology, and medicine could be taught at a distance. While a whole literature exists on this topic alone, early solutions ranged from decisions not to include the subject at all, to including periods of residential laboratory work as part of the course, to devising and using home-based experimental work. As the technology available developed, more sophisticated solutions such as the virtual microscope and other forms of simulation have been introduced. Changes to the form and shape of the curriculum itself reflected changes in the locus of control. Whereas previously higher education provision had reflected the teacher-centred nature of existing curricula, economic and market pressures pushed providers towards a more client-centred curricula. Thus there appears to be a tendency

among providers to construct curricula which can be presented as a series of increasingly shorter modularised courses which are planned to take days or weeks of part-time study rather than months or years. It could be argued that the curriculum of vocational education and training is similarly changing. For example the growth of competence-based training qualifications has encouraged the development of links between modules of training traditionally provided for induction, skills development or up-dating purposes for basic grade staff, to enable portfolios of work to be developed for assessment purposes.

International Review of Research in Open and Distance Learning 


\section{Sensitivity to the effects of cultural diversity in determining good practice}

Attention has been increasingly drawn to the diversity of problems faced by those attempting to design and introduce good open and distance education practice. It increasingly appears that the importance of inherent differences in organisational cultures, academic cultures, education and training philosophies, and teaching and learning values and traditions within different cultural groups have not been adequately recognised by those attempting to transplant models of practice from other contexts. Robinson (1999), for example, has pointed out the need for distance educators "to understand more fully the cultural contexts of learners and to build better bridges into and out of cultures of learning" (p. 45). Organisations which do not value the rather different demands of distance teaching from conventional face-to-face teaching can place unrealistic demands on their staff and on their organisational systems. Academic cultures which give a different emphasis to critical peer review, and with entrenched academic hierarchies may find the course team approach to developing materials less relevant than other approaches. Similarly, a culture of elitism rather than of learner centredness and inclusiveness will result in fundamental differences in the way in which student recruitment is undertaken, in the language or languages in which materials are prepared and support given, and in which student and programme evaluation findings are interpreted. At its simplest, are high drop-out and poor results interpreted as meaning that the students do not have the ability to cope, or that the provision does not meet learners' needs because of problems with its design and implementation? The growing interest in the ideas of Argyris and Schon (1978) and the development of a learning organisation suggest that there is a growing awareness of these issues.

\section{The challenge of access and equity}

Finally, the issue of access and inclusiveness is one which is coming increasingly to the fore in the developed, newly developed and developing worlds. Widening participation in education and training is now seen as an economic and social imperative. How this participation is to be achieved is, however, problematic, and certainly distance education is seen by many as the solution with most potential. However, it is clear from the funding regimes which have been put in place for many distance education programmes that the apparently low costs of this form of provision is the key attraction to many of those seeking to optimise student or trainee numbers on decreasing budgets. The fact that low variable costs per additional student recruited comes with the high fixed costs associated with initial course development, and with fixed variable costs where learner support is integral to the programme is often overlooked or ignored. There is a growing recognition of the frequent lack of resources - financial, personnel, time, facilities - which so often accompany commitments to produce "low cost"

International Review of Research in Open and Distance Learning 
distance education (Robinson, in press). Paper after paper at international conferences bear testimony to the disastrous effects on the development of open and distance education programmes of inappropriate organisational cultures, inadequate communication infrastructures, and inadequately trained and prepared staff (e.g., Mugadzaweta \& Benza, 1999; Murugan, 1999).

It should be pointed out that there was a distinct lack of early reliable cost estimates related to production and distribution. With the exception of people such as Rumble $(1976,1986,1997)$ writing on cost effectiveness, there was little written about the organisation and administration of distance education. More recently, with the growth of the market in all forms of open and distance education, concern about real costs has come to the fore, with a recognition of the need for much greater transparency about all costs associated with any programme. For example, a recent review (Marchmont, 2000) of the costs of e-learning identified a number of different models for examining costs. While each of the models has its own strengths and weaknesses, among the points they make are the need to distinguish between different types of costs and benefits, to link costs to break-even points in relation to student numbers as well as to average costs, and to link cost structures to the different phases of project development. One example given by Marchmont (2000) is for a three-phase model that would cost each phase separately: planning and development, production and delivery, and maintenance and evaluation. Perhaps to that should be added a fourth phase of up-dating and revision or remake. The importance of identifying otherwise hidden costs associated with programmes, such as for instance, staff time for learner support is also emphasised.

Issues of access and equity are not limited to availability of resources, but the role played by resource availability is fundamental to the sustainability of good open and distance education practice. If genius is one tenth inspiration and nine tenths perspiration, then it can also be argued that good practice in distance education is one tenth presentation and nine tenths preparation. There are no short cuts to good practice. 


\section{References}

Abdullah, S. (1998). Helping faculty to make a paradigm shift from on-campus teaching to distance education at the Institut Teknologi Mara, Malaysia. In C. Latchem \& F. Lockwood (Eds.), Staff Development in Open and Flexible Learning. London: Routledge.

Argyris, C., \& Schon, D. A. (1978). Organizational learning: A theory of action perspective. Reading: Addison Wesley.

Bates, A. W. (1982). Trends in the use of audio-visual media in distance teaching systems. In J. S. Daniel, M. A. Stroud \& J. R. Thompson (Eds.), Learning at a Distance: A World Perspective. Edmonton, AB: Athabasca University and International Council for Correspondence Education.

Bates, A. W. (1991). Third generation distance education: The challenge of new technology. Research in Distance Education 3(2), 1015.

Brookfield, S. (1986). Understanding and facilitating adult learning. Milton Keynes: Open University Press.

Brown, S., (Ed.). (1997). Open and distance learning: Case studies from industry and education. In Open and Distance Learning series. London: Kogan Page.

Calder, J. \& McCollum, A. (Eds.). (1998). Open and flexible learning in vocational education and training. In Open and Distance Learning series. London: Kogan Page.

Calder, J. \& Wijeratne, R. (1999). The approaches to study of distance learners in two cultures: A comparative study. In R. Carr, O. Jegede, W. Tata-meng \& Y. Kin-sun. (Eds.), The Asian Distance Learner. (pp. 116-129). Hong Kong: Open University of Hong Kong.

Carr, R. (1990). Open learning: An imprecise term. ICDE Bulletin, 22, 47-50.

Cookson, P. S. (1990). Introduction to part two: The Learner, learning, instruction and learner support. In M. Moore (Ed.), Contemporary Issues in American Distance Education. Oxford: Pergamon Press.

Daniel, J. (1996). Mega-universities and knowledge media: Technology strategies for higher education. London: Kogan Page.

Dodds, T. (1995). The use of distance learning in non-formal education. London: International Extension College.

Edwards, R. (1997). Changing places? Flexibility, lifelong learning and a learning society. London: Routledge.

International Review of Research in Open and Distance Learning 
Entwistle, N. (1981). Styles of learning and teaching. Chichester: John Wiley and Sons.

Evans, T. (1994). Understanding learners in open and distance education. London: Kogan Page.

Farnes, N. (1993). Modes of production: Fordism and distance education. Open Learning 8(1): 10-20.

Guri-Rozenblitz, S. (1993). Differentiating between distance/open education systems - Parameters for comparison. International Review of Education 39(4), 287-306.

Holmberg, B. (1986). Growth and structure of distance education. London: Croom Helm.

Inglis, A. (in press). Selecting an integrated electronic learning environment. In F. Lockwood \& A. Gooley (Eds.), Innovation in Open and Distance Learning. London: Kogan Page.

Keegan, D. (1996). Foundations of distance education. London: Routledge.

Kember, D. (1999). The learning experience of Asian students: A challenge to widely held beliefs. In R. Carr, O. Jegede, W. Tat-meng \& Y. Kin-sun (Eds.), The Asian Distance Learner. (pp. 82-99). Hong Kong: The Open University of Hong Kong.

Knowles, M. (1975). Self-directed learning. Chicago: Follett.

Kolb, D. (1984). Experiential learning: Experience as the source of learning and development. Englewood Cliffs: Prentice Hall.

Latchem, C. \& Lockwood, F. (Eds.) (1998). Staff development in open and flexible learning. London: Routledge.

Lewis, R. (1986). What is Open Learning? Open Learning 1(2), 5-10.

Marchmont, O. (2000). Funding learning: The economics of e-learning. Exeter: University of Exeter.

Marton, F. \& Saljo, R. (1976). On qualitative differences in learning: Outcome and process. British Journal of Educational Psychology 46, 4-11.

Moore, M. (1990). Introduction: Background and overview of contemporary American distance education. In M. Moore (Ed.), Contemporary Issues in American Distance Education. (pp. xii-xxvi). Oxford: Pergamon Press.

Morgan, A. (1993). Improving your students' learning: Reflections on the experience of study. London: Kogan Page.

International Review of Research in Open and Distance Learning 
Mugadzaweta, J. G. \& Benza, T. (1999). Distance education in Zimbabwe. Pan Commonwealth Forum on Open Learning: Empowerment through Knowledge and Technology. Brunei Darussalam: Commonwealth of Learning. (Retrieved June 20, 2000:

http://www.col.org/forum/PCFpapers/Mugadzaweta.pdf).

Murugan, K. (1999). Distance education in the Commonwealth Caribbean: Survival of the fittest. Pan Commonwealth Forum on Open Learning: Empowerment through Knowledge and Technology. Brunei Darussalam: Commonwealth of Learning. (Retrieved June 20, 2000:

http://www.col.org/forum/PCFpapers/murugan.pdf).

Nipper, S. (1989). Third generation distance learning and computer conferencing. In R. Mason \& A. Kaye (Eds.), Mindweave: Communication, Computers and Distance Education. (pp. 63-73). Oxford: Pergamon.

Open University (1973). Report of the Vice-Chancellor 1971. Milton Keynes: Open University Press.

Pask, G. \&. Scott, B. C. E. (1972). Learning strategies and individual competence. International Journal of Man-Machine Studies 4, 217-253.

Peters, O. (1993). Understanding distance education. In K. Harry, M. John \& D. Keegan (Eds.). Distance Education: New Perspectives. (pp. 10-18). London: Routledge.

Phipps, R. \& Merisotis, J. (1999). What's the difference?: A review of contemporary research on the effectiveness of distance learning in higher education. Washington: The Institute for Higher Education Policy. (Retrieved June 20, 2000: http://www.ihep.com/difference.pdf).

Raggatt, P. (1993). Post-Fordism and distance education - A flexible strategy for change. Open Learning 8(1), 21-31.

Richardson, J. (1997). Approaches to studying in distance education: Qualitative and quantitative investigations. Milton Keynes: Open University.

Robinson, B. (1999). Asian learners, western models: Some discontinuities and issues for distance education. In R. Carr, O. Jegede, W. Tat-meng \& Y. Kin-sun (Eds.). The Asian Distance Learner. (pp. 33-48). Hong Kong: Open University of Hong Kong.

Robinson, B. (in press). Innovation in open and distance learning: some lessons from experience and research. In F. Lockwood \& A. Gooley. (Eds.). Innovation in Open and Distance Learning. London: Kogan Page.

Robinson, K., (Ed.). (1989). Open and distance learning for nurses. Harlow: Longman. 
Rowntree, D. (1974). Educational technology in curriculum development. London: Harper and Row.

Rowntree, D. (1992). Exploring open and distance education. London: Kogan Page.

Rumble, G. (1976). The economics of the Open University of the United Kingdom. Milton Keynes: Open University.

Rumble, G. (1986). Costing distance education. London: Human Resource Development Group, Commonwealth Secretariat.

Rumble, G. (1996). Labour market theories and distance education: A response. Open Learning 11(2), 47-52.

Rumble, G. (1997). The costs and economics of open and distance learning. London: Kogan Page.

Simpson, O. (2000). Student support in open and distance learning. London: Kogan Page.

Smith, P. (2000). Preparing for flexible delivery in industry: Learners and their workplaces. Unpublished doctoral dissertation, Deakin University, Australia.

Tait, A. \& Mills, R. (Eds.). (1999). Patterns of flexibility of the individual learner: The convergence of open and distance learning and conventional education. London: Routledge.

Tough, A. (1979). The adult's learning projects. Toronto: Ontario Institute for Studies in Education.

Webberley, R. \& Haffenden, A. (1987). Skills training and responsive management. In M. Thorpe \& D. Grugeon (Eds.), Open Learning for Adults. (pp. 137-146). London: Routledge.

Wedermeyer, C. A. (1981). Learning at the back door: Reflections on nontraditional learning in the lifespan. Madison, Wisconsin: The University of Wisconsin Press.

Citation Format

Calder, Judith. (2000) Beauty Lies in the Eye of the Beholder. International Review of Research in Open and Distance Learning: 1, 1. http://www.icaap.org/iuicode?149.1.1.10 


\title{
Current Developments and Best Practice in Open and Distance Learning
}

\author{
Armando Rocha Trindade \\ Hermano Carmo \\ José Bidarra
}

\begin{abstract}
Through the many documents regularly emitted by those dedicated to this activity, it is comparatively easy to describe factual developments in the field of open and distance education in different places in the world. However, it is much more difficult to produce judgements of value about their quality. Quality is a subjective rather than an absolute concept and may be examined from different analytical perspectives: consumers' satisfaction level, intrinsic value of scientific and technical content of learning materials, soundness of learning strategies, efficiency of organisation and procedures, adequate use of advanced technologies, reliability of student support mechanisms, etc. These parameters should be put into the context of specific objectives, nature of target populations and availability of different kinds of resources. In a specific geographic, social, economic and cultural situation a given set of solutions might be judged as adequate and deserving the qualification of "good practice", while in a different context it could be considered of rather poor quality. The selection of examples in this article is the sole responsibility of the authors: neither should the chosen cases be considered as clearly better than any other one, nor missing cases be interpreted as lack of appreciation or a negative judgement. Finally, the authors are aware of the risks of interpreting trends and trying to extrapolate them into the near future: readers should use their own judgement in accepting (or forcefully rejecting) these projections.
\end{abstract}

\section{Distance Learning Nowadays}

\section{Definitions}

We do not intend to propose new designations or definitions in the field that is currently and briefly described as open and distance learning (ODL). Nevertheless, we propose to widen the corresponding field of application to include most of the possible contexts of education and training, taking into account their initial and continuing features, consider degree and non-degree programmes, and 
embrace all levels of formal education, from school to advanced higher education. There are many different situations of lifelong education and training (see Fig. 1 below). In order to embrace all these different educational situations we are forced to adopt, for the sake of simplicity, inclusive ("passepartout") designations.

Figure 1: Different types of education and training situations and connections between various types.

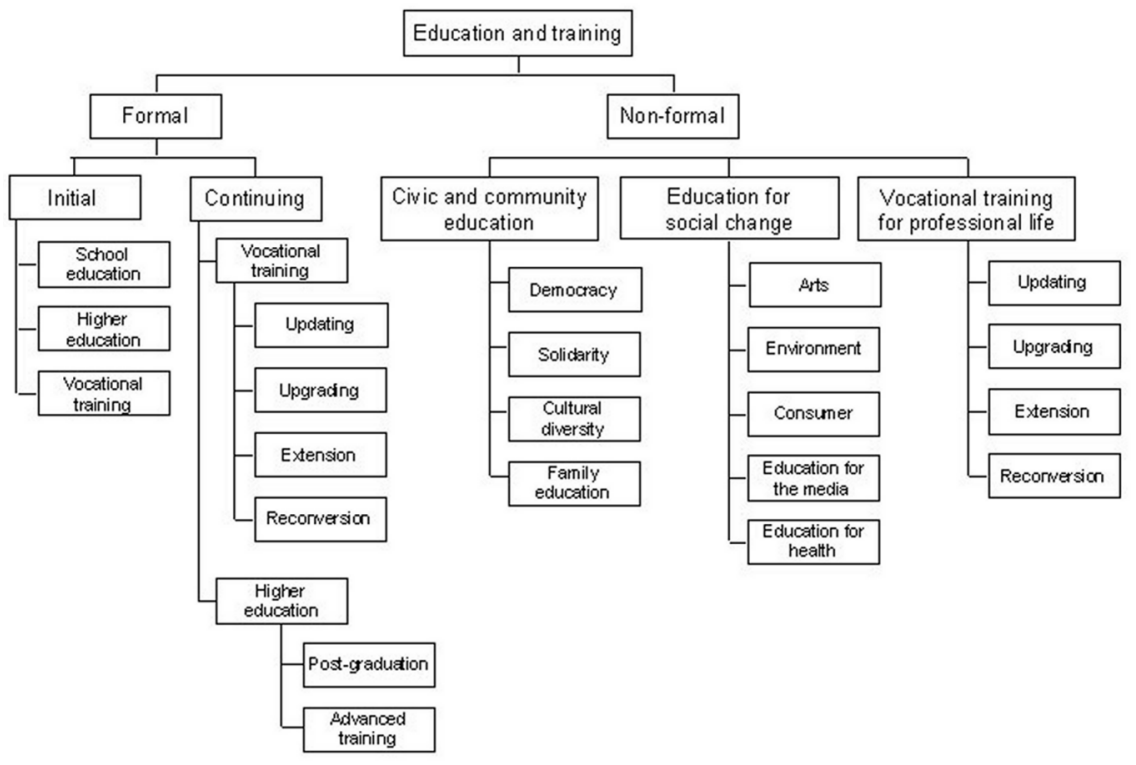

From another point of view, even if we were limited to the context of formal education, it would be possible, according to each precise situation, to use different expressions like distance learning, resource-based learning, distance teaching, distributed learning, flexible learning, remote classroom teaching, and many more. Moreover, looking at the semantics of the word open (frequently used in this field in expressions like open universities and open learning), it may mean either that distance education is the prevailing method used by the teaching system or that there are no prerequisites for access, even for degree programmes.

This situation implies that students and trainees need to have access other than by interpersonal contact to appropriate learning materials: buying books, cassettes or CD-ROMs, receiving broadcasts, using mail or e-mail, accessing the Web. This is, however, not enough, even if these materials have been designed as suitable for self-learning. Distance learning methodology also requires that some kind of support mechanism be available to students, so they can overcome their learning difficulties, get supplementary information, evaluate their own progress and exchange ideas with teachers, tutors and fellow students. (Holmberg, 2000;

International Review of Research in Open and Distance Learning 
Keegan, 1993).

Given these two requisites, teaching and training systems may assume different shapes and mobilise different kinds of technological facilities, according to their objectives, target populations and available resources. We shall call them, from now on, open and distance learning $(O D L)$ systems, whatever the relative proportion of time allocated to self-learning activities and face-to-face ones. The term open and distance learning provides an umbrella designation for all kinds of systems fitting roughly the above requisites (Trindade, 1992).

\section{Systems and Organisations}

Credible ODL systems must have means of establishing an individual link with each member of their universe of users. This means that each student or trainee is identified as a specific person, to whom correspondence is addressed, assignments are sent, marks are attributed and whose questions receive timely answers. In the case of formal programmes, it is the individual student whose learning achievement is assessed and to whom a certificate, diploma or degree may eventually be awarded.

Whatever the format and nature of the ODL system, the above requirements imply that reliable communications and good logistics are available. Both are essential so that the distance between the system and its users does not introduce unacceptable delays between the generic availability of learning materials and their actual handling by the user; between posing a question and getting an answer; between sending an assignment and receiving the corresponding evaluation.

These same requisites become more stringent when the volume of users expands from small to medium, to large, to extra-large. Dealing effectively with tens or even hundreds of thousands of students in absentia requires: following very sound organisational principles and good implementation, systematic monitoring of deviations from established procedures and timings, regular review of users' comments and criticisms as well as careful analysis of final results.

Contrary to conventional, classroom-based teaching, ODL systems are essentially aimed at providing mass education or training; therefore, they have to rely more on capital- and methodology-intensive investments than on manpowerintensive ones. Hence, compared with a ratio of 15 or 20 students to 1 teaching staff in a conventional face-to-face university, for large systems like the so-called Open Universities, the ratio is frequently between 80:1 and 100:1 and in some mega distance education universities, the ratio may actually ascend to 800:1. Obviously, due to the heavier weight of logistics and the presence of instructional designers and media producers in those systems, the ratio between non-teaching and teaching staff is usually higher in distance learning institutions than in con-

International Review of Research in Open and Distance Learning 
ventional ones.

However, the economics of distance education systems (as compared with their conventional counterparts) is clearly favourable in terms of cost-effectiveness; and the more so as the volume of students increases. This is true for both classical open universities (Daniel, 1996) and virtual or networked ones (Ash, 2000; Ortner \& Nickolmann, 1999).

Systems with these characteristics usually rely on flexible organisations and creative management styles to address instructional design and media production issues related to the priorities in development of ODL materials. The relations between instructional design and media production issues and the roles of authors, designers and managers are illustrated in Table 1.

Table 1

\begin{tabular}{|c|c|c|c|}
\hline \multirow{2}{*}{ Main Issues } & \multicolumn{3}{|c|}{ Priorties for the: } \\
\hline & Author & Designer & Hanager \\
\hline $\begin{array}{l}\text { 1. Content is precise and } \\
\text { clear }\end{array}$ & 14.photity & 2 renotery & Fonotity \\
\hline $\begin{array}{l}\text { 2. Communications have } \\
\text { the highest standards for } \\
\text { leaming purposes }\end{array}$ & 27 phonty & 1* photely & 2 prototy \\
\hline $\begin{array}{l}\text { 3. Deadines and costs are } \\
\text { under cortrol }\end{array}$ & II ponotely & I phorty & 14 peorty \\
\hline
\end{tabular}

Relationships between author, designer and manager issues and instructional design/media production issues

\section{Modes of Operation}

The distinction between ODL single-mode and dual-mode organisations is a classical one (Holmberg, 1981). The first designation applies to organisations where distance learning activities are largely dominant as compared with faceto-face ones. This means that, for single-mode systems, students work mostly by themselves outside a campus, their direct contact with the system (e.g., working with tutors, visiting study centres or following summer intensive courses) occupying just a small fraction of the yearly workload. This is the usual organisational pattern of open universities, also known as dedicated distance learning universities.

A different arrangement is followed when conventional universities decide to introduce distance learning methods in some programmes, aimed at extra-mural students, in parallel with their conventional operation. The expression dualmode system reflects the coexistence of distance education and conventional types of operation. This solution has been adopted by an increasing number of 
traditional universities as a means to provide education to students unable to follow courses regularly on campus, thereby expanding the social usefulness and the geographical radius of their influence.

Dual-mode institutions tended to use their distance learning stream mostly for non-degree programmes such as adult and continuing education, while the more prestigious graduate and post-graduate programmes were taught in the conventional, classroom mode. This was the current situation in many North America dual-mode universities some years ago.

In other cases, equivalent formal programmes were taught in the two modes, albeit for different target groups (intra- and extra-mural students), as in the case of the more than 20 French universities associated in the Fédération Interuniversitaire d' Ensignement à Distance (FIED) (http://telesup.univ-mrs.fr) or the University of Southern Queensland (Australia), which considers itself as a model of dual-mode university (http://www.usq.edu.au/).

When the distance learning stream is offered in dual-mode institutions, however, it tends to be assigned a lower priority and to be allocated fewer resources than the conventional stream. Perhaps this is to be expected due to the cultural inertia of older university institutions that tend to frown upon "dangerous innovations" introduced in their usual and comfortable status quo.

Meanwhile, a new model has begun to appear, avoiding the drawbacks of the dual-mode of operation and taking full advantage of the merging of the two teaching methods. We call it the mixed mode, whereby the distance learning and the conventional streams are simultaneously applied, in the same programme, for the same students. From this perspective, one part of the student workload, formerly spent in the classroom and taught by a teacher, is replaced by selflearning activities.

An example of mixed mode is the successful experience of Tele-schools in many regions of the world, some of which have been in operation for more than 40 years. Examples are the Telescola in Portugal, the New Zealand Correspondence School (http://www.correspondence.school.nz) and Tele-ensino in Ceará, Brasil. Designed to provide basic education in remote areas with the sole support of local monitors, they are supported by mail, radio broadcasts, television and, more recently, by more sophisticated communications.

Another example of a mixed mode ODL system from higher education field is the China Central Radio and Television University, one of the largest ODL systems in the world, which delivers course content through satellite transmissions to classrooms. Students work by themselves and interact with teachers working in the central system via wide-band terrestrial cable communications. One of its decentralised structures, the Shanghai Television University, has developed interesting new applications of advanced technologies to improve student's access to learning materials (http://www.shtvu.edu.cn).

International Review of Research in Open and Distance Learning 
The recently created (2000) Universidad Virtual de Andalucia consists of ten universities and polytechnics in this southern region of Spain. Distance education courses are available to students in parallel with current face-to-face teaching activities (http://www.ugr.es).

\section{Convergence of Learning Paradigms}

The classroom mode and the distance learning mode are converging. This is not only due to the success of ODL dual- and mixed-mode experiences but also to progress in information and communication technologies and their permeating all learning environments in most developed countries. Using computers and accessing the Web in schools and universities, taking advantage of quality learning products in CD-ROM, linking institutions through video and computer conferencing all create favourable conditions for increasing students' autonomy and stimulating self-learning. This convergence of technologies obviously means that a shift will be necessary in teachers' profiles and roles. Rather than being the sole owners of knowledge transmitted in the classroom, teachers will become mediators between students and their access to information provided by various sources. This trend has been followed for a number of years through the research activities of the International Council for Open and Distance Education, (http://www.icde.org), the worldwide umbrella organisation for ODL systems (Hall, 1996).

At the Lisbon Summit on Work and Employment in March 2000, heads of state and prime ministers of the European Union agreed to a major joint effort to introduce information and communication technologies (ICT) in all kinds of teaching institutions. This massive project (http://www.portugal.ue-2000.pt/) is intended to improve learning and to prepare future citizens for the needs of the information society.

It is important to note that even dedicated distance learning systems sometimes include classroom instruction, not only to satisfy the need for presential activities in some particular courses but also to reinforce student-system interaction. Giving human faces to otherwise "absent" teachers breaks the isolation of the distance learning student. We have found, by direct experience, that students welcome face-to-face seminars and intensive courses, even if they must sometimes travel from faraway places.

\section{Experimental, Laboratory and Hands-on Experience}

We must accept the fact that in many fields of knowledge, pure distance learning is not suitable for acquiring all necessary attitudes and skills. Some obvious cases in higher education are may be cited:

International Review of Research in Open and Distance Learning 
- health sciences, especially hospital practice

- experimental sciences, which require some time in laboratory environments

- applied psychology, implying direct inter-personal experience

- the final stages of training in law, where oratory and public argumentation skills are of paramount importance

An obvious approach to this difficulty is to separate all theoretical content from the corresponding applications and practice. The former may be efficiently taught in the distance learning mode, and even applications may be presented as case-studies with the full power of sound, image and interactivity as an illustrative introduction to the real, hands-on practice.

Similarly, computer simulation can substitute for real application and practice, as has already happened, successfully, with flight simulators and will happen more and more in the future by progressively maturing the concept of dry lab. However, we are bound to accept the absolute need, in many cases, for face-toface sessions in the appropriate actual working environment.

Many distance teaching systems include face-to-face activities in their programmes, sometimes as intensive courses of an experimental nature. Other institutions avoid offering programmes that require a significant component of experimental practice.

It should be noted, however, that the need to offer opportunities for experimental practice may not be needed in certain continuing (even if advanced) education and training programmes. For a fully qualified and experienced professional the illustration, through appropriate media, of new methods, techniques or equipment may be sufficient to assure the fulfilment of programme objectives.

To further those aims, distance teaching institutions have been very active in establishing partnerships with companies and other organisations. A good example is EuroPACE (http://www.europace.be), a trans-European network of approximately 60 member organisations all over Europe, 45 of which are universities. By using various models, it utilises virtual environments to demonstrate and develop the potential of telematics for vocational training and university teaching. 


\section{Functions of an ODL System}

\section{A General Approach}

Taking as an example of an open university as a fully integrated, dedicated ODL system, we can list the major functions or system capacities for performing the corresponding tasks (Trindade, 1999):

- Specification of programme objectives and target population

- Programme design and curriculum development

- Content authoring

- Instructional design

- Production of learning materials

- Selection and enrolment of students

- Distribution of information and learning materials

- Tutoring and student support

- Assessment and certification

- General and special monitoring

These functions have been listed more or less in the chronological order in which they occur, from the inception of a new programme until the end of its first academic year of operation. Obviously, a number of sub-tasks are embedded in some of these items. For example, conducting a human and material resources feasibility study is part of specifying objectives and the target population, designing the main learning strategies is a sub-task within curriculum development, and selecting media is part of both authoring and production of learning materials. Monitoring is a major aspect of quality assurance, as it provides information and data suitable to have a retroactive effect in improving the performance of all the other functions. Most items in the list do not require further detailing or comment; we shall just deal with the ones deserving a special analysis in the present context.

\section{Distribution Technologies}

A main task for systems using distance learning methodologies (as a major component or just as part of their activities) is to make sure that all learning materials reach students in a timely way. One must take into account that, in

International Review of Research in Open and Distance Learning 
an ODL situation, all relevant information should be accessible, in full, to the student. It is not enough, for instance, to provide students with an extensive bibliographical list, without making sure that all the corresponding references are equally and readily available.

Learning materials may include books and other written documents, radio and television broadcasts, audio and video recordings, interactive courseware and all kinds of documents and information circulating in communication nets (Bates, 1995).

It is currently accepted that all these kinds of documents do not substitute for each other, but rather they complement each other. Books (or the printed page) remain a major tool for studying and learning, as they adapt better to different locations and situations than do documents delivered by electronic media. Experience shows, moreover, that even if texts are originally "published" on the Web, most users print them immediately on paper, rather than studying their content from the screen of a computer.

Moving images and sound are a very useful means of acquiring information of different sorts, often complementary to the information that can be transported by sheets of paper. Broadcasts and permanent magnetic or optical recordings represent two different ways of accessing the information contained therein.

Computers and information technology have made it possible to present directly to the user written content integrated with sound and fixed or moving images. The Internet has added the new dimension of interactivity, allowing users to introduce and to modify data as well as to receive the corresponding feedback.

By adopting a non-sequential (hypertext) architecture in texts and introducing components of sound, fixed images and video clips, we can create new degrees of freedom in the way a document is approached and studied. We can also include a constructionist or "play" component that may increase appeal and facilitate learning (Bidarra \& Guimarães, 1999).

Books and other written documents, cassettes and CD-ROMs can be made available to users either by conventional mail or by distribution in commercial circuits. Sound and video can be broadcast through terrestrial or satellite links, either clear or encrypted, just requiring the users to possess the appropriate receiving equipment.

New communication technologies have created new opportunities for information distribution. All sorts of documents can now be transferred through local, regional or international telephone/computer networks. Mobile phones and portable computers (recently combined into one) have introduced new degrees of spatial freedom.

In addition to supporting materials specially conceived and produced for use in a given distance learning situation, and linking a teaching system and its

International Review of Research in Open and Distance Learning 
individual end-users, the Internet provides access to a huge number of supplementary information sources. However, it is still necessary to ensure that this information is positively related to the subject of study and that sources are credible. Only then can it be judged to be useful and relevant for each previously defined learning objective. This problem has been properly solved by giving students access to the full content of the bibliography recommended for each course, included in an online library. The Open University of Hong Kong (http://www.lib.ouhk.edu.hk) has just implemented such a virtual library, containing more than a half-million books and articles, duly authorised by their publishers.

\section{Student Support Mechanisms}

In a conventional learning situation, interpersonal interactions are usually defined as teacher/student, student/teacher and student/student relationships, and depicted in a triangular pattern. In an entirely distance learning mode, direct contacts of this kind are, except on rare occasions, almost always compromised; some virtual substitutes have to be introduced. Students, prone to be affected by unsolved scientific or pedagogic difficulties in their learning process, by discouragement and demoralisation or by doubts that they are following the right path in the process of knowledge acquisition, should not be forced to work in isolation.

Student support mechanisms are designed to overcome these difficulties. By creating opportunities for contact between students and the teaching system, questions can be asked and answered, advice provided and moral support given whenever needed. Mail and telephone have been used as means for these interactions, as well as study centres where students can meet teachers and tutors at mutually arranged times.

E-mail has introduced a new and more efficient dimension in this process. Even if asynchronous in nature, it is much quicker than conventional mail and much less expensive than the use of phone or of having to travel for a face-to-face meeting. However, we must bear in mind that person-to-person communications are timeconsuming, so the need for adequate student support mechanisms affects the required minimum number of assigned teaching staff. In organisational terms this means that the design of the system cannot afford to become teaching staff-intensive by being too generous with "permanent" availability of tutors to contact students on a person-to-person basis.

On the other hand, e-mail is the perfect tool to diffuse collectively generalinterest information to students: administrative documents and data, formative tests, examination results, news and events.

From another point of view, computer mediated communication (CMC) has 
made it possible to assure student-student interaction through discussion and collaborative-learning groups, thus breaking the traditional and awkward isolation of the distance learning student. Online educators have realised that they can generate effective (small) group discussions when they provide learners with specific tasks to accomplish. It is important to consider the quality of resources, scheduling with precise deadlines and consistent online support.

\section{Technological Facilities}

A distance teaching system needs to have the best technological infrastructure it can afford, namely in data processing for academic and administrative management, and internal circulation of information and technologies for producing and publishing learning materials. However, in distributing these materials and assuring good communications with students, some other considerations must be taken into account.

In the case of a system aiming at providing education to the largest possible population of users, there is a risk of using technologies that are not available to the majority of the target population. This would create social and economic discrimination, with the possibility of excluding the less-favoured part of the universe of potential users from the corresponding benefits.

This is the current situation in developing countries, where information and communication technologies are not widely distributed throughout the population. In many cases, even conventional mail is slow and erratic and telephones scarce and unreliable. A way out of this dilemma is to put distance education into a small number of selected resource centres, where a suitable concentration of the necessary technologies can be made locally available to users (Buitendach, 1997).

The situation may improve in the future through the use of mobile and wireless ICT's, thus increasing the technological autonomy of these education and training centres. Nevertheless, we must recognise that, in many parts of the world and even in some remote regions in developed countries, technology is sometimes at odds with social equity. In Angola, a joint project between Portugal's Universidade Aberta (http://univ-ab.pt) and the Cabinda Gulf Oil Company, a Portuguese language course designated Virtual Journeys, had to rely on a mix of traditional communication means supported by digital media such as CD-ROMs, e-mail and hypertext materials on the Web.

\section{Systems with Missing Functions}

To assure feasibility and sustainability of design, planning and implementation, decisions must take into account the social, economic and cultural context as well

International Review of Research in Open and Distance Learning 
as available resources for launching specific ODL systems. Even when available resources prevent the system to display a full set of ODL requirements, the social utility and opportunity to reinforce the local capacity for human resources development can be key factors in the decision-making process.

We can find several examples of systems working with an incomplete set of functions. For instance, a possibly hard decision for an ODL institution is to avoid the costs (both initial and operating ones) of authoring and producing its own learning materials, choosing instead to import them from an external, credible source. The resulting problem of assuring the cultural and social (as well as pedagogic) compatibility of these materials with the local context can be a major one deserving careful consideration.

Making sure that a suitable number of competent tutors are available and that other student support mechanisms are satisfactory is both expensive and sometimes difficult to achieve. A possible solution is to create partnerships with other institutions working at the same level in the face-to-face, conventional mode. In some other cases, mostly due to legal reasons, assessment and certification procedures are assured by other institutions, again as a form of collaborative partnership. Whatever the situation, the principle of creating partnerships and other forms of networking with similar (and not so similar) organisations is a sound one: synergies are created, economies of scale are achieved and resources (both human and material, usually scarce) are optimised.

\section{Curriculum Development}

\section{Curriculum Flexibility}

One common criticism of earlier distance education practices was their supposed behaviourist, programmed-learning approach. Rigid curricula and content, and uniform learning strategies required of students, without consideration for their different cognitive profiles, were clear drawbacks, even when compared to the advantages of having introduced flexibility of time and place.

The situation has evolved positively meanwhile and curriculum flexibility, associated with the credit-point approach, has been introduced as a matter of course in most distance education systems. This applies also to higher education institutions offering degree programmes, although sometimes subject to limitations imposed by national laws and regulations.

We must also take into account that, apart from the fundamentals of most sciences having a moderate to long lifetime, knowledge is evolving quite rapidly and courses need to be updated more and more frequently. Combined with changes in instructional methods and technologies, the rapid evolution of knowledge

International Review of Research in Open and Distance Learning 
has produced forces for innovation in curriculum development, leading to new degrees of flexibility in courses and subjects.

Updating of instruction is more easily taken for granted in vocational training. Nevertheless, the flexibility of objectives and content brings an added value to these ODL programmes, for it improves their accommodation to the special needs and interests of employers and potential end-users, thus increasing their social and market value. Curricular flexibility has become a major issue in these times of globalisation. While trans-national operation of ODL systems has been made possible by quick and comparatively inexpensive worldwide communications, one has to keep in mind that social, cultural and technological contexts vary widely from region to region across the globe. This means that a distance learning programme devised for a specific target population in a given country might be unsuitable for a different cultural setting; its objectives may not fit exactly users' needs in another kind of environment. This is not just a question of linguistic compatibility, for it is comparatively easy to translate all kinds of content from one language into another; rather, a requisite of cultural contextualisation, so that objectives remain relevant and materials are still appealing and adequate, from the point of view of very different set of users.

We can achieve a higher degree of transferability of content and objectives by "slicing" them into their elementary parts. Taking a course on ecology, as an example, we see that geographic and climatic contexts change widely from continent to continent and from latitude to latitude. Separating the corresponding characteristics into a set of nearly homogeneous regions makes it possible to increase the relevance of this course (or parts of it) for different target populations, in various regions of the globe.

The same reasoning applies to vocational training. To increase transferability and accessibility, instead of devising for each subject of qualification, widespectrum, long-duration programmes, subjects can be separated into smallduration, narrow-band learning modules. Combining selected modules makes for an easier fit to different training requirements. We have called this "The Salami Concept", for it evokes the kind of dish that should not be eaten in large bites but rather by cutting it into thin slices, thus becoming much more palatable. Modularization of content and the consistent use of the credit-point system, allowing for capitalisation of successfully acquired credits of qualification, are proper tools for increasing curriculum flexibility (Jones, Pritchard \& Trindade, 1998). This approach seems to be also adequate for all kinds of continuing education and training programmes that will become in the future a major task for ODL systems. 


\section{Flexibility of Learning Strategies}

Learning strategies can be more or less adequate and efficient according to the cognitive profiles of users. Profiles can range from intellectual-minded persons, at ease with theorisation and abstractions, to the pragmatic and applicationdriven students, who prefer to deal with concrete situations. There are also other possible, intermediate profiles to be considered. Some students are naturally more autonomous and creative in their learning activities so they feel at ease with innovative approaches, with alternative options, and even with the challenge of trying to construct knowledge by themselves. Others prefer a solid and sure approach to fixed objectives and clear and straight content (Kolb, 1984).

In most courses, it seems possible to design different learning strategies suitable for these different kinds of users, albeit serving the same objectives and including approximately the same nature of content.

There is obviously a need for fundamental research on these kinds of issues, dealing with metacognitive profiles, with the process of learning itself and with the devising of alternative learning strategies, for the sake of improving the overall efficiency of learning.

\section{Options on Learning Materials and Processes}

In Europe and the United States there has been some divergence of outlooks about the nature of ODL materials. Following the positive influence of the pioneer British Open University (http://www.open.ac.uk), most ODL systems in Europe place a strong emphasis on the conception and production of high quality learning materials, having embedded an instructional design suitable to facilitate autonomous self-learning. This type of learning is, of course, very expensive and even more so when, besides textbooks, audio, video and multimedia, interactive materials are also produced.

Many United States ODL systems have adopted a different approach, closer to the concept of the asynchronous, remote classroom. Lectures in universities, made by eminent teachers and scientists, are recorded and then broadcast to distance learning students. This live instruction is complemented by the same textbooks used by intra-mural students. In a variation of this approach, systematic and intensive use of videoconferencing multiplies the number of remote classroom sites, operating in a bilaterally interactive, synchronous mode. Another approach uses computer conferencing via Internet, linking a teacher to any number of students. However, when the number of remote sites and the number of students involved increases significantly, the capacity for meaningful teacher-student interaction is naturally compromised.

International Review of Research in Open and Distance Learning 
It is interesting to note that both methods seem to yield good enough results, despite their conceptual and practical differences (Bidarra \& Mason, 1998). In the American case, extra-mural students are brought, in psychological terms, closer to the actual on-campus learning environment, as there is not much difference in their way of studying, compared with residential students. In contrast, European ODL students are led to accept, from the very beginning of their activity, that they will belong to a special, different kind of institution. This requires their adjustment to particular rules of the game, namely the need for self-management of time and assignments, as well as autonomy (also meaning a certain degree of isolation) in their learning.

\section{The Internet in ODL Operations}

The extraordinary expansion and accessibility of the Internet and the World Wide Web over the last decade seems to offer ODL operators a very valuable tool to further the educational aims of people in our contemporary world. If we look around we realise that it is about the Internet that profound academic debate now takes place.

The usually asynchronous nature of the medium and its vast reach make it a powerful tool for both students and teachers around the world who are interested in the same field of knowledge. However, the expression Internet-based learning that we have heard frequently in recent times is, from our point of view, a term we should avoid. We believe that all technologies should be considered as mere tools in the service of distance learning, rather than a seemingly essential factor involved in the learning process. Actually, any tool implies much more than just using intensively a given communication facility: it comprises all the human factors and qualified work involved in conceiving appropriate learning materials; devising a sound pedagogical strategy; providing students, individually, with efficient support mechanisms; assessing their progress; and certifying their results.

Tailor-made, on-demand electronic education raises more than pedagogical, technical or logistic issues. It raises the problem of copyright regulations covering electronic documentation on the Web and of reusing the same hypermedia elements in various combinations (in customised courses) offered to different institutions and companies. Just as the introduction of copying machines led to new legislation on copyright, the electronic distribution of information on a global scale will need to be accommodated as well.

In a nutshell, the results of using the Internet in ODL activities will be only as good as the underlying learning methods, objectives, content and the corresponding implementation. Validation of overall system quality depends, in part, on the credibility of the institution responsible for the whole initiative.

International Review of Research in Open and Distance Learning 
Furthermore, because the Internet is a totally open system, there is a clear risk that unscrupulous organisations may appear to be, from the point of view of a naive prospective user, reliable distance teaching organisations. An attractive home page may describe fees, courses, programmes, degrees and certificates to be awarded. Serious-looking scientific content may be presented, as browsed and downloaded from other sources, and a series of assignments proposed to users. In due time, an impressive (even if worthless) diploma may be delivered.

From another point of view, the use of the Internet fits into the technological change necessary to accommodate some developments in ways and methods of learning. According to Reinhardt (1995), in the information economy knowledge is power but traditional teaching tends to be expensive and slow. With the new technologies learning can be more productive. Table 2 illustrates Reinhardt's comparison of the old and the new models of learning to establish a definite change in educational paradigm.

\section{Table 2}

\begin{tabular}{|c|c|c|}
\hline Old Moded & New Model & Technology Implications \\
\hline Clessroom lectures & Indwidual exploraton & $\begin{array}{l}\text { Networked PCs with access } \\
\text { to infomaton }\end{array}$ \\
\hline Passive absorpoion & Apprenticeship & $\begin{array}{l}\text { Requires skils } \\
\text { development and } \\
\text { simuldobons }\end{array}$ \\
\hline Indhidual wook & Team learning & $\begin{array}{l}\text { Benafts from collaborative } \\
\text { bols and e-mal }\end{array}$ \\
\hline Omnisciert leocher & Teacher as gide & $\begin{array}{l}\text { Relies on occess to experts } \\
\text { cver network }\end{array}$ \\
\hline Stable cortert & Fastchanging cortert & $\begin{array}{l}\text { Requires networks and } \\
\text { publshng tods }\end{array}$ \\
\hline Homogensity & Diversty & $\begin{array}{l}\text { Requires a venidy of } \\
\text { occess tocls and methods }\end{array}$ \\
\hline
\end{tabular}

The old and new paradigms of learning

The idea that the new knowledge media can bring about radical changes in pedagogic methods and in the processes of educational communication reflects a decisive paradigm change. This new relationship between technology and pedagogy has led to a break with the tradition of a teaching methodology based on the "recommended" manual, the teacher's role as primary source of knowledge, and the observance of a fixed curriculum. According to this new paradigm, when we speak of knowledge media we are underlining the importance of knowledge in the global equation; we are not talking about "content ...[for the] information superhighway" (Eisenstadt, 1995). This would be the same as saying that

International Review of Research in Open and Distance Learning 
Beethoven wrote musical notes, i.e., content to play at auditoriums. This qualitative change is important for Eisenstadt who defines knowledge as an emergent property that transcends the concepts of space and time traditionally used in the teaching-learning situation. In other words, it transcends the notion that the student has an empty "reservoir" that has to be filled in from the teacher's full reservoir each time a class is scheduled. Thus knowledge can better be defined as a dynamic process driven by each human being in a unique way. The Internet and the Web are the tools most suited to support this new scenario.

\section{The Evolution of Universities}

\section{General Aspects}

Many factors have influenced, in recent times, the situation and evolution of universities. Wherever they are state-supported institutions (which is mainly the case in Europe) governments tend to apply pressure in order to increase their student capacity, while being reluctant to increase their budgets; they ask universities instead to find alternative sources of financing. Public opinion, on the other end, pushes in that same direction, more and more candidates asking year after year for admission to higher education. One way out of this dilemma is to find appropriate measures to increase the productivity of teaching and learning.

In the United States the problem is somewhat different, the university system being more or less able to cope with the demand for higher education, even if its cost may draw severely on families' budgets. There is, however, strong competition among institutions in recruiting new students.

In both cases, for increasing capacity or for winning over the competition, there is a need to change the perspective of universities, from traditionally aiming at serving elite users, to aiming instead at a process of mass production of graduates. The recently recognised need for lifelong education for all members of the active population of a country (at all levels of education and training, as an efficient means to fight unemployment and to progress in careers) will put an additional burden on university life.

The creation of dedicated Open Universities in the 70s and 80s in all regions of the world was one possible answer to this difficulty. The Open University, UK (http://www.open.ac.uk), the Universidad Nacional de Education a Distancia, Spain (http://www.uned.es) and the FernUniversität, Germany (http://www.fernunihagen.de), in Europe; the UNISA, South Africa, (http://www.unisa.ac.za), that was actually founded as soon as 1946; the Télé-Université (http://www.teluq.uquebec.ca/) and the Athabasca University (http://www.athabascau.ca) in Canada; the Universidad Nacional Abierta, Venezuela (http://www.una.edu.ve) and the Uni-

International Review of Research in Open and Distance Learning 
versidad Estatal a Distancia, Costa Rica (http://www.uned.ac.cr) in South America; the Indira Gandhi Open University, India (http:/www.ignou.edu), the Sukhothai Tammathirat Open University, Thailand (http://www.stou.ac.th) and the University of the Air, Japan (http://www.u-air.ac.jp/hp), in Asia are just a few examples of this type of institution (see, for Web addresses of other ODL institutions, the ICDL database: http://www-icdl.open.ac.uk/).

From another perspective, there is no conventional way for face-to-face teaching institutions to cope with these challenges, without sacrificing their standards of quality; they had to find (and have actually found) unconventional methods of dealing with the problem.

Many conventional institutions have decided to introduce ODL streams of activity as dual- or mixed-mode operations. In the latter case, this means reducing classroom hours and assigning the corresponding saved time to distance learning activities. Freeing classroom space simultaneously means increasing the physical capacity of the institution to accept new students.

Single-mode ODL institutions, in most cases, are able to increase their volume of students without a proportional increase in expenses. Properly designed Open Universities should in principle be able to adapt easily to a significant expansion of their student population (Daniel, 1996), thus in fact lowering student per capita operating costs.

\section{Virtual Universities}

Another interesting approach to the problem of increased demand for higher education has recently begun to appear: the so-called "virtual university". This term intends to mean that, contrary to usual expectations, such institutions have no campus (in a physical sense): ODL students live in a virtual environment, despite their possibility to contact each other, as well as their teachers and tutors, in cyberspace. This situation can occur in a single-mode institution or in dual- and mixed-mode ones; or it can encompass, within the same institutional setting, any number of collaborating organisations.

There is no conceptual difference between a virtual university and other kinds of ODL institutions, just an instrumental one. Virtual systems make an intensive use of ICT technologies, such as WebCT or Lotus Learning Space, to distribute selected learning materials, facilitate access to alternative sources of information and data, make possible teacher-student (as well as student-student) interactions, and enable tutoring and assessment of results. ICT technologies are also used for giving lectures, organising seminars and discussing content.

Perhaps the term virtual, as opposed to real, is not a good choice because institutions strive to develop "real" learning situations online. Harasim, Hiltz, Teles and Turoff (1995) and others (Bacsich, 1997; Bates, 1997; Mason, 1998; Tiffin 
\& Rajasingham, 1995) have explored the possibilities of the new technologies for networked learning. Most of the research and field experience generated in the past decade indicates that computer networking, especially computer mediated communication, can support distance learning courses delivered entirely or partially online. This kind of course delivery can enrich and expand traditional educational activities and support and develop new types of educational interaction both on-campus and off-campus.

The Universitat Oberta de Catalunya (UOC) in Spain (http://www.uoc.es/), a single-mode system, is a case of good practice and a paradigmatic example of a virtual university. The UOC structures its educational strategy around the concept of a virtual campus, which is based on the use of computers and communication networks. Thus, users are able to overcome the boundaries of time and space and engage in interactive contact with all members of the university community: students, tutors, professors and administrative staff. In order to ensure that students have access to resources and receive individualised attention, the UOC has established a network of support centres extending throughout Catalonia. These centres are equipped with a media room, videoconferencing facilities, meeting halls and computer rooms and also organise different activities and cultural events.

Many experiments with networked learning systems have been conducted and the term virtual university is often linked with formerly conventional institutions, that have created dual-mode or mixed-mode systems. Typical cases are Simon Fraser University (http://www.sfu.ca/cde/) and the University of British Columbia (http://www.ubc.ca) in Canada, Stanford Online (http://www.online.stanford.edu) in the United States and the University of Southern Queensland (http://www.usqonline.com.au/) in Australia.

This virtual university approach to higher education ODL is obviously suited for co-operation among similar (and compatible) institutions, wherever they may exist. A very promising idea is for institutions to pool together programmes, courses and learning materials to diversify offerings to students or to create composite programmes, on the understanding they will be mutually recognised. We believe that this kind of joint certification, validated by credible institutions, may increase the interest of prospective users and the intrinsic value of the degrees or diplomas awarded. A typical case of such bilateral arrangements is the association between the Carl von Ossietsky University of Oldenburg (Germany) and the University of Maryland in the United States Joint delivery of a number of online degree courses http://www.umuc.edu/mde/ creates an example of transcontinental ODL operation. The consortium of twenty-one research institutions called Universitas 21 is a case study chosen by Bates (2000) as a typical example of partnerships that provide major (global) advantages to distance teaching organisations. Universitas 21 is a loose consortium of institutions from former British Commonwealth countries, including Scotland, England, Australia, New Zealand, Canada, Hong Kong, and Singapore. It also 
includes the University of Michigan in the United States. Their purposes include common use and certification of existing courses developed by the different partners and joint conception and production of common programmes and materials, thus drawing on the complementary strengths of each partner. On another level, this consortium has agreed to offer a master's programme in sustainable resource management (http://www.universitas.edu.au/projects). Each institution will provide at least two courses dealing with the needs for sustainable resource management in Southeast Asian countries. Each institution will ultimately decide which courses to accept into its own programme. Distributed learning technologies are the basis for the implementation of this joint project.

Another case in point is the Western Governors University

(WGU) (http://www.wgu.edu/wgu/index.html), a unique mega-institution that offers degrees and certificates based completely on competencies - the ability to demonstrate skills and knowledge in a series of assessments, rather than required courses. WGU gathered hundreds of the best distance-delivered classes from 44 institutions across the United States and Athabasca University in Canada into an online catalogue. In this way, students can find credit college classes to complete a credit-based degree programme and gain the competencies necessary for a WGU degree or certificate. By bringing all these classes together in one place, WGU makes it easy for students to find and select classes offered by different institutions in the same subject area according to their needs and learning style. Most of these classes are delivered online within a flexible schedule, while others are term-based and delivered in alternate formats

Another recent example is the German Virtuelle Hochschule Bayern (http://www.vhb.org/). Formerly conventional universities and polytechnics of the region of Bavaria are pooled together, for the purpose of delivering a wide set of distance learning programmes.

Finally, we believe that most of the existing associations, consortia and networks of distance education institutions all over the world, if they are not already offering collaborative programmes based on advanced communications, will do so in the near future. Inter-governmental organisations like the Commonwealth of Learning (with headquarters in Canada) (http://www.col.org/col.htm) and the South East Asia Ministers of Education Organisation (SEAMEO) (http://www.seameo.org) are following the same path.

In conclusion, the concept of networked learning, made possible by the intensive use of ICT's, has created a new flexibility in inter-institutional operations and increased higher education's trans-national scope. This is not only useful for students aiming at getting a degree or diploma, but also for those just looking for classes to take for their own enjoyment and enrichment. Others may be making an incursion into a wholly new promising field, from a continuing education perspective. The possibility of enrolling in any number of interesting high-level courses delivered by a set of prestigious universities will be no less appealing. Due to the foreseeable convergence of their principles, methods and instruments 
of operation, we believe, nevertheless, that the concepts of virtual university, distance teaching university and open university will merge, in the long run, into a single one (whatever name it will be known as).

\section{Conclusion}

At present, globalisation has touched many fields of human activity and introduced many different ways of facilitating day-to-day life. Examples include: direct dialling and instant telephone communications between many places on the planet; e-mail correspondence among increasing numbers of people; access to the Internet for information and data, entertainment, getting things done or having problems solved, shopping and conducting business; getting immediate cash in a foreign country through an ATM; and use of credit cards for shopping or payment of services in many different regions of the world. Globalisation also means quicker international travel, explosion of trans-national tourism, higher degree of mobility of people and merchandise, and worldwide diffusion of news, styles and ideas. It will also mean better opportunities for learning.

However, in other manifestations of globalisation such as worldwide free trade, creation of grand-regional political association of states, and trans-national merging of large businesses and companies, there are still many risks and unknown consequences to be considered. Unless new mechanisms of international solidarity are put into existence, there is the possibility that the gap will widen between developed and developing regions of the world. On the other hand, globalisation and the consequent increase in global competition could precipitate a higher degree of instability of markets and a steady decline of security in employment. Such changes may be triggered by the accelerating diffusion of technological and methodological innovation, thus reducing the lifetime of technical and scientific qualifications.

One response to the danger of losing one's job due to the erosion of professional qualifications or to the loss of markets, causing the breakdown of enterprises, is to increase the average level of active population qualifications. This could be accomplished through both enhanced initial education and training and through expansion of continuing education. The latter will involve upgrading, updating, extending or reconverting professional knowledge and skills, in order to keep abreast of market needs, either as an employee or a self-employed person. Higher education should be able to produce, in the long run, enough graduates to assure that they reach roughly one-half of the active population. Continuing education and training should take the shape of genuinely learning, touching not only the whole occupationally active population but also all remaining members of the civil society. Conventional, classroom-based teaching and training institutions cannot possibly meet these huge quantitative requirements. Distance education methods and techniques are the only realistic way of dealing with this explosion

International Review of Research in Open and Distance Learning 
of universal demand.

Mass education at all levels will be a permanent requirement to meet the challenges of the Knowledge Society. To meet this obvious need, it is expected that conventional institutions will adapt to the use of distance learning methods of operation, so as to increase both their productivity and capacity. Existing dedicated single-mode ODL institutions will probably continue to grow and new ones will be created. On the other hand, the creation of associations, consortia and networks among all these kinds of organisations is a reasonable way to create economies of scale and to share resources and development costs with the possible added value of increasing the global quality of the system.

Many classical approaches to ODL methodology have already been proven by many years of successful operation. On the other hand, development of new methods and facilitation of learning through innovative use of ICT's continues to be a prospect of existing ODL systems. It should be taken into account, nevertheless, that all pedagogic experiences have to be thoroughly evaluated before they can be considered as reliable and adequate.

As ODL systems proliferate, quality assurance will become a major issue. Taking into account our proposed definition of ODL, it is acceptable to evaluate separately its different features, as to their intrinsic quality. Learning materials, with respect to both their scientific content and pedagogic strategies; student support mechanisms; communications; organisation and logistics - all are features to measure and appraise. Self-evaluation of institutions through permanent and generalised monitoring are necessary tools for achieving quality assurance.

Another approach to evaluating quality is by means of peer evaluation, a common form of assessment in higher education. However, the universe of peerage should be restricted to those belonging to the ODL community. This is not a defensive approach: the fact that ODL methods are in essence different from classroom teaching makes those not familiar with that methodology poor judges. Moreover, it is a well-known fact that in many cases and in different regions of the world, conventional universities have been strong opponents to the creation of distance teaching universities.

A pragmatic approach to counter the opposition to ODL is to judge quality in terms of consumer satisfaction. The full specification of objectives to be attained in a given programme will provide users with a yardstick to assess, not only their own performances, but also the reliability and adequacy of the teaching system or institution they have chosen. Their subsequent fitness when entering the profession and their potential to succeed in it will reflect, in the medium term, the quality and value of these qualifications.

Thus open and distance learning systems will be evaluated by public opinion in terms of credibility and prestige, or lack of it; natural selection will kill the bad 
ones and will make the remaining flourish. These will then become examples of good practice.

International Review of Research in Open and Distance Learning 


\section{References}

Ash, C. (2000). A new cost analysis model for networked learning. Proceedings of the First Research Workshop, EDEN: Prague.

Bacsich, P. (1997). Re-engineering the campus with Web and related technology for the virtual university. Conference paper. (Retrieved March 10, 1998: http://www.cms.shu.ac.uk/public/events/flish97/bacsich-paper.htm )

Bates, A. W. (1995). Technology, Open Learning and Distance Education. London and New York: Routledge.

Bates, A. W. (1997). Technology, distance education and national development. Proceedings of the 18th ICDE World Conference, May 1997, University Park, PA: Pennsylvania State University.

Bates, A.W. (2000). Managing technological change: Strategies for college and university leaders. San Fransisco: Jossey-Bass.

Bidarra, J. \& Guimarães, N. (1999). A case for learning sites with video bytes: The hyperscapes experience. Proceedings of Online Educa, November 1999, Berlin.

Bidarra, J. \& Mason, R. (1998). The potential of video in open and distance education. Revista Ibero-Americana de Educacion a Distancia (RIED), 1(2).

Buitendach, A. (1997). The practice of ODL to facilitate work-based learning. Proceedings of ICDE-SCOP Meeting, Lisbon.

Carmo, H. (1998). Educação intercultural e ensino a distância: a questão da formação de formadores. In Seminar Erasmus, May 1998, University of Florence.

Daniel, J. (1996). Mega-universities and knowledge media: Technology strategies for higher education. London: Kogan Page.

Eisenstadt, M. (1995). The knowledge media generation. KMI, The Open University. (Retrieved March 10, 1998: http://kmi.open.ac.uk/kmi-misc/kmifeature.html)

Hall, James, (1996) The educational paradigm shift: Implications for ICDE and the distance learning community. Open Praxis, 2, 27-36.

Harasim, L., Hiltz, S.R., Teles, L., \& Turoff, M. (1995). Learning networks: A field guide to teaching and learning online. Cambridge, MA: MIT Press.

Holmberg, Börje (1981). Status and trends of distance education. London/New York: Kogan Page/ Nichols Publishing.

International Review of Research in Open and Distance Learning 
Holmberg, Börje (2000). Status and trends in distance education research. Proceedings of the First Research Workshop, EDEN: Prague.

Jones, D. R., Pritchard, A. L., \& Trindade, A. R. (1998). Credit transfer and internationalisation of distance education. Open Praxis (2), 5-11.

Keegan, D. (Ed.). (1993). Theoretical principles of distance education. London: Routledge.

Kolb, D.A. (1984). Experiential learning: Experience as the source of learning and development. Englewood Cliffs: Prentice Hall.

Mason, R. (1998). Globalising education: trends and applications. London: Routledge.

Ortner, G. E. \& Nickolmann, F. (Eds.). (1999). Socio-economics of virtual universities. Weinheim: Deutcher Studien Verlag.

Reinhardt, A. (1995, March). New ways to learn. Byte. (Retrieved May 24, 2000: http://www.byte.com/art/9503/sec7/art1.htm)

Tiffin, J. \& Rajasingham, L. (1995). In search of the virtual class: Education in an information society. London: Routledge.

Trindade, A. R. (1992). Distance education for Europe: Terms of reference for a european distance education structure. Lisbon: Universidade Aberta.

Trindade, A. R. (1999). Pursuing quality in educational systems. Proceedings of ICDE Conference on Distance Learning and 21st Century Education Development, Beijing: Tsinghua University.

Citation Format

Trindade, Armando Rocha, Carmo, Hermano \& Bidarra, José (2000) Current Developments and Best Practice in Open and Distance Learning. International Review of Research in Open and Distance Learning: 1, 1. http://www.icaap.org/iuicode?149.1.1.5 


\title{
Book Review: Distance Learners in Higher Edu- cation: Institutional Responses for Quality Out- comes
}

\author{
Wil Verreck \\ Open University Netherlands
}

The main message of this book is that we should not forget for whom distance education is meant, that is the learner. To counter the upheaval of research and development efforts around Web-based teaching, it states: educators "must do more than provide access to information" (p. viii). Edited by Chère Campbell Gibson, who wrote two chapters and the retrospective conclusion, there are seven chapters that provide a brief review and some guidelines on topics related to existing knowledge about learners in distance education and a first chapter giving an overview of what is known about the characteristics of the distance learner.

In chapter one, Melody M. Thompson describes demographic and situational characteristics (age, gender, ethnic background, disability, location, life role) related to success as a student as well as affective characteristics (personality type, learning style, motivations). She concludes that a dynamic conception of the distance learner is required in which education for all changes to education for each. In chapter two, Elizabeth Burge writes about gender and the need for distance educators to change the focus from "receive, retain and return" to "respect, re-frame and re-apply" for more study success by women. Barriers to access, appropriate technology and sense of a safe place are discussed and result in some long lists of constructivist, women-friendly guidelines regarding technology. In chapter three, Irene Sanchez and Charlotte N. Gunawardena write about cultural diversity and the influence of culture on learning. A history of theory development on cognitive control, flexibility and strategies is followed by a case study (Sanchez's Ph.D. work) on Hispanic adult learners. These two authors pose the question (without answering) whether matching teaching and learning style will always be to the benefit of the learner who must function in a diverse society. In chapter four, Chère Campbell Gibson discusses the self-concept of learners, and its relation to persistence. A dynamic self-concept is proposed including process-related and content-related factors, and enhancers and detractors of this concept are indicated as well as strategic inteventions that may be undertaken. In chapter five, Christine Olgren writes on learning outcomes and the effects of learning strategies and motivation. From a constructivist perspective, she indicates four types of cognitive learning strategies (selection, rehearsal, organization and elaboration) as well as metacognitive influences and strategies. Implications for course design are outlined. In chapter six, Terry D. 
Anderson and D. Randy Garrison discuss learning in a networked world leading to new roles and responsibilities. A model of transactional relationships in higher education is presented, including six types of interactions (amongst learner, teacher and content) for meaningful learning. In chapter seven, Chère Campbell Gibson discusses the distance learner in context and elaborates on the applicability of ecological systems theory of micro-, meso-, exo- and macrosystems. Learning in context means to empower the learner and an orientation day for the entire family is suggested as an intervention. In chapter eight, Daniel Granger and Meg Benke discuss support to learners at a distance from a marketing perspective, through the trajectory from inquiry to completion. This chapter reads more like a textbook on these aspects, that is, it prescribes how to design distance education. In the retrospective final chapter, Chère Campbell Gibson summarizes the book in five strong suggestions: know the learner; provide orientation; design with variety, active engagement and choice; evaluate authentically; and provide an integrated system of support.

As the book has no pretentions to be complete in its review, it is stimulating and interesting reading, and causes one to reflect, which is enough value for the price. One of my own reflections at the end is induced by the frequent advice throughout the chapters to take into account learner characteristics when designing distance education. Assuming that the influence of those characteristics is sufficiently demonstrated, is it possible to provide for them in design and delivery of distance education? At what price? And finally, should it be done? A definite answer to this question still awaits.

Citation Format

Verreck, Wil. (2000) Book Review: Distance Learners in Higher Education: Institutional Responses for Quality Outcomes. International Review of Research in Open and Distance

Learning: 1, 1. http://www.icaap.org/iuicode?149.1.1.8 


\title{
Book Review: Online Education: Learning and Teaching in Cyberspace
}

\author{
Insung Jung \\ Korea National Open University
}

In his recent book, Online Education: Learning and Teaching in Cyberspace, Greg Kearsley provides a comprehensive description of all aspects of online education. He brings his personal experience and knowledge to the rather interesting task of making sense out of the vast materials and practices in Internetbased, online education in a way that is useful to anyone who is interested in online education. The beauty of this book is twofold: clear flow for reading and richness in resources. Readers can easily understand the author's main ideas through well-organized headings. The style of writing is also clear and easy to follow. Moreover, the book provides ample Web resources on various aspects of online learning and teaching. All the Web resources introduced in this book can readily be accessed by clicking the links provided at the accompanying site, http://home.sprynet.com/ ${ }^{\text {gkearsley/cyber.htm. }}$

As Kearsley points out in the preface, this book is a comprehensive, but introductory book for people who "have some basic familiarity with computer concepts and applications" (p. xii). If you are looking for more in-depth, professional discussions of online learning and teaching, this book would be a near disappointment.

This book contains 13 chapters and an appendix. The first chapter, Introduction, discusses the major themes that characterize online education. While the earlier types of computer-based instruction focused on individualized learning experiences through drills, tutorials or simulations, recent online education is more focussed on various types of interaction and collaboration. Online education is characterized by nine themes, including: collaboration, connectivity, student-centeredness, unboundedness, community, exploration, shared knowledge, multisensory experience, and authenticity. Obviously these themes are drawn from the professional literature in the field of online education. However, it seems to me that these concepts still need to be elaborated and succinctly organized into a more coherent theoretical framework.

Chapter two discusses the scope of online education across different learning settings such as K-12 schools, government agencies, non-profit organizations, the home, and public spaces. If you look at the Web sites listed in this chapter, you will develop a good understanding of what is actually occurring in the field of online education.

Chapter three discusses the basic elements of online education. The author 
examines synchronous and asynchronous interaction devices, as well as more recent Internet tools. The benefits and limitations of different online devices and applications in the educational context are also discussed along with example Web sites.

Chapter four covers research about online education. Drawing on research findings, student achievement, evaluation of online courses, school-level impact, nature of class interaction, and virtual conferences are discussed. However, once again, readers should be reminded that this book is introductory in nature. The book provides only few examples of research findings, accompanied by the author's feelings and understanding regarding each topic. This is presumably because there is not yet enough research accumulated in the field of online education to draw any definite conclusions.

Chapters five and six discuss how online education is different from classroom instruction, from learners' as well as teachers' points of view. It is argued that learning online is much different than learning in a traditional classroom. One of the pedagogical features of online learning is that it usually provides the learner with a great deal of autonomy. Therefore, to be successful in online learning, learners have to be more active and more technology literate. Engagement theory, as proposed by Kearsley and Shneiderman in 1998 and described in this book "suggests that learners must be actively engaged in meaningful tasks for effective learning to occur" (Kearsley, 2000, p. 67). From the teachers' point of view, interactivity and participation, feedback, workload, moderating and facilitating, effectiveness, faculty collaboration, and student evaluation are all critical aspects of online education. These aspects change the roles of teachers dramatically. I personally believe that while the Web and Internet are new technologies, the problems of providing instruction via these technologies, (i.e., Web-based online education) are not totally new. Nor is providing instruction via these media necessarily pedagogically innovative. What we have is an application of the new technology to distance education - a teaching approach that has provided a flexible and open learning environment for more than a century. Online education thus shares many features with traditional forms of distance education such as correspondence study, videoconferencing lectures, and TV courses. What online education offers that is unique among communications technologies, is the facility of combining the attributes of each of the older media. Online education thus provides a learning environment in which text, pictures, video and audio are integrated into one system, access to huge databases is simple and easy, and more flexible interactions - especially asynchronous learner-learner interaction - are far simpler than before.

Chapter seven contributes to the discussion of major issues in design and development of online courses. This chapter covers design principles in creating an online course, integrating online and on-campus activities, authoring courses and assuring quality of courses. Even though this chapter does not provide specific guidelines for designing and developing online courses, it does offer critical

International Review of Research in Open and Distance Learning 
ingredients of good quality online courses.

Chapters eight through ten bring to our attention the various issues involved in organizational, policy, and societal impacts of online education. Chapter eight discusses the organizational changes that online education entails in terms of facilities, jobs, policies, procedures, leadership, and the relationships among institutions. Policy on ownership, quality control, student and faculty workloads, accreditation and certification is discussed in chapter nine. Useful sites that provide guidance to policy issues are also offered. Chapter ten provides a brief, but straightforward discussion of societal impacts such as information "haves" and "have-nots", good or evil aspects of technology use, privacy concerns, quality issues, cost-benefit issues, and resistance to change.

Chapter eleven addresses some of the practical issues encountered in the implementation of online courses. Chapter twelve offers some speculation about the future directions of online education. Technological developments such as ubiquitous computing, intelligent software, virtual reality, speech processing, automatic language translation, and knowledge management systems are briefly discussed in the context of education. The last chapter lists resources for further information.

As mentioned above, this book covers all the major issues in online education and provides useful Web resources and reading lists. However, the organization of the chapters may have been a little too random and linear. I am compelled to suggest in this review that the book could have been organized in a more structured way. For example, the first four chapters could have been grouped together under the theme of theoretical, practical and technological characteristics of online education, chapters five and six under the theme of pedagogical features of online education, chapters seven, eight, and eleven under the category of design and implementation of online education, and chapters nine and ten under the category of policy issues in online education. Chapter twelve could have been the last chapter of the book if the information provided in chapter thirteen were moved to the appendix.

On the whole, Kearsley did a nice job of introducing online education to the general public and education professionals. I would recommend this book to three groups of specialists: educational decision makers, teachers and preservice teachers, and professors in schools of education majoring in other than educational technology. This book will widen their perspectives and better equip them with a more refined vision of online education.

Citation Format

Jung, Insung. (2000) Book Review: Online Education: Learning and Teaching in

Cyberspace. International Review of Research in Open and Distance Learning: 1, 1.

http://www.icaap.org/iuicode?149.1.1.6

International Review of Research in Open and Distance Learning 


\title{
Book Review: Higher Education in an Era of Dig- ital Competition: Choices and Challenges
}

\begin{abstract}
Elizabeth Stacey
Deakin University

Donald Hanna describes his book as a framework for viewing digital technologies in the global higher education sector rather than a book about technology. This is how it must be considered, as it focuses primarily on the changes required of traditional American universities as they respond to the possibilities provided by new digital technologies, rather than detailing these technological innovations. The book develops five main themes which Hanna describes as the emergence of a global learning society, the possibilities and challenges of new technologies and the response to this change in the higher education sector, with attention to issues such as changing patterns of learning and leadership in this global environment. The term "global" is limited here in its application mainly to the North American scene with a few additional comparative perspectives added from British writers. However, as many of the issues covered in the book are being dealt with in other countries, it has appeal for a wider audience. It will make a good text for programs that focus on learning in the tertiary sector and will be a useful compendium for institutional administrators and policy makers in North America who are not familiar with the history and very current issues of adapting to a digital age.
\end{abstract}

It begins with a comprehensive overview of the changes that universities in the United States are facing, as economic and demographic changes to society combine with the potential of new technologies to provide a demand for a more flexible and technologically mediated mode of lifelong learning. Issues are discussed within a useful review of research and writing in this field though again from an American perspective only. In the first chapters Hanna sets the university context well and gives a good discussion of the changes in university pedagogy that have been encouraged and facilitated by the digital medium of the Internet, such as collaborative and cooperative learning and problem-based learning. Chris Dede, writing next about technological possibilities in the next decade and providing futuristic scenarios, supports Hanna's stance on the need for pedagogical change, claiming lecture-based traditional universities won't satisfy a generation raised on computer mediated learning. His message about knowledge networking and distributed learning moving beyond an information superhighway concept of the Internet, is one administrators should heed as he concludes that it will not be the technical development of new technologies that will make the most difference in the changing university, but the professional development of educators and learners.

Hanna goes on to discuss a range of new models of university organization to 
Book Review: Higher Education in an Era of Digital Competition: Choices and Challenges

meet changing demands and, as he does in each of his chapters, provides a brief historical context. He reviews the model of extended traditional universities and analyses varying strategies for market response which they have developed, from program and institutional replication through remote campuses, to program diversification and niche marketing, giving examples of each response. He cites comparison of the costs of on campus lecture models of teaching to technology mediated programs and identifies the need for leadership which embraces change to be developed at the faculty level rather than centrally in the institution for it have most effect.

In his discussion of distance education and technology-based universities Hanna looks beyond the United States for the first time and provides a useful discussion of some larger distance universities from the UK Open University and Asian distance providers to a recent and well informed analysis of Athabasca University's programs. He also provides case studies of alternative institutional models already in existence, from profit making institutions to corporate universities, while also discussing the move to university-corporation partnerships. Though Hanna finds no examples of truly global universities he sees these case studies as future possibilities for a global model.

Hanna's associate authors take up the many issues that a new university model must address. Janet Poley discusses characteristics of effective leaders who utilize information technology in an age of knowledge as well as superficially addressing the issues of access and equity both in developing nations with limited technological capability and in the role of women in this field. John Tallman clarifies the issues of intellectual property and copyright and Donald Olcott, Jr. discusses "technoethic" issues from privacy and quality issues in learning online to designing culturally sensitive content and providing truthful advertising. He also writes with Kathy Schmidt on redefining faculty policies and processes to fit academics who must learn to design programs for a digital age, and they provide an integrated technology systems design which analyses appropriate technologies for relevant purposes. Gary Brown considers the way the Web should expand assessment of learning and Donald Hanna concludes by summarizing the main considerations that institutions must face as they make choices about change. His final list of strategic challenges is a good checklist for institutions entering the era of digital competition (familiar strategies to many Australian universities which makes me hopeful that we're already ahead of the competition).

This book gives a substantial overview of the new university from an American perspective but, given its title, it seems surprising that it hasn't considered the global competition already available digitally. It is unfortunate that the book has ignored some substantial work including Diana Laurillard's, Rethinking University Teaching: A Framework for the Effective use of Educational Technology, a book that has influenced university thinking worldwide since it was published in 1993 (New York: Routledge). It leaves the reader with a need to balance their perspectives by consulting recent comparative texts such as the edited

International Review of Research in Open and Distance Learning 
Book Review: Higher Education in an Era of Digital Competition: Choices and Challenges

collection from Terry Evans and Daryl Nation, Changing University Teaching: Reflections on Creating Educational Technologies (2000, London: Kogan Page) which gathers writers from many countries to look at similar issues from a more global perspective.

Citation Format

Stacey, Elizabeth. (2000) Book Review: Higher Education in an Era of Digital Competition:

Choices and Challenges. International Review of Research in Open and Distance Learning: 1, 1.

http://www.icaap.org/iuicode?149.1.1.4

International Review of Research in Open and Distance Learning 